\title{
Pegylated Interferons: Clinical Applications in the Management of Hepatitis C Infection
}

\author{
S. James Matthews and Christopher McCoy
}

\section{Introduction}

Currently, there are two pegylated interferon (PEG-IFN) products available for the treatment of hepatitis $\mathrm{C}$ virus (HCV) infection [(pegylated interferon, PEGIFN alpha-2a (PEGASYS $\left.{ }^{\circledR}\right)$, and pegylated interferon, PEG-IFN alpha-2b (PEGINTRON $\left.^{\circledR}\right)$ ]. Pegylation is a process by which the interferon-alpha is bound to a polyethylene glycol moiety (Kozlowski \& Harris, 2001). The PEG-IFN-alpha-2a product is bound to a single-branched bis-monomethoxy polyethylene glycol (PEG) chain (40,000 daltons) for a final molecular weight of 60,000 daltons or $60 \mathrm{kDa}$ (kilodaltons). Four major positional isomers exist for this compound (Bailon et al., 2001) In contrast, PEG-IFN-alpha-2b is formed by attaching a single chain of PEG (12 kDa mono-methoxy PEG) to interferon-alpha-2b via an ester linkage. The PEG moiety is conjugated to the $\mathrm{His}^{34}$ amino acid residue, forming 12 positional isomers (Wang et al., 2000). The combined molecular weight of PEG-IFN-alpha-2b is smaller, about $31 \mathrm{kDa}$. The chemical structure and linkages of PEG-IFNs (alpha-2a and alpha-2b) are shown in Figure 1.

Pegylation does change the pharmacokinetic properties of unmodified interferonalpha demonstrably (Luxon et al., 2002; Kozlowski \& Harris, 2001). These properties allow for once-weekly dosing, more stable interferon-alpha blood concentrations throughout the dosing interval, and improved efficacy (Luxon et al., 2002; Pockros et al., 2004; Lindsay et al., 2001).

Currently, the National Institutes of Health identifies the use of PEG-IFN-alpha plus ribavirin (RBV) as the preferred therapy for the treatment of chronic HCV infection. While an improvement over rates of treatment success with unmodified interferons, the critical endpoint, a sustained virological response (SVR), defined as an undetectable level of HCV RNA 6 months after the completion of therapy, remains low particularly for genotype 1 , at $42-52 \%$. Higher rates are observed in patients with genotype 2 or 3, at 76-84\% (Fried et al., 2002; Hadziyannis et al., 2004; Manns et al., 2001; National Institutes of Health Consensus Development Conference Statement: Management of Hepatitis C, 2002). Efforts to develop more effective dosing regimens, especially for subjects with genotype 1 and patients who do not respond or relapse after completion of therapy, are under study. This chapter will review the pharmacokinetics, efficacy in phase II and III clinical studies, 


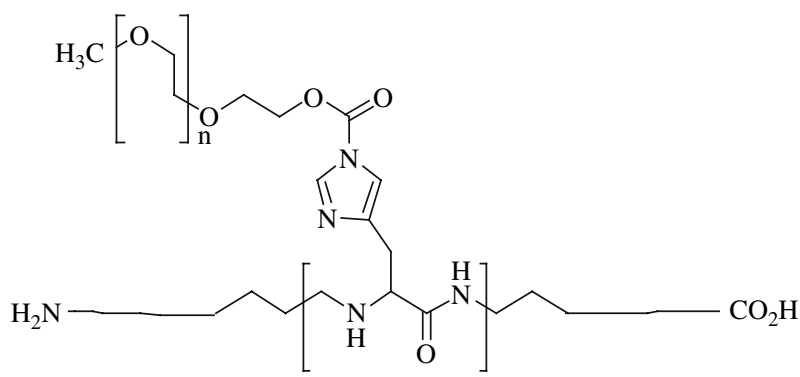

His -34

Pegylated IFN-alpha 2b

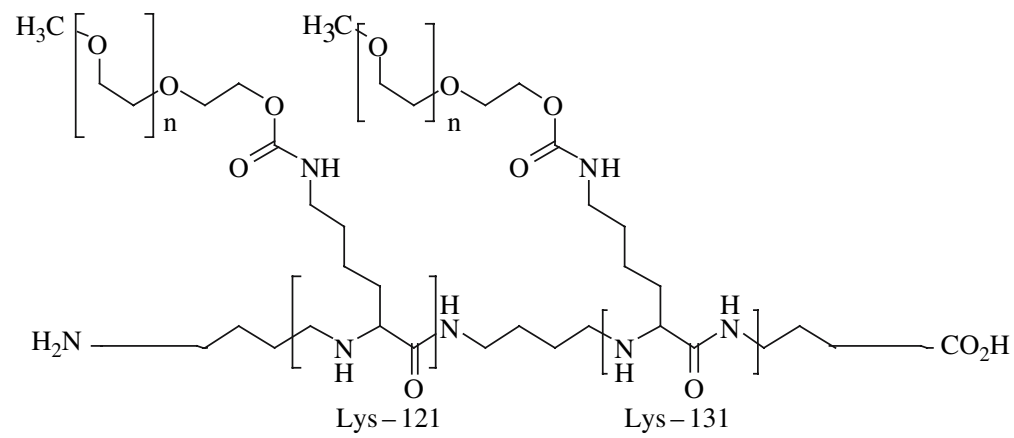

Pegylated IFN - alpha 2a

Fig. 1 Pegylated IFN-alpha 2a-Primary sites of pegylation are on amino terminus of the side chains of lysines-121 and 131

Pegylated IFN-alpha 2b-Primary site of pegylation is on imidazole side chain of histidine-34

and therapeutic options for the use of the PEG-IFNs in difficult-to-treat conditions. Safety and drug interaction considerations will also be reviewed.

\section{Pharmacokinetics}

This review will involve comparisons among unmodified interferon-alpha, PEGINF-alpha-2a, and PEG-INF-alpha-2b. The pharmacokinetic parameters of the two PEG-IFNs are quite different and vary markedly from the corresponding unmodified interferon (Table 1). There are no significant differences in core parameters between male and female subjects, or among Black, Latino, and Caucasian patients with chronic HCV infection (PEGASYS ${ }^{\circledR}$; Hoffmann-La Roche, Basel, Switzerland, 2004; PEG-Intron ${ }^{\circledR}$; Schering Corporation, Kenilworth, NJ, 2005; Brennan et al., 2005).

PEG-IFN products are absorbed slowly. The absorption half-life for unmodified interferon-alpha and PEG-IFN-alpha-2a and -alpha-2b are 2.3, 50, and 4.6 hours, 


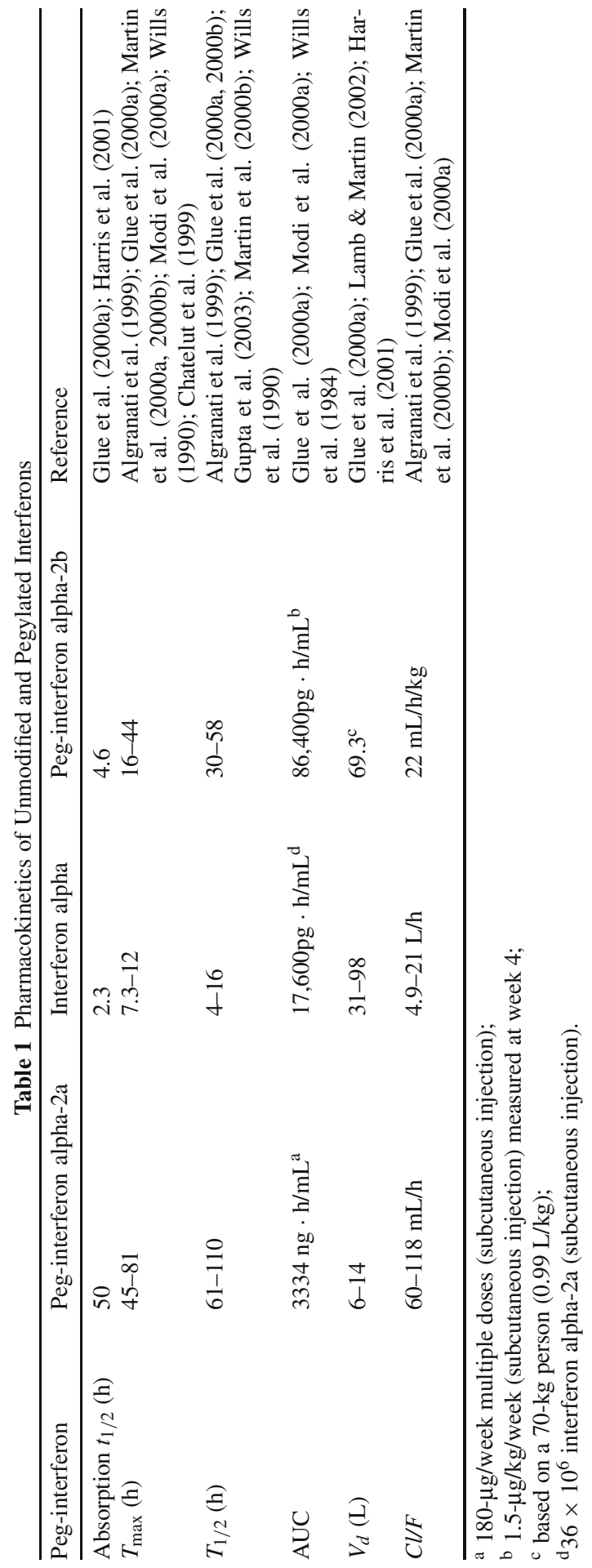


respectively (Harris et al., 2001; Glue et al., 2000). The time to achieve the maximum serum $\left(T_{\max }\right)$ concentration is markedly increased by pegylation. The $T_{\max }$ for unmodified interferon-alpha varies from 7.3 to 12 hours versus approximately 45 to 81 and 16 to 44 hours for PEG-IFN-alpha-2a and -alpha-2b in healthy adults and patients with compensated chronic HCV infection (Algranati et al., 1999; Glue et al., 2000; Wills, 1990; Wills et al., 1984; Chatelut et al., 1999; Martin et al., 2000, 2000a; Modi et al., 2000). Near-dose proportional maximum serum concentrations $\left(C_{\max }\right)$ of PEG-IFN-alpha-2a are obtained approximately 80 hours after the first dose (Heathcote et al., 1999). Dose-related but not dose-proportional increases between the dose and $C_{\max }$ are noted with PEG-IFN-alpha-2b (Glue et al., 2000, 2000a).

Absorption of PEG-IFN-alpha-2a has been shown to be particularly delayed in elderly males (mean $T_{\max }=116$ hours) versus a mean of 81 hours in young males (Martin et al., 2000). Age does not affect the absorption of PEG-IFN-alpha-2b (Gupta et al., 2003). For children, limited data exist on the pharmacokinetics of PEG-IFN-alpha. Schwarz (2003) presented data on the absorption of PEG-IFNalpha-2a after subcutaneous administration in 14 treatment-naïve HCV-infected children. The children received PEG-IFN-alpha-2a $\left[\left(180 \mu \mathrm{g} / 1.73 \mathrm{~m}^{2}\right) \times\right.$ patient body surface area] for 48 weeks. Rapid and sustained absorption was noted after the first dose, with mean concentrations 24 and 96 hours after a dose of $22.3 \mathrm{ng} / \mathrm{ml}$ and $19.0 \mathrm{ng} / \mathrm{ml}$, respectively. Steady-state concentrations were reached by week 12 of therapy.

The mean apparent volume of distribution $\left(V_{d}\right)$ of unmodified interferon-alpha2a and PEG-IFN-alpha-2a are markedly different, at 31 to $73 \mathrm{~L}$ and approximately 6 to 14 L, respectively (Harris et al., 2001; Lamb \& Martin, 2002) (Table 1). In contrast, the mean apparent $V_{d}$ for unmodified interferon-alpha-2b is approximately $98 \mathrm{~L}$ (1.4 liters/kg) versus $69.3 \mathrm{~L}$ (0.99 liters/kg) for PEG-IFN-alpha-2b for a $70-\mathrm{kg}$ person (Glue et al., 2000). The volume of distribution of PEG-IFN-alpha-2a is also lower than unmodified and PEG-IFN-alpha-2b. The lower $V_{d}$ for PEG-IFN-alpha2a limits the distribution to well-perfused organs, allowing for a fixed-dose regimen (irrespective of body weight). On the other hand, the distribution of PEG-IFN-alpha$2 \mathrm{~b}$ is closer to that of unmodified interferon.

Unmodified interferon-alpha is eliminated by glomerular filtration with reabsorption occurring in the proximal tubules (Wills, 1990). The liver plays a small part in the elimination of unmodified interferon-alpha. Additional catabolism may occur via interactions with cellular interferon receptors (Glue et al., 2000). In contrast, animal studies demonstrate that PEG-IFN-alpha-2a is metabolized mainly by the liver (Modi et al., 2000a). Non-renal clearance of PEG-IFN-alpha-2b accounts for approximately two-thirds of the total clearance (Gupta et al., 2002).

Unmodified interferon-alpha is rapidly eliminated from the body, with an average half-life between 4 and 16 hours (Glue et al., 2000; Wills, 1990). The mean apparent clearance varies from 4.9 to 21 liters/hour (Table 1) (Wills, 1990). Elimination half-lives for the PEG-IFN products are far longer. The mean half-life for PEG-IFN-alpha-2a varies from 61 to 110 hours, and the mean apparent clearance varies from 60 to $118 \mathrm{~mL} /$ hour in subjects with stable renal function. The mean halflife for PEG-IFN-alpha-2b is 30 to 58 hours (Table 1) (Glue et al., 2000, 2000a). 
Steady-state concentrations of PEG-IFN-alpha-2a occur after 5-8 weeks of weekly administration (Modi et al., 2000).

Renal dysfunction affects the pharmacokinetics of PEG-IFNs differently (Martin et al., 2000a; Lamb et al., 2001; Gupta et al., 2002). For PEG-IFN-alpha-2a, the $C_{\text {max }}$, distribution, and apparent total body clearance in subjects with stable chronic renal impairment were comparable to patients with normal renal function. Clearance $(\mathrm{Cl} / \mathrm{F})$ of PEG-IFN-alpha-2a was $25-45 \%$ lower in patients on hemodialysis, however, compared with subjects with normal kidney function (PEGASYS ${ }^{\circledR}$ package insert, 2004; Martin et al., 2000; Lamb et al., 2001). Dosage adjustment is recommended in patients with end-stage kidney disease on hemodialysis (PEGASYS ${ }^{\circledR}$ package insert, 2004).

In contrast, the $C_{\max }$ and $\mathrm{AUC}$ (area under the concentration-time curve) increased up to two times in patients with decreased renal function receiving PEG-IFN-alpha-2b compared with patients with normal baseline renal function (Gupta et al., 2002). The mean half-life increased and the mean apparent body clearance decreased by $40 \%$ and $45 \%$, respectively. Renal clearance accounts for approximately $30 \%$ of the total body clearance of PEG-IFN-alpha-2b. Patients with a calculated creatinine clearance less than $50 \mathrm{~mL} / \mathrm{min}$ should receive PEG-IFNalpha-2b therapy only after assessing the risks and benefits (PEG-Intron package insert, 2005).

As to removal of PEG-IFNs by hemodialysis, Barril (2004) performed an in vitro study comparing the effect of permeability and pore size of hemodialysis membranes on the blood levels of unmodified interferon-alpha-2a versus PEG-IFNalpha-2a and PEG-IFN-alpha-2b. Pore size was more important than permeability in the removal of interferon products from the blood. Unmodified interferon and PEG-IFN-alpha-2b, but not PEG-IFN-alpha-2a, were cleared appreciably by membranes with middle to middle-large pore size (43-60 ̊) high-flux dialysers. Given that PEG-IFN-alpha-2a is not as dependent upon renal clearance for elimination, it is the preferred choice for patients with renal dysfunction. In the case that a patient requires hemodialysis, PEG-IFN-alpha-2b may require supplemental dosing depending on the type of dialyser being used.

Concern about the effect of fixed dosing of PEG-IFN-alpha-2a in patients at the extremes of body weight has been raised. Although the drug has a low volume of distribution, morbidly obese patients may not achieve therapeutic interferon concentrations, while lighter patients may experience an increase in adverse events due to supratherapeutic levels. Obesity has been identified as an independent risk factor for nonresponse to unmodified and PEG-IFNs (Fried et al., 2002; Hadziyannis et al., 2004; Manns et al., 2001). It is unknown whether the decreased efficacy can be attributed to lower interferon levels, intrinsic resistance to the effects of interferon, or the presence of negative prognostic factors in obese patients (Swain et al., 2005). It has been reported that the $C_{\max }$ and AUC of unmodified interferon are $35 \%$ and $25 \%$ lower in obese subjects versus non-obese patients (Lam et al., 1997). Bressler (2005) noted a $21 \%$ reduction in trough levels of PEG-IFN-alpha-2a in obese versus non-obese subjects receiving the $180-\mu \mathrm{g}$ dose. The trough concentrations after PEG-IFN-alpha-2a at $270 \mu \mathrm{g} /$ week were similar to those noted in the $180-\mu \mathrm{g} /$ week dose in non-obese subjects. In a single-dose study, the AUC for PEG-IFN-alpha-2a 
and $-2 b$ was not related to body weight. However, the number of obese patients was small (Bruno et al., 2005). The significance of this finding will need to be determined in clinical trials. The manufacturer of PEG-IFN-alpha-2a is undertaking a study to determine the effectiveness of higher doses of PEG-IFN-alpha-2a in patients with $\mathrm{HCV}$ infection and who are over $85 \mathrm{~kg}$ (ClinicalTrials.gov Identifier: NCT00077649). Swain (2005) reported a higher incidence of serious adverse events in lighter patients $(\leq 75.5 \mathrm{~kg}$ ) receiving fixed-dose PEG-IFN-alpha-2a, but the number of withdrawals due to adverse events was not increased.

The pharmacokinetics of the two available PEG-IFNs vary. The decision to treat with one product over the other should take into consideration renal function and body size.

\section{Drug Interactions}

Drug-drug interactions for the PEG-IFNs are infrequent but are marked by consequence. Additive side effects are the most notable mechanism of interaction. Agents with similar adverse drug event profiles (e.g., hepatotoxins, or drugs that cause anemia) run highest on the list. As the metabolism and elimination of PEG-IFNs are not dependent on extensive oxidative metabolism, through any of the major cytochrome P450 enzyme systems, these agents are not subject to the inductive or inhibitory activity of other drugs. Additionally, neither PEG-IFN product exerts an effect on the majority of P450 enzyme systems, including 2C9, 2C19, 2D6, and $3 \mathrm{~A} 4$ (Package insert, FDA Briefing Document, 2002). PEG-IFN-alpha-2a demonstrates mild inhibition of cytochrome P450 1A2, the enzyme responsible for metabolism of drugs such as theophylline, risperidone, clozapine, tricyclic antidepressants, and caffeine (FDA Briefing Document, 2002).

Treatment with PEG-IFN-alpha-2a once weekly for four weeks in healthy subjects taking theophylline was associated with a $25 \%$ increase in the total theophylline area under the concentration-time curve. The resultant effects were adverse effects of theophylline, including nausea, vomiting, palpitations, and seizures. The effect could be offset by a $25 \%$ reduction in the dose of theophylline. PEGIFN-alpha-2a does not uniformly affect the disposition of methadone metabolism (Sulkowski et al., 2005a). Methadone exposure was increased by a mean of 10 $15 \%$ in patients co-treated for four weeks. The levels of methadone doubled in two patients. No subject had clinical signs or symptoms of intoxication or withdrawal related to methadone. Mauss (2004) examined the effect of PEG-IFN-alpha-2b on 50 patients on methadone maintenance. While there was a high rate of discontinuation of therapy among this group of patients, there was no increase in adverse effects. RBV does not affect the disposition of PEG-IFN-alpha but contributes significantly to the untoward effects on hematological counts, particularly red blood cells (RBC).

Directly hepatotoxic agents used in combination with PEG-IFN can elicit additive drug toxicity. Concomitant use of the nonnucleoside reverse transcriptase inhibitor nevirapine, a known hepatotoxin, has been associated with a higher 
incidence of advanced liver fibrosis (Macias et al., 2004). Numerous case reports and retrospective reviews identify didanosine, when used in combination with PEG-IFN products with ribavirin, as a prominent risk factor for cases of fatal hepatic failure, peripheral neuropathy, pancreatitis, and lactic acidosis (Bani-Sadr et al., 2005). Use of ritonavir or ritonavir plus saquinavir in HIV patients infected with the hepatitis $\mathrm{C}$ or $\mathrm{B}$ virus has also been associated with increased rates of severe hepatotoxicity.

PEG-IFNs, in combination with RBV, may additionally antagonize stavudine and zidovudine antiretroviral activity, secondary to inhibition of intracellular phosphorylation. Use of alternate antiretroviral agents is recommended. For all co-infected patients (HCV and HIV infection), increased vigilance for signs of hepatotoxicity is highly recommended.

\section{Mechanism of Action}

PEG-IFNs were developed in order to achieve a more sustained antiviral and immunodulatory effect than unmodified interferon (Kamal et al., 2002). Their mechanism of action is the same as for unmodified interferon. The chapter by Dr. Dash in this manuscript provides extensive insight into the mechanism of interferon action and resistance.

PEG-IFN-alpha combined with RBV is the recommended treatment for the management of patients with chronic HCV infection (National Institutes of Health Consensus Development Conference Statement: Management of Hepatitis C, 2002). When combined with PEG-IFN, RBV significantly improves the possibility of achieving an SVR in patients with chronic HCV infection when compared with an interferon-alpha by itself, therapy with RBV, or PEG-IFN-alpha alone (Fried et al., 2002; Manns et al., 2001). When used as monotherapy in patients with chronic HCV infection, RBV has been shown to improve serum alanine aminotransferase (ALT) concentrations (Bodenheimer et al., 1997; Dusheiko et al., 1996). No significant decrease in HCV RNA concentrations were noted during therapy. On the other hand, Pawlotsky (2004) noted a moderate $\left(-0.5\right.$ to $\left.-1.6 \log _{10}\right)$ but transient (days 2 and 3 and disappearing by day 4) decrease in HCV RNA concentrations in 4 of 7 subjects receiving monotherapy with $\mathrm{RBV}$.

The exact mechanism of action of RBV when combined with interferon-alpha therapy is unknown. The chemical structure of RBV is depicted in Figure 2 Several hypotheses have been proposed. RBV may act by inhibiting DNA, RNA, and protein synthesis, leading to a decrease in production of pro-inflammatory cytokines such

Fig. 2 Ribivirin<smiles>NC(=O)c1ncn([C@@H]2O[C@H](CO)[C@@H](O)[C@H]2O)n1</smiles> 
as interferon- $\gamma$ and may induce apoptosis of cells in the inflammatory infiltrate in the infected liver (Meier et al., 2003). Modulation of the T helper 1/Th2 cytokinemediated immune response with an emphasis on the type 1 cytokine profile is consistent with the results of combined therapy with PEG-IFN-alpha-2a (Kamal et al., 2002; Tam et al., 1999; Hultgren et al., 1998). The mutagenic activity of RBV on $\mathrm{HCV}$ is also a possible mechanism (Asahina et al., 2005).

\section{Pharmacodynamics}

Administration of unmodified interferon-alpha or PEG-IFN-alpha products results in a multiphase decline of HCV RNA concentrations. A study by Zeuzem (2001) noted a rapid first-phase decline in HCV RNA concentrations in $79 \%$ and $76 \%$ of patients receiving unmodified interferon and PEG-IFN-alpha-2a, respectively. This response was noted within 48 hours of initiation of interferon therapy. The first phase of viral decline is thought to reflect an interferon-induced blockade of virus production or release, as well as the degradation rate of free virus (Neumann et al., 1998). After about 24 to 48 hours, the viral decline slows and a second phase of HCV RNA decay is noted. The second-phase decline is thought to reflect the degradation rate of infected cells or the elimination of virus from infected hepatocytes (Neumann et al., 1998; Lutchman \& Hoofnagle, 2003). The decrease in HCV RNA concentrations was faster in both phases in patients infected with a non-1 HCV genotype (Zeuzem et al., 2001). The degree of second-phase decline of HCV RNA was predictive of SVR (Zeuzem et al., 2001). A similar pattern of HCV RNA decline has been noted in patients who are infected with HCV genotype 1 and receive PEGIFN-alpha-2b (Buti et al., 2002).

Herrmann (2003) studied the effect of the addition of RBV on the viral kinetics of unmodified interferon-alpha-2b and PEG-IFN-alpha-2a in patients with genotype 1 chronic hepatitis $\mathrm{C}$ infection. In addition to the two phases reported by Zeuzem (2001), they noted a third phase of viral decay in $57 \%$, 56\%, and $89 \%$ of patients receiving unmodified interferon-alpha-2b with RBV and PEG-IFN-alpha-2a without and with RBV, respectively. The third phase of viral decline began at day 7 to day 28 after initiation of therapy. The third-phase kinetic parameters were predictive of an end-of-treatment response (ETR - undetectable HCV RNA concentrations at the end of 48 weeks of therapy) $(P=0.001)$ but not SVR $(P=0.11)$. This third phase was attributed to a treatment-enhanced loss of HCV-infected cells. Pawlotsky (2002) and Neumann (2002) found that a triphasic HCV RNA decay pattern was more common in HCV genotypes 4 and 1 (38\%) versus genotypes 2 and $3(3 \%)$. All genotype 1 patients who had a bi-phasic response to PEG-IFN-alpha-2a plus RBV had a rapid viral response (RVR) (a second slope greater than $0.3 \mathrm{IU} / \mathrm{ml} /$ week), whereas only $62 \%$ of those with a tri-phasic response had an RVR.

Zeuzem (2005) investigated whether individualizing therapy for chronic HCVinfected patients based on viral responses to treatment increased the likelihood of achieving an SVR. An SVR was defined as an undetectable serum HCV RNA $(<50$ 
IU/mL) 24 weeks after the end of therapy. Study results indicated that individualized therapy was no better than standard therapy in the management of patients.

\section{Therapeutic Efficacy}

Determination of genotype is the first step in the consideration of treatment with either of the PEG-IFNs. This will help determine the length of therapy and the likelihood of treatment success, aiding the patient and provider in the benefit versus risk analysis. Patients infected with genotype 2 or 3 respond better to therapy than subjects infected with genotype 1 or 4 (National Institutes of Health Consensus Development Conference Statement: Management of Hepatitis C, 2002; Sherman et al., 2004)

\section{Monotherapy with PEG-IFN-Alpha}

Combination therapy with PEG-IFN and RBV is the therapy of choice for the management of HCV infection. However, in those situations where the patient is intolerant or has a contraindication to the use of RBV, monotherapy with PEGIFN is indicated. Four randomized controlled trials in interferon-naïve subjects with chronic HCV infection demonstrated the superiority of treatment with PEG-IFNalpha-2a over unmodified interferon-alpha-2a (Reddy et al., 2001; Heathcote et al., 2000; Zeuzem et al., 2000; Pockros et al., 2004). A sustained biochemical response, end-of-treatment virological response, sustained virological response, and histological response were therapeutic endpoints. A sustained biochemical response was defined as a normal serum ALT at week 72, and a histological response was defined as $\mathrm{a} \geq 2$-point decrease in the total histological activity index (HAI) in liver biopsy results between baseline and week 72 . An end-of-treatment virological response and a sustained virological response were defined as an undetectable plasma HCV RNA after 48 weeks of therapy and an undetectable HCV RNA concentration $(<100$ copies/mL) at week 72 , respectively.

The specific relative rates of response are summarized in Table 2 For all therapeutic endpoints, a statistically significant benefit was seen with treatment with PEG-IFN-alpha-2a over unmodified interferon. The greatest relative benefit for all parameters was noted with treatment at the highest dose, of $180 \mu \mathrm{g} / \mathrm{week}$. The $135-\mu \mathrm{g} /$ week dose achieved an identical SVR as the $180-\mu \mathrm{g} /$ week dosing regimen, but the histological response was inferior and no different from that of unmodified interferon-alpha-2a (Pockros et al., 2004). The histological response correlates to SVR (Reddy et al., 2001; Heathcote et al., 2000; Zeuzem et al., 2000; Cammà et al., 2004). A histological response, however, was found in some patients who failed to respond to therapy or who relapsed after an end-of-treatment response (Heathcote et al., 2000). These data indicate that therapy with PEG-IFN can have a beneficial effect even without an SVR. 


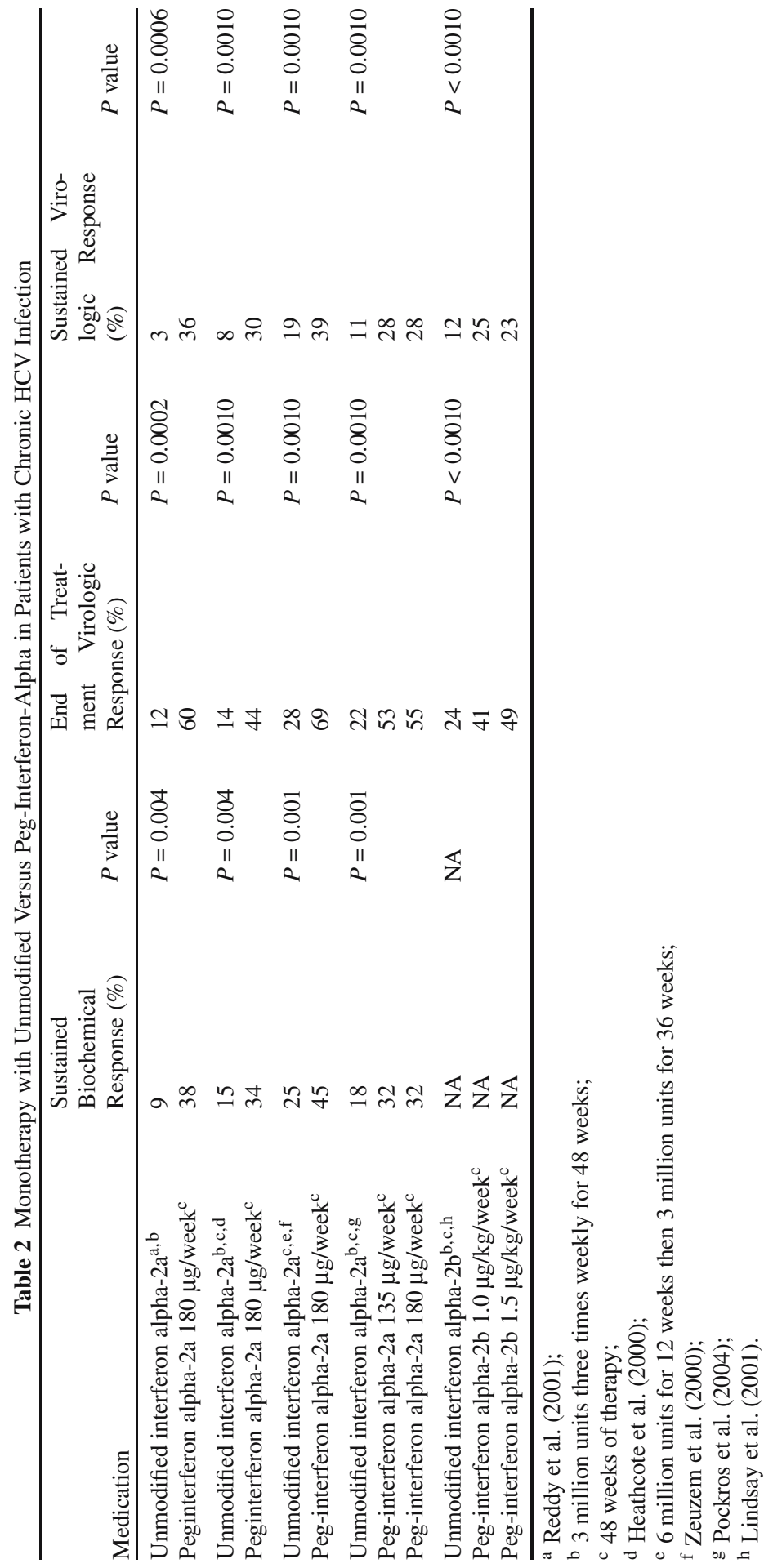


The likelihood of achieving an SVR was lower in patients infected with HCV genotype 1 when compared to non-1 genotypes. The chance of achieving an SVR in patients infected with HCV genotype 1 varied from $12-31 \%(180 \mu \mathrm{g}$ PEGIFN-alpha-2a weekly for 48 weeks) versus unmodified interferon-alpha-2a (2-7\%) (Reddy et al., 2001; Heathcote et al., 2000; Pockros et al., 2004; Zeuzem et al., 2000). In patients infected with HCV non-1 or unknown genotype, the response was approximately $41-51 \%$ in the $180-\mu \mathrm{g} /$ week PEG-IFN-alpha-2a groups versus 0-19\% for unmodified interferon-alpha-2a (Reddy et al., 2001; Heathcote et al., 2000; Pockros et al., 2004).

Lindsay (2001) performed a randomized, double-blind study (for PEG-IFNalpha-2b doses) comparing PEG-IFN-alpha- $2 b$ with unmodified interferon-alpha- $2 b$ in interferon-naïve patients with chronic HCV infection (Table 2). An end-oftreatment virological response was recorded in $24 \%, 41 \%$, and $49 \%$ of patients receiving unmodified interferon, PEG-IFN-alpha-2b $(1.0 \mu \mathrm{g} / \mathrm{kg} /$ week $)$, and PEGIFN-alpha-2b (1.5 $\mu \mathrm{g} / \mathrm{kg} /$ week), respectively. The end-of-treatment virological response was statistically greater for all of the PEG-IFN dosing groups when compared with unmodified interferon $(P<0.001)$. The SVR for the $1.0-\mu \mathrm{g} / \mathrm{kg} /$ week $(25 \%)$ and $1.5-\mu \mathrm{g} / \mathrm{kg} /$ week $(23 \%)$ doses of PEG-IFN-alpha-2b were identical and significantly different from unmodified interferon-alpha-2b $(12 \%)(P<0.001$ for both PEG-IFN doses).

\section{Combination Therapy with PEG-IFNAlpha-2a and RBV}

Major randomized controlled trials have been used to develop consensus guidelines for the use of PEG-IFN combined with RBV for the management of patients with chronic HCV infection (Manns et al., 2001; Fried et al, 2002; Hadziyannis et al., 2004). Like monotherapy, the treatment duration and the likelihood of achieving an SVR are determined by HCV genotype. In this section, we will review the available information concerning the treatment of chronic HCV genotypes 1-6.

Overall SVR and SVR by genotype results are listed in Table 3 Combination therapy with PEG-IFN plus RBV generally exceeds monotherapy and combination therapy with unmodified IFN in terms of the SVR rates $(P=0.01$, Manns et al., 2001; $P<0.001$, Fried et al., 2002). The overall SVR in patients receiving PEGIFN-alpha plus RBV for 48 weeks varied in these trials from 54-63\%. The dose of RBV studied was from $800 \mathrm{mg}$ daily in the Manns study (2001) to between 1-1.2 g daily based on body weight in other major studies (Fried et al., 2002; Hadziyannis et al., 2004).

Manns (2001) suggest that higher doses of RBV can maximize response. In their randomized, open-label trial, they noted that the likelihood of achieving an SVR was higher for all genotype groups in patients receiving higher RBV doses, between $10.6-15 \mathrm{mg} / \mathrm{kg}$ per day. From this finding and the desire to determine if the results from controlled randomized studies could be replicated in a community setting, the WIN-R study (Jacobson et al., 2005) was designed. This study was a U.S. community-based trial enrolling 4,913 patients. The relative benefit of combining $1.5 \mu \mathrm{g} / \mathrm{kg} /$ week of PEG-IFN-alpha-2b with either a fixed dose (FD $800 \mathrm{mg} / \mathrm{day}$ ) or 
Table 3 Efficacy of (Combination Therapy) PEG-IFN Plus RBV in Subjects with Chronic HCV Infection

\begin{tabular}{|c|c|c|c|}
\hline Regimen & $\begin{array}{l}\text { SVR } \\
\text { Overall } \\
(\%)\end{array}$ & $\begin{array}{l}\text { SVR } \\
\text { Genotype } \\
1(\%)\end{array}$ & $\begin{array}{l}\text { SVR } \\
\text { Genotype } \\
2 \text { or } 3(\%)\end{array}$ \\
\hline $\begin{array}{l}\text { Interferon alpha-2b plus RBV (1-1.2 g/day) } \\
\quad\left(48 \text { weeks) }{ }^{\mathrm{a}}\right.\end{array}$ & 47 & 33 & 79 \\
\hline $\begin{array}{l}\text { PEG-IFN alpha- } 2 \mathrm{~b} 1.5 \mu \mathrm{g} / \mathrm{kg} / \text { week plus RBV } \\
800 \mathrm{mg} \text { daily(48 weeks) }\end{array}$ & 54 & 42 & 82 \\
\hline $\begin{array}{l}\text { PEG-IFN alpha-2b1.5 } \mu \mathrm{g} / \mathrm{kg} / \text { week then } 0.5 \\
\mu \mathrm{g} / \mathrm{kg} / \text { week plus RBV } 1-2 \mathrm{~g} \text { daily }(48 \text { weeks) }\end{array}$ & 47 & 34 & 80 \\
\hline $\begin{array}{l}\text { Interferon alpha-2b plus RBV 1-1.2 g/day (48 } \\
\text { weeks) }^{\mathrm{c}}\end{array}$ & 44 & 36 & 61 \\
\hline $\begin{array}{l}\text { PEG-IFN alpha-2a } 180 \mu \mathrm{g} / \text { week plus placebo } \\
\text { (48 weeks) }\end{array}$ & 29 & 21 & 45 \\
\hline $\begin{array}{l}\text { PEG-IFN alpha-2a } 180 \mu \mathrm{g} / \text { week plus RBV } \\
1-1.2 \mathrm{~g} / \text { day ( } 48 \text { weeks) }\end{array}$ & 56 & 46 & 76 \\
\hline $\begin{array}{l}\text { PEG-IFN alpha-2a } 180 \mu \mathrm{g} / \text { week plus RBV } \\
800 \mathrm{mg} / \mathrm{d}(24 \text { weeks })^{\mathrm{d}}\end{array}$ & NA & 29 & 84 \\
\hline $\begin{array}{l}\text { PEG-IFN alpha-2a } 180 \mu \mathrm{g} / \text { week plus RBV } \\
1-1.2 \mathrm{~g} / \mathrm{d}(24 \text { weeks })\end{array}$ & NA & 41 & 81 \\
\hline $\begin{array}{l}\text { PEG-IFN alpha-2a } 180 \mu \mathrm{g} / \text { week plus RBV } \\
800 \mathrm{mg} / \mathrm{d} \text { (48 weeks) }\end{array}$ & NA & 40 & 79 \\
\hline $\begin{array}{l}\text { PEG-IFN alpha-2a } 180 \mu \mathrm{g} / \text { week plus RBV } \\
1-1.2 \mathrm{~g} / \mathrm{d} \text { (48 weeks) }\end{array}$ & 63 & 52 & 76 \\
\hline
\end{tabular}

${ }^{a}$ Manns et al. (2001);

b $1.5 \mu \mathrm{g} / \mathrm{kg} /$ week PEG-IFN alpha-2b for 4 weeks followed by $0.5 \mu \mathrm{g} / \mathrm{kg} /$ week for 44 weeks;

${ }^{c}$ Fried et al. (2002);

${ }^{\text {d }}$ Hadziyannis et al. (2004), PEGASYS ${ }^{\circledR}$; Hoffmann-La Roche, Basel, Switzerland,2004.

a weight-based dose (WBD 800-1400 mg/day) of RBV was examined. Treatmentnaïve patients infected with $\mathrm{HCV}$ genotype 1 received 48 weeks of therapy, and patients with $\mathrm{HCV}$ genotype 2 or 3 received either 24 or 48 weeks of therapy. The overall SVR in the WBD and FD groups was $44 \%$ and $41 \%$, respectively $(P=0.02)$. These results were lower than those reported by Manns (2001) (54\%) utilizing a similar protocol with fixed-dose RBV. This may have been a reflection of the greater need for dose reductions of RBV in the WBD group due to anemia. Afdhal (2006) investigated the influence of RBV dose and the presence of liver fibrosis and cirrhosis on SVR in the WIN-R trial. With advanced histological changes, specifically patients classified at Metavir stage 3 to 4, SVR rates were significantly better for patients receiving the weight-based dose versus the fixed dose of RBV (43\% versus $37 \%, P=0.02)$. Patients with cirrhosis had the lowest overall SVR $(34 \%)$ when compared with subjects with stages $0-3(44-46 \%)(P<0.0001)$.

\section{Genotype 1}

When analyzing the response in HCV genotype 1 infected patients receiving combination therapy with PEG-IFN-alpha plus RBV for 48 weeks, response rates varied from 42-52\% (Manns et al., 2001; Fried et al., 2002; Hadziyannis et al., 2004). 
Combination PEG-IFN plus RBV regimens are significantly better than unmodified interferon/RBV combinations $(P=0.02$, Manns et al., 2001; $P=0.01$, Fried et al., 2002). An even higher rate of response was noted by Sakai (2006), at $61 \%$ in treatment-naïve Japanese patients infected with HCV genotype 1b. Post hoc subgroup analyses, by Fried (2002) and Hadziyannis (2004) and Zarski (2005), demonstrate a significantly greater chance of achieving an SVR in patients infected with HCV genotype $1 \mathrm{~b}(53 \%)$ versus $1 \mathrm{a}(45 \%)(P=0.004)$.

Even lower rates of treatment success were reported in the community-based trial, WIN-R, wherein SVRs in patients infected with HCV genotype 1 were $34 \%$ (WBD) and 29\% (FD) $(P=0.004)$ (Jacobson et al., 2005). Subjects with a low viral load ( $<2$ million copies/mL) had a greater likelihood of experiencing an SVR than patients with a high viral load ( $\geq 2$ million copies $/ \mathrm{mL}), 35 \%$ versus $31 \%, P=0.006$ (Jacobson et al., 2006).

Hadziyannis (2004) studied the effect of treatment duration and RBV dose on the likelihood of achieving an SVR in HCV genotype 1 infected patients. They found a significant correlation with SVR in patients treated for 48 weeks versus those treated for 24 weeks $(P<0.001)$. They also reported a significant effect of weight-based RBV versus low-dose RBV (800 mg daily) on the achievement of an SVR ( $P=$ 0.005). Subjects with bridging fibrosis or cirrhosis responded best to weight-based RBV and 48 weeks of therapy.

\section{Genotype 2 or 3}

The SVR for patients infected with genotype 2 or 3 varied between $76-82 \%$ in patients receiving PEG-IFN-alpha/RBV for 48 weeks (Table 3) (Manns et al., 2001; Fried et al., 2002; PEGASYS ${ }^{\circledR}$; Hoffmann-La Roche, Basel, Switzerland, 2004). Hadziyannis (2004) found no difference in the achievement of an SVR in patients infected with genotype 2 or 3 based on length of therapy or RBV dose $(p>0.2$ for both). In fact, the 24-week regimen (800-mg dose of RBV) had the highest SVR (84\%). Manns (2001) reported no differences in SVR between PEG-IFNalpha- $\mathrm{b} / \mathrm{RBV}$ study groups and unmodified interferon/RBV in patients infected with genotype 2 or 3 treated for 48 weeks.

In the community-based WIN-R study, fixed-dose RBV (800 mg/day) was as equally effective as WBD RBV (800-1400 mg daily) in inducing an SVR in patients with chronic HCV genotype 2 or 3 infection ( $60 \%$ versus $62 \%, P=0.26$ ) (Jacobson et al., 2005). Patients with genotype 2 had a higher SVR than those with genotype 3 (72\% versus 63\%) ([Brown et al., 2006). The authors suggested that patients infected with HCV genotype 3 may benefit from WBD of RBV.

Zeuzem (2004) performed a phase 4 study to investigate the safety and efficacy of treatment for 24 weeks with $1.5 \mu \mathrm{g} / \mathrm{kg} /$ week of PEG-IFN-alpha-2b with weight-based RBV (800-1,400mg/day) in patients infected with HCV genotype 2 or 3. The overall SVR was $81 \%$, and the SVR for HCV-2 and HCV-3 was $93 \%$ and $79 \%$, respectively. The reduced SVR in patients infected with HCV genotype 3 was attributed to the presence of a high baseline viral load and high-grade hepatic 
steatosis. The authors raised the question of whether patients infected with HCV-3 with poor prognostic factors should be treated for longer than 24 weeks. Controlled studies will be necessary to answer this question.

\section{Genotype 4}

Hepatitis $\mathrm{C}$ virus genotype 4 is more common in Africa and eastern Mediterranean countries and has a prevalence of $60 \%$ in Saudi Arabia and up to $90 \%$ in Egypt. Fried (2001) and Hadziyannis (2004) noted SVR rates in HCV genotype 4 infected patients receiving PEG-IFN-alpha-2a plus weight-based RBV for 48 weeks at $77-82 \%$. The study size was small, however. Khuroo (2004) performed a metaanalysis of available trials of PEG-IFN-alpha plus RBV for the management of chronic HCV genotype 4 infection. They reported an overall predicted SVR rate of $72 \%$ in patients treated for 48 weeks with PEG-IFN-alpha (2a: $180 \mu \mathrm{g} /$ week; or $2 \mathrm{~b}: 1.5 \mu \mathrm{g} / \mathrm{kg} /$ week) and RBV (1-1.2 g/day based on body weight). Trials utilizing these guidelines have reported SVR values between 61-69\% (Elmakhzangy et al., 2005; Hasan et al., 2004; Kamal et al., 2005). Kamal (2005) investigated the effect of the duration of therapy on the achievement of an SVR in patients infected with HCV genotype 4. Patients were randomized to receive PEG-IFN-alpha-2b (1.5 $\mu \mathrm{g} / \mathrm{kg} /$ weeky) with RBV (1-1.2 g/day) for 24, 36, or 48 weeks. An SVR occurred in $24 \%, 66 \%$, and $69 \%$ of patients treated for 24,36 , and 48 weeks, respectively. No statistical difference was found between 36 or 48 weeks of therapy $(P=0.3)$. The 36- and 48-week regimens were statistically different when compared to the 24 -week arm of the study ( $p<0.001$, for both). An early virological response at 12 weeks was predictive of an SVR as long as therapy was at least 36 weeks in duration. The authors concluded, however, that patients with high baseline HCV RNA viral loads may do better with 48 weeks of therapy.

\section{Genotype 5 or 6}

Much less data exist on the management of patients infected with chronic HCV genotype 5 or 6 . In a retrospective review of patients with HCV genotype 5 infection, D'Heygere (2005) reported an SVR of 55\%. Patients were treated for 48 weeks with $180 \mu \mathrm{g} /$ week of PEG-IFN-alpha-2a and RBV (1-1.2 g/day). Bonny (2005) reported an SVR similar to that of unmodified interferon (64\%), in treatment-naïve patients infected with HCV genotype 5, receiving PEG-IFN-alpha-2b or PEG-IFNalpha-2a plus RBV (60\%). Both regimens were administered for 48 weeks. Nguyen (2003) reported an SVR of 54\% in patients treated with peginterferon/ribavirin for 24 weeks. The SVR rate in two small studies of HCV genotype 6 infected individuals utilizing unmodified interferon/ribavirin were $79 \%$ and $62.5 \%$, respectively (Dev et al., 2002; Hui et al., 2003). Therapy duration was 52 and 48 weeks, respectively. A study to determine the ideal length of therapy in patients infected with 
HCV genotype 6 receiving peginterferon-alpha-2b/ribavirin therapy is under way (ClinicalTrials.gov Identifier: NCT00255008).

\section{Comparative Efficacy Between Pegylated Products}

To date, there have been no large head-to-head trials evaluating the safety and/or efficacy between the two products. As of preparation of this chapter, the manufacturer of PEG-IFN-alpha-2b (Schering-Plough) is funding a head-to-head safety and efficacy trial of the two PEG-IFN products entitled the "Individualized Dosing Efficacy Versus Flat Dosing to Assess Optimal Pegylated Therapy (IDEAL) Trial." Treatment-naïve patients infected with HCV genotype 1 are being randomized to receive PEG-IFN-alpha-2b at a dose of 1.0 or $1.5 \mu \mathrm{g} / \mathrm{kg} /$ week plus weight-based RBV (800-1,400 mg/day) or $180 \mu \mathrm{g} /$ week PEG-IFN-alpha-2a with RBV (1-1.2 $\mathrm{g} /$ day) for a total of 48 weeks. The primary endpoint of the study will be the SVR rate. One concern about the design of the study is the way the protocol deals with alterations in the RBV dose. Patients in the PEG-IFN-alpha-2b arms will have a two-step dose reduction process. If necessary, the dose of RBV will be decreased to between 600 and 1,000 mg depending on the starting dose. If necessary, the dose may be reduced by another $200 \mathrm{mg}$. In contrast, for the PEG-IFN-alpha-2a group, the dose is reduced to $600 \mathrm{mg} / \mathrm{day}$. Since it is known that the RBV dose is extremely important to the achievement of an SVR, the study design could reflect a bias in favor of PEG-IFN-alpha-2b.

\section{Importance of Completing the Therapeutic Regimen}

Ferenci (2005) investigated the importance of completing the prescribed regimen with PEG-IFN-alpha-2a and RBV on the likelihood of achieving an SVR in patients infected with HCV genotype 1 . Patients who received $\geq 80 \%$ of the prescribed RBV dose experienced a greater chance of having an SVR than those who received $<80 \%$. The SVR rate was also lower in patients who received $\geq 80 \%$ of the prescribed PEG-IFN-alpha dose but less than $80 \%$ of the RBV dose when compared with subjects who completed $\geq 80 \%$ of the RBV dose $(48 \%$ vs. $69 \%, P=0.014)$. Patients who completed $\geq 80 \%$ of both PEG-IFN and ribavirin had the lowest SVR (29\%). Ribavirin dose changes after 24 weeks in patients infected with HCV genotype 2 or 3 had no effect on SVR rates. Shiffman (2004) found similar results in a retreatment study in patients who had failed previous unmodified interferon-based therapy. In this trial, the reduction of the PEG-IFN-alpha-2a dose during the first 20 weeks of therapy did not greatly affect SVR. However, the reduction of the RBV dose from $>80 \%$ to $<60 \%$ of the target dose during the first 20 weeks did significantly reduce the SVR rate $(21 \%$ vs. $11 \%, P=0.03)$. Decreases in dosages of either medication had little effect on SVR after 20 weeks of therapy. 


\section{Predictors of Response and Duration of Therapy}

Significant predictors of SVR (by multiple regression analysis) for patients receiving monotherapy with PEG-IFN-alpha-2a include the following baseline parameters: genotype non-1, serum HCV RNA levels $<2$ million copies/mL, absence of cirrhosis, alanine aminotransferase quotient (ALT) $>3$ (average ALT values prior to therapy, divided by the upper limit of normal), body weight $<85 \mathrm{~kg}$, age $<40$ years, and HAI >10 (histological activity index) (Lee et al., 2002). Race and gender were not statistically significant predictors in this review. In contrast, logistic regression analysis of baseline characteristics in patients receiving PEG-IFN-alpha-2b revealed only two significant predictive factors (an HCV genotype other than 1 and an HCV RNA viral load $\leq 2$ million copies/mL serum) (Lindsay et al., 2001).

Lee (2002) performed an analysis of outcomes in patients with chronic HCV infection receiving peginterferon-alpha-2a monotherapy to determine the predictive value of periodic HCV RNA concentrations for the achievement of an SVR. Patients with an undetectable HCV RNA ( $<100$ copies/mL) or a $\geq 2 \log _{10}$ drop in viral load from baseline at week 12 (EVR: early virological response) showed a negative predictive value of 0.98. Accordingly, if a patient does not achieve an EVR by week 12 , only $2 \%$ of subjects would achieve an SVR. It is important to note that due to assay variability, the measured HCV RNA concentration may vary up to $0.5 \log _{10}$. The issue should be considered when making decisions about stopping or continuing therapy. From these data, for patients receiving monotherapy with peginterferon-alpha for chronic HCV infection, decisions on whether to continue or stop therapy should be based on the HCV RNA concentration at week 12 of therapy utilizing the EVR criteria (National Institutes of Health Consensus Development Conference Statement: Management of Hepatitis C, 2002).

For combination therapy, multiple logistic regression analysis revealed only three baseline factors associated with a significant likelihood of achieving an SVR in patients receiving PEG-IFN-alpha-2a with RBV (Fried et al., 2002). These are a non-1 HCV genotype, age $\leq 40$ years of age, and weight $\leq 75 \mathrm{~kg}$. Manns (2001) performed a similar analysis of significant predictors of SVR in subjects receiving PEG-IFN-alpha-2b and RBV. These are a non-1 HCV genotype, a lower baseline viral load, lighter weight, younger age, and absence of bridging fibrosis/cirrhosis. Significant factors predictive of an SVR in patients with HCV genotype 2 or 3 were treatment duration of at least 16 weeks, baseline HCV RNA concentrations, and hepatic steatosis less than 5\% (Zeuzem et al., 2004). For patients infected with HCV genotype 4, Kamal (2005) identified, by multivariate analysis, viral load ( $\leq 2$ million copies $/ \mathrm{mL}$ ), age $\leq 40$ years, and therapy duration as significant predictors of an SVR.

Davis (2002) reviewed two studies using PEG-IFN-alpha-2a or -2b plus RBV to determine whether an early virological response to therapy could predict the likelihood of achieving an SVR and be used to develop early stopping rules for therapy. The early virological response (EVR) that had the best negative predictive value for SVR (98.4\%) was determined to be a fall in HCV RNA from baseline by $\geq 2 \log _{10}$ units or an undetectable level as measured by a quantitative PCR method 
at 12 weeks of therapy. Therefore, if therapy was discontinued in those patients who had not demonstrated an EVR, 1.6\% of subjects would have achieved an SVR had therapy continued. Subgroup analysis by HCV genotype also showed that the above definition of EVR was applicable regardless of infection with genotype 1 or genotype 2 or 3 . The negative predictive value for patients infected with genotype 1 or genotype 2 or 3 was $99 \%$ and $91 \%$, respectively. The author recommended that patients infected with genotype 1 who achieve an EVR at 12 weeks should complete a full 48 weeks of combination therapy. Subjects who do not achieve an EVR should have therapy discontinued. If an EVR is achieved but HCV RNA is still detectable, patients should be retested at 24 weeks and, if still positive for HCV RNA using a sensitive qualitative PCR method, therapy should be discontinued. Patients infected with HCV genotype 2 or 3 need not undergo viral load testing at 12 weeks and should automatically be treated for a total of 24 weeks. Caution should be used in extrapolating these findings to other $\mathrm{HCV}$-infected patient populations.

\section{Efficacy of Longer Treatment Duration}

Clinical trials have been performed to determine if prolonging therapy with PEGIFN plus RBV has an effect on SVR rates over the current 54-63\%. Berg (2006) randomized treatment-naïve patients infected with HCV genotype 1 into two groups. Group A received PEG-IFN-alpha-2a (180 $\mu \mathrm{g} /$ weekly) plus RBV (800 mg daily) for 48 weeks, and Group B received the same regimen for 72 weeks. Patients were followed for 24 weeks after therapy completion. Study results showed no advantage for prolonging therapy in the overall population. The overall SVR for Groups A and B were 53\% and 54\%, respectively. Subgroup analysis did show an advantage for 72 versus 48 weeks of therapy in subjects who were HCV RNA positive at week 12 (SVR, 29\% vs. 17\%, $P=0.04$ ). Relapse rates were lower in subjects with a slow virological response in Group B versus Group A who became HCV RNA negative for the first time at week 12 or 24. Patients with an EVR (undetectable HCV RNA concentrations at 4 or 12 week) had SVR rates between $76-84 \%$. The duration of treatment was not a factor in these subjects. Although adverse events were similar in severity and incidence, discontinuation rates were greater in Group B. The authors recommend that prolonged therapy be reserved for patients infected with HCV genotype 1 who are HCV RNA positive at therapy week 12 but with undetectable concentrations at week 24 of therapy.

Sánchez-Tapias (2006) investigated whether extending the duration of therapy in patients with detectable HCV RNA concentrations at week 4 of therapy (RVR) would improve SVR rates in subjects with chronic HCV infection. Patients received the same dosing regimen of PEG-IFN-alpha-2a and RBV as mentioned above. Patients without an RVR were randomly assigned to receive either 48 weeks (Group A) or 72 weeks (Group B) of therapy and 24 weeks of followup. The overall SVR rates for Group A and Group B were $32 \%$ and $45 \%$, respectively $(P=0.01)$. Although the end-of-treatment response was identical in both groups $(61 \%)$, the relapse rate was significantly higher in Group A versus Group B (48\% and 26\%, 
respectively). In patients with HCV genotype 1 infection, the SVR was $28 \%$ (Group A) and 44\% (Group B) $(P=0.003)$. As in the study by Berg (2006), the dropout rate was higher in the 72-week versus the 48-week group. Both studies by Berg (2006) and Sanchez-Tapias (2006) indicated that it is difficult for patients to complete 72 weeks of therapy. . The RBV dose used in these studies was low when compared to current standards, and this may have influenced response to therapy. More study will be necessary to determine the value of prolonging PEG-IFN-alpha therapy utilizing weight-based ribavirin (i.e., 1-1.2 g/daily) in HCV-infected patients with a slow virological response to therapy.

\section{Use of Rapid Virological Response at 4 Weeks to Determine Shorter Duration of Therapy n Select Groups of Patients with Chronic HCV Infection}

Investigations into the possibility of treating select patients for a shorter period of time have been undertaken. Shorter duration of therapy with equal efficacy has the advantage of increased cost efficiency and potentially reduced adverse drug events. Zeuzem (2006) performed a study to investigate whether 24 weeks of PEG-IFNalpha-2b plus RBV (weight-based) would be as effective as 48 weeks (historical control group) in patients infected with chronic HCV genotype 1 and low baseline HCV RNA concentrations $(\leq 600,000 \mathrm{IU} / \mathrm{mL})$. When SVR was compared, the 24week regimen (50\%) was inferior to the 48-week regimen (69\%). Subgroup analysis, however, showed that those subjects with undetectable serum HCV RNA after 4 weeks of therapy (rapid virological response, RVR) had an SVR rate of $89 \%$. If the serum HCV RNA was undetectable after both 4 and 24 weeks of therapy, the SVR was $92 \%$. Liver biopsy revealed the presence of mild inflammation and an average Knodell fibrosis score of 1.2. Adverse events that led to the discontinuation of therapy or dose reduction were less in the 24-week study compared to rates during the initial 24 weeks and 48 weeks in the historical control group.

Jensen (2006) performed a retrospective analysis reviewing the association between an RVR at 4 weeks and SVR in patients receiving PEG-IFN-alpha-2a with RBV, infected with HCV genotype 1. They utilized data from the Hadziyannis study (2004). The primary focus of the analysis was on those patients who achieved an SVR after 24 weeks of therapy and had an RVR. Of the patients treated for 24 weeks, 24\% achieved an RVR. Eighty-nine percent of patients with an RVR at 4 weeks achieved an SVR after 24 weeks of therapy versus $19 \%$ without an RVR. The authors compared the length of therapy and noted no difference in SVR in patients with an RVR at 4 weeks treated for 24 or 48 weeks. Multiple logistic analyses revealed an RVR at 4 weeks and baseline HCV RNA concentration $(<2,000,000$ $\mathrm{IU} / \mathrm{mL}$ versus $>600,000 \mathrm{IU} / \mathrm{mL}, P<0.026$ ) correlated with an SVR. It is important to note that only $7 \%$ and $18 \%$ of subjects in this study had cirrhosis or bridging fibrosis on liver biopsy, respectively. Whether these results can be extrapolated to patients with more severe liver disease is unknown. Ferenci (2006) reported a 75\% 
SVR in patients (HCV genotype 1 or 4 ) treated with PEG-IFN-alpha-2a and RBV for 24 weeks and an RVR at 4 weeks of therapy. In this prospective study, patients with an SVR had lower baseline HCV RNA concentrations than those who relapsed after an end-of-therapy response.

The European Medicines Agency (EMEA) has approved short-course therapy (24 weeks) of combined PEG-IFN-alpha-2b (1.5 $\mu \mathrm{g} / \mathrm{kg} /$ week) plus RBV (800-1,200 $\mathrm{mg} /$ daily) in patients with chronic HCV genotype infection with low viral HCV load. Patients must also have an undetectable serum HCV RNA at 4 and 24 weeks of therapy.

Trials to investigate the efficacy of a shorter duration of therapy for the patients with HCV genotype 2 or 3 who experience an RVR after 4 weeks of PEG-IFNalpha- $2 \mathrm{~b}$ or $-2 \mathrm{a}$ combined with RBV have been performed. In the study by Mangia (2005), patients received $1.0 \mu \mathrm{g} / \mathrm{kg} /$ week PEG-IFN-alpha-2b plus RBV 1-1.2 g daily via a randomization to one of two groups. Group 1 received therapy for 24 weeks. Patients who experienced an RVR at 4 weeks (Group 2) received therapy for 12 weeks, and subjects who did not have an RVR were treated for 24 weeks. Overall, patients in Group 1 and Group 2 that had an RVR had an SVR rate of 91\% and $85 \%$, respectively. Patients with an RVR infected with genotype 2 had an SVR rate of $89 \%$ and $87 \%$ in Groups 1 and 2, respectively. Although the SVR rate in patients infected with HCV genotype 3 who achieved an RVR was not statistically different, the response was $100 \%$ in Group $1(n=10)$ and $77 \%$ in Group $2(n=24)$.

Von Wagner (2005) performed a similarly designed study in patients infected with chronic HCV genotype 2 or 3 who received PEG-IFN-alpha-2a (180 $\mu \mathrm{g} /$ week) plus RBV (800-1,200 mg daily). Patients were treated for 4 weeks, and those subjects with an undetectable HCV RNA (RVR) were allocated to receive a total of 16 (Group A) or 24 weeks (Group B) of therapy. Subjects with detectable HCV RNA concentrations at 4 weeks received 24 weeks of therapy (Group C). An SVR was achieved in $82 \%$ and $80 \%$ of patients in Groups A and B, respectively. Interestingly, subjects without an RVR (Group C) had an SVR of 36\% versus $81 \%$ in Group B even though both groups received therapy for 24 weeks. As in the study above, the SVR for subjects infected with HCV genotype 2 was greater than in those with HCV genotype 3, 92\% versus $73 \%$. Baseline viral load did not affect the SVR rate for patients with HCV genotype 2. However, a baseline viral load >800,000 IU/mL significantly affected the SVR rate in patients infected with genotype 3 compared with lower viral loads $(P=0.003)$. Patients infected with HCV genotype 3 and a baseline viral load $>800,000 \mathrm{IU} / \mathrm{mL}$ experienced a higher SVR rate when treated for 24 weeks than 16 weeks, although the difference was not statistically different $(P>$ 0.2 ). These results strongly favor a shorter duration of therapy in patients infected with HCV genotype 2 who experience an RVR to therapy. The results in patients infected with HCV genotype 3 raise the question of whether 24 weeks or longer of therapy may be necessary to assure maximum SVR rates. This may be especially true in subjects with high baseline HCV RNA viral loads. The Genotype 3 Extended Treatment for Hepatitis C (GET-C) Study is designed to determine the efficacy of 24 or 48 weeks of therapy with PEG-IFN-alpha-2b plus RBV in patients infected with HCV genotype 3 and high baseline viral loads (ClinicalTrials.gov identifier NCT00255034). 


\section{Health-Related Quality-of-Life and Cost-Effectiveness Analysis of Peginterferon-Alpha with or Without Ribavirin}

Current treatment regimens for the management of chronic HCV infection can affect quality of life and are costly. Rasenack and colleagues (2003) have compared the effect of monotherapy with PEG-IFN-alpha-2a or unmodified interferon on the health-related quality of life in treatment-naïve subjects with chronic HCV infection. The Fatigue Severity Scale (FSS), including the visual analogue scale (VAS), was used to measure fatigue severity. Health-related quality of life measures were assessed using the Short-Form health survey (SF-36). Therapy duration in both groups was 48 weeks. The PEG-IFN-alpha-2a patients had better mean FSS total scores and FSS VAS scores during the first 24 weeks and at week 48, respectively, when compared with subjects receiving unmodified interferon. The SF-36 domain scores were better at week 12 but not at week 24 or 48 in patients in the PEGIFN-alpha-2a versus the unmodified interferon group. Overall, subjects receiving PEG-IFN-alpha-2a reported less fatigue and less body pain and performed better on a daily basis than patients receiving unmodified interferon. The mean FSS and SF-36 scores were improved in patients who achieved an SVR versus those subjects who did not experience an SVR.

The question as to whether monotherapy with PEG-IFN-alpha is cost-beneficial has been studied in a cost-benefit analysis of treatment-naïve subjects with chronic $\mathrm{HCV}$ infection. Outcome data were reviewed from published studies of PEG-IFNalpha monotherapy (Shepherd et al., 2004). The authors concluded that the use of peginterferon-alpha was overall cost-effective, with an increase in this benefit in subjects infected with genotypes 2 and 3 .

Hassanein (2004) performed a health-related quality-of-life analysis utilizing data from a large multinational study of patients with chronic HCV infection. Patients were treated with PEG-IFN-alpha-2a with or without RBV or unmodified interferon-alpha-2b plus RBV. The Fatigue Severity Scale (FSS) and the SF-36 Health Survey were used to assess the effect of therapy on health-related quality of life. Patients receiving PEG-IFN-alpha-2a plus placebo fared better on healthrelated quality-of-life measures (SF-36 and FSS) versus subjects in the PEG-IFNalpha-2a/RBV and unmodified interferon/RBV groups. Patients receiving PEGIFN-alpha-2a/RBV reported better health-related quality-of-life measures on both SF-36 and FSS surveys over the 48 weeks of therapy than those receiving unmodified interferon/RBV. Significant differences were reported in vitality, social functioning, body pain, and total fatigue and fatigue severity. Improvements in healthrelated quality-of-life scores in favor of the PEG-IFN/RBV group were observed as early as week 2 of therapy. Patients who achieved an SVR had improved quality of life, with the greatest improvement over baseline in role-emotional, vitality, general health, and role limitation physical domains in the SFG-36 survey. Fatigue severity decreased significantly in subjects experiencing an SVR versus those who did not. Studies investigating the cost-effectiveness of treatment of chronic HCV infection utilizing PEG-IFN-alpha-2b/RBV compared with unmodified interferon/RBV have been published (Bernfort et al., 2006; Buti et al., 2005; Siebert et al., 2003). 
Although the studies varied in design, the PEG-IFN-alpha-2b/RBV regimens were cost-effective when compared with unmodified interferon/RBV regimens in the Swedish, Spanish, and German healthcare systems.

Sullivan (2006) analyzed the cost-effectiveness of the combination of PEG-IFNalpha-2a/RBV compared with unmodified interferon-alpha-2b/RBV. The authors concluded that the combination of PEG-IFN-alpha-2a plus RBV prolongs life expectancy and saves medical costs when compared with unmodified interferonalpha-2b with RBV in the U.S. healthcare system. Hornberger (2005) reported similar findings with PEG-IFN-alpha-2a/RBV compared with no therapy in subjects with mild chronic HCV infection. The authors utilized United Kingdom treatment patterns in the design of their study.

Improvement in the quality of life, especially early in therapy, with PEG-IFN with or without RBV may reduce the need to alter doses based on subjective findings, encourage patients to complete the duration of therapy, and increase the likelihood of achieving an SVR. Therapy of chronic HCV infection with PEG-IFN with or without RBV is cost-effective when compared with unmodified interferon therapy in a variety of healthcare systems.

\section{Special Patient Populations}

\section{Acute HCV Infection}

Another avenue to decrease the impact of prolonged HCV infection and its complications is to treat patients upon presentation with acute HCV infection. Acute HCV infection may be difficult to identify and is often asymptomatic. Infection is acquired through intravenous drug abuse, needle-stick injury in healthcare workers, medical procedures utilizing inappropriately sterilized equipment, and sexual activity. Spontaneous viral clearance may occur in $14-46 \%$ of patients and may occur within 8 to 14 weeks of the onset of disease (Seeff, 2002; Kamal et al., 2006). The optimal timing to initiate therapy and the length of treatment have not been definitively determined. Kamal and colleagues (2006, 2006a) have investigated these two issues in randomized controlled clinical trials. In the first study, Kamal (2006) enrolled 129 patients with acute $\mathrm{HCV}$ infection to determine the optimal time to initiate therapy. Patients were divided into three groups and therapy was begun 8 weeks, 12 weeks, and 20 weeks after onset of disease. Patients in each group received PEGIFN-alpha-2b $(1.5 \mu \mathrm{g} / \mathrm{kg} /$ week $)$ for a total of 12 weeks. Patients who did not want therapy were followed as a control group. Approximately $30 \%$ of subjects in the control group had a spontaneous clearance of HCV. The overall SVR was $88 \%$. The SVR rates for the weeks of initiation of therapy were 95\% (week 8), 93\% (week 12), and $76 \%$ (week 20). The overall SVR rates by genotype were $72 \%$ (genotype 1), $100 \%$ (genotype 2), 93\% (genotype 3), and 84\% (genotype 4). Predictors of an SVR were non-1 genotype and a low baseline HCV RNA viral load. Kamal (2006a) performed a study to determine the optimal duration of therapy for the management 
of acute HCV infection. Patients were randomized to receive 8 weeks, 12 weeks, or 24 weeks of therapy. Participants received the same dose of peginterferon-alpha- $2 b$ listed above. The overall SVR rate was $80 \%$ with $68 \%, 82 \%$, and $91 \%$ of patients achieving an SVR after 8, 12, and 24 weeks of therapy, respectively. As a result of these two studies, the authors made the following recommendations for the treatment of patients with acute HCV infection. Patients infected with HCV genotype 1 (especially with a high baseline viral load) should begin therapy at 8 weeks after infection and continue for 24 weeks. Subjects infected with genotype 2 or 3 should begin therapy at 12 weeks after infection and continue therapy for 8 to 12 weeks. They made the caveat that the number of patients in the study infected with genotype 2 or 3 was small, however. Patients infected with genotype 4 should begin therapy at 12 weeks' post-infection and be treated for 12 weeks. Eight weeks of therapy may be an option in patients infected with HCV genotype 4 with low baseline viral loads. To avoid unnecessary treatment, initiation of therapy is delayed to account for the possibility of spontaneous viral clearance. More studies will be necessary to validate these suggestions.

\section{African American Patients}

African Americans (AA) appear to have a decreased response to interferon therapy with or without RBV for chronic HCV infection as compared with Caucasians (CA). Conjeevaram (2006) conducted a trial comparing the efficacy of PEG-IFN-alpha2a (180 $\mu \mathrm{g} /$ week)/RBV (1-1.2 g/day) in AA versus CA who were treated for 48 weeks with a 24-week followup. Both groups were infected with HCV genotype 1. A difference between the two groups in virological response was evident from week 4 until week 48. Significantly more CA had undetectable HCV RNA serum levels than AA at all time points. The SVR rate was $28 \%$ and $52 \%$ in the AA and CA groups, respectively $(P<0.0001)$. The proportion of subjects that completed $80 \%$ of the maximum doses of both drugs differed significantly (54\% AA and $73 \%$ CA, $P<0.0001)$. In addition, the AA patients had a higher mean body mass index, higher incidence of hypertension and diabetes, and lower neutrophil and hemoglobin levels than the CA patients. These factors may decrease response to therapy or tolerance of adverse effects of treatment regimens with PEG-IFN and RBV. In spite of these facts, the authors concluded that the amount of therapy completed, baseline viral loads, or disease characteristics did not explain the study findings. In a smaller study utilizing the identical medication regimen as above, Jeffers (2004) reported an SVR rate of $26 \%$ in the AA group and $39 \%$ in the CA group. The lower-than-expected response in the CA group was attributed to the small number in the study arm, the high drop-out rate, and the fact that fewer subjects were available for followup.

Jacobson (2004) compared the value of PEG-IFN-alpha-2b (1.5 $\mu \mathrm{g} / \mathrm{kg} /$ week) with either weight-based (WB) (800-1,400 mg/day) or standard (SD) RBV doses ( $800 \mathrm{mg} /$ day) in AA infected with HCV genotype 1. The SVR rates in the two dosing groups were $21 \%$ (WB) and $10 \%$ (SD). Dose reductions of RBV for anemia 
were higher in the WB (12\%) versus the SD (8\%) group, but therapy discontinuation for adverse events was comparable between the two groups.

The Virahep-C trial is attempting to determine the etiology for the lower response rates to PEG-IFN/RBV regimens in AA versus CA. Howell (2006) noted that the poor virological response in AA could not be explained by altered pharmacokinetics or pharmacodynamics of PEG-IFN-alpha-2a during the first 4 weeks of therapy. Rhodes (2006) investigated the effect of the major histocompatibility complex on the likelihood of achieving an SVR in AA and CA patients. They reported that the HLA alleles $A^{*} 02, B^{*} 58$, and DPB*1701 are associated with an SVR. However, these alleles do not explain the observed difference in SVR rates between AA and CA. Su (2006) studied whether differences in interferon signaling could explain the observed SVR differences between AA and CA. The single nucleotide polymorphism rs3213545 in the OASL gene ("T" allele) was associated with SVR in both AA and CA. The "T" allele was found in approximately $51 \%$ and $31 \%$ of CA and AA, respectively. An SVR rate of 50.7\% was observed in subjects with the "T" allele and $34.1 \%$ of participants without the allele. Burton (2006) looked at whether baseline $\mathrm{HCV}$-specific immune responses could account for the difference in PEG-IFN/RBV-induced SVR between AA and CA.They measured the response of peripheral blood mononuclear cells to HCV antigens (core, E2, NS3, NS4, and NS5) of 179 AA and 174 CA. Approximately $31 \%$ of AA who had a combined baseline HCV antigen response at or above a specific threshold experienced an SVR versus only $23 \%$ with a lesser response. Similarly, $53 \%$ of CA who achieved the threshold response achieved an SVR versus $39 \%$ with a lesser response. In AA patients, 30.6\% who achieved the threshold response achieved an SVR versus $22.5 \%$ with a lesser response. The authors conclude that regardless of race, baseline HCVdirected immunity is important to achieve an SVR. These results indicate that a definitive cause of the observed lower SVR rates in AA versus CA receiving PEGIFN-alpha/RBV therapy remains elusive. The reduced response to pegylated interferons/RBV therapy in AA versus CA may result from a combination of negative predictive factors present in the AA population rather than a single etiology.

\section{Persistently Normal Alanine Transaminase (PNALT) Levels}

Persistently normal ALT (PNALT) levels in patients with chronic HCV infection may be present in up to $30 \%$ of subjects with chronic HCV infection (National Institutes of Health Consensus Development Conference Statement: Management of Hepatitis C, 2002). Shiffman (2006) reported that patients with PNALT levels have lower HCV RNA titers and lower liver inflammation and fibrosis scores on biopsy than patients with persistently elevated ALT levels. Approximately two-thirds of patients had portal fibrosis, and $10 \%$ revealed bridging fibrosis on liver biopsy. Quality of life is similarly impaired in subjects with PNALT as in HCV-infected patients with elevated ALT concentrations (Gane et al., 2005). These data indicate that patients with PNALT levels and chronic HCV infection should be considered for therapy since ALT concentrations do not correlate with liver pathology and patients 
are at risk for disease progression. Zeuzem (2004a) reported the results of an international, multicenter, randomized trial of the efficacy of PEG-IFN-alpha-2a (180 $\mu \mathrm{g} /$ week) plus RBV (800 mg daily) in chronic HCV-infected patients with PNALT levels. Patients were treated for 24 weeks (Group A) or 48 weeks (Group B). Patients with cirrhosis, other liver diseases, or co-infection with the human immunodeficiency virus (HIV) were excluded. An SVR was achieved in 30\% (Group A) and $52 \%$ (Group B) of patients $(P<0.001)$. For HCV genotype 1 infected patients, an SVR occurred in 13\% (Group A) and 40\% (Group B) $(P<0.001)$. Patients infected with genotype 2 or 3 achieved an SVR 72\% (Group A) and 78\% (Group B) of the time $(P=0.45)$. Thirteen percent and $56 \%$ of subjects infected with HCV genotype 4 achieved an SVR in Group A and B, respectively. Treatment duration (48 weeks) and low baseline HCV load correlated with the likelihood of achieving an SVR in patients with genotype 1 or 4 but not for patients infected with genotype 2 or 3 . Patients younger than 40 years of age had a higher chance of achieving an SVR than subjects over 40 years of age. Arora (2006) assessed the effect of achieving an SVR on overall quality-of-life measures in subjects with chronic HCV infection and PNALT. Patients who experienced an SVR had improved quality of life and lower fatigue than patients who did not respond to therapy.

Zehnter (2006) compared the value of PEG-IFN-alpha-2a (180 $\mu \mathrm{g} /$ week) combined with RBV (1-1.2 g/day) in 911 patients infected with HCV genotype 1 and elevated ALT concentrations and 265 subjects with PNALT levels. Patients received therapy for 48 weeks with a 24-week followup off therapy. Patient groups were well matched; however, subjects with PNALT levels tended to be younger. The SVR rates were $74 \%$ and $51 \%$ in subjects with PNALT levels versus those with elevated ALT concentrations, respectively. The authors surmised that the higher SVR in the patients with PNALT levels could be attributed to the younger age in this group. Overall, patients with PNALT concentrations should be considered for treatment based on factors similar to those in patients with elevated ALT levels. Therapy choices appear to be the same as in patients with chronic HCV infection and elevated ALT concentrations.

\section{Nonresponders and Relapsers to Unmodified Interferon with or Without Ribavirin}

Patients who do not achieve an SVR to interferon with or without RBV are designated as nonresponders. Null responders are nonresponders who fail to achieve less than a $2 \log _{10}$ decline in HCV RNA concentrations from baseline 12 weeks after therapy initiation. These patients rarely respond to additional therapy, and the most appropriate therapy for these patients is best determined in controlled trials (DiBisceglie et al., 2006). Evidence from Tang (2005) that rapid clearance of HCV may be important in enhancing host response to the virus may provide clues to the design of new treatment combinations for these difficult-to-treat patients. Although patients who relapse are not technically nonresponders, they will be discussed here. 
The lead-in component of the HALT-C trial is investigating the value of retreatment of patients with chronic HCV infection and advanced fibrosis or cirrhosis who failed therapy with unmodified interferon with or without ribavirin (Shiffman et al., 2004). Subjects received PEG-IFN-alpha-2a at $180 \mu \mathrm{g} /$ week with RBV (1-1.2 g/day). Patients with undetectable HCV RNA levels at week 20 were treated for a total of 48 weeks and followed for SVR at 24 weeks' post-therapy. Patients with detectable HCV RNA concentrations at 20 weeks were entered into the maintenance phase of the study. Although $32 \%$ of subjects were HCV RNA negative at week 48, the relapse rate was high and only $18 \%$ achieved an SVR. Factors associated with an SVR were absence of cirrhosis, prior treatment with interferon monotherapy, genotype 2 or 3 , HCV RNA concentrations $<1.5$ million IU/mL, and an AST:ALT ratio $<1.0$.

Diago (2006) performed an induction dose study with PEG-IFN-alpha-2a plus RBV in HCV genotype 1 infected patients who had not responded to $\geq 22$ weeks of unmodified interferon/RBV. No patients had cirrhosis. Patients were randomized to $180 \mu \mathrm{g} /$ week, $270 \mu \mathrm{g} /$ week, or $360 \mu \mathrm{g} /$ week of PEG-IFN-alpha-2a with RBV (1-1.2 g/day) for 12 weeks followed by PEG-IFN at $180 \mu \mathrm{g} /$ week with the same RBV dose for an additional 36 weeks. An SVR was achieved in 18\% (180 $\mu \mathrm{g} / \mathrm{week})$, $30 \%(270 \mu \mathrm{g} /$ week $)$, and $38 \%$ (360 $\mu \mathrm{g} /$ week) in the respective dosing regimen arms. Izumi (2006) investigated the effect of PEG-IFN-alpha-2a (180 $\mu \mathrm{g} /$ week) plus RBV (600-1,000 mg/day) in Japanese patients with chronic HCV infection who had not responded to prior unmodified interferon monotherapy. A much higher rate of SVR was noted in this population than was found in the HALT-C trial or by Diago (2006). Forty-eight percent of patients had an SVR overall, and $50 \%$ of subjects infected with HCV genotype 1 b experienced an SVR after 48 weeks of therapy.

Similar retreatment studies in subjects who did not respond to unmodified interferon with or without RBV have been performed by Taliani (2006), Jacobson (2005a), and Poynard (2005) utilizing PEG-IFN-alpha-2b with RBV. Although study population, trial design, and dosing regimens were different, the SVR rates are similar to those found with PEG-IFN-alpha-2a (180 $\mu \mathrm{g} / \mathrm{week} / \mathrm{RBV})(15-21 \%)$. Gaglio (2005) found that fixed-dose RBV was equally as effective as weight-based dosing in patients who failed prior unmodified interferon-based therapy. Jacobson (2005a) noted an SVR of only $8 \%$ in subjects who were nonresponders to unmodified interferon/RBV therapy versus an SVR rate of $21 \%$ in subjects with no response to unmodified interferon monotherapy. Factors associated with an SVR in these studies were low baseline HCV RNA levels, low $\gamma$-glutamyltransferase $(\gamma$-GT), weight $>75 \mathrm{~kg}$, genotype non-1, and nonresponse to interferon monotherapy.

The "RENEW" study was designed to compare the benefits of $1.5 \mu \mathrm{g} / \mathrm{kg} /$ week versus $3.0 \mu \mathrm{g} / \mathrm{kg} /$ week of PEG-IFN-alpha-2b with RBV (800-1,400 mg daily) in the management of patients who had failed previous HCV therapy with unmodified interferon/RBV (Gross et al., 2005). Ninety-one percent of subjects had HCV genotype $1,40 \%$ had a Metavir score 3 or 4 (F3/4), and 16\% were African American (AA). Treatment duration was 48 weeks with a 24 -week followup. An SVR occurred in $12 \%$ and $17 \%$ in the $1.5-$ and the $3.0-\mu \mathrm{g} / \mathrm{kg} /$ week dosing groups, respectively $(P=0.03)$. Overall, patients with F3/4 and African Americans had lower SVR rates; however, subjects in these groups receiving the higher dose of 
PEG-IFN achieved comparable SVR rates to the other study members. The SVR rate for the 1.5- and 3.0- $\mathrm{gg} / \mathrm{kg} /$ week PEG-IFN-alpha-2b dosing regimens for AA subjects were $2.0 \%$ and $14 \%$, respectively (Gross et al., 2005a). Therapy discontinuations and dose changes were comparable between the two dosing groups. Despite differences in study design, patient population, and dosing, the SVR rates with both PEG-IFN products in nonresponders to unmodified interferon-based regimens were remarkably similar (15-21\%). Induction dosing with PEG-IFN-alpha-2a appeared to improve the chance of achieving an SVR, but further studies with larger numbers of patients will be necessary to validate these findings.

The likelihood of achieving an SVR is greater in patients who relapse after unmodified interferon monotherapy or combination therapy with RBV. Relapse is defined as a detectable HCV RNA in serum after a patient has had an end-of-therapy response (undetectable HCV RNA). Yoshida (2005) conducted a study including 119 patients who had relapsed after interferon monotherapy or combination therapy with RBV. Patients were assigned to receive either 24 or 48 weeks of PEG-IFN 180 $\mu \mathrm{g} /$ week with $800 \mathrm{mg} /$ day of RBV. Forty-seven percent of patients had advanced fibrosis. Overall, the SVR was $40 \%$. Thirty-five percent and $51 \%$ of patients with genotype $1 / 2$ or 3 experienced an SVR, respectively. Nevens (2005) found an overall SVR of $43 \%$ in subjects receiving $180 \mu \mathrm{g} /$ week of PEG-IFN-alpha-2a and RBV (1-1.2 g/day). Patients had relapsed after receiving unmodified interferon with or without RBV.

In the EPIC trial reported by Poynard (2005), patients who relapsed after therapy with unmodified interferon with RBV were treated for 48 weeks with 1.5 $\mu \mathrm{g} / \mathrm{kg} /$ week of PEG-IFN-alpha-2b with weight-based RBV. Nonresponders to this therapy were placed into the maintenance phase of the study. An overall SVR of $39 \%$ was achieved in relapse patients. The SVR rate was higher in the patients infected with HCV genotype 2 or 3 than in those with genotype 1 (58\% vs. 29\%). Similarly, Jacobson (2005a) reported an overall SVR of $42 \%$ in subjects who had relapsed after combination interferon/ribavirin therapy. Even though the medication regimens and patient populations were different, the overall SVR for patients who relapsed after unmodified interferon with or without ribavirin were comparable between the two peginterferons.

Herrine (2005) investigated the value of combining PEG-IFN-alpha-2a 180 $\mu \mathrm{g} /$ week with or without RBV with amantadine (AMD) or mycophenolate mofetil (MMF) in patients who had an increase in HCV RNA levels during therapy (breakthrough) or relapse during or after receiving unmodified interferon/RBV therapy. Subjects were assigned to one of four treatment groups. Group A received PEGIFN-alpha-2a plus RBV (800-1,000 mg daily), Group B received PEG-IFN-alpha2a plus $1 \mathrm{~g}$ of MMF orally twice daily, Group C received PEG-IFN-alpha-2a and AMD $200 \mathrm{mg}$ daily, and Group D received PEG-IFN-alpha-2a plus AMD $200 \mathrm{mg}$ daily plus ribavirin (800-1,000 mg daily). Treatment duration was 48 weeks with a 24-week followup period. An SVR was achieved in $37.5 \%$ (Group A), $17.2 \%$ (Group B), 9.7\% (Group C), and 45.2\% (Group D) of subjects. Only Groups D and $\mathrm{C}$ were significantly different when compared, $P=0.02$. The study revealed no clear advantage of combining amantadine to PEG-IFN/RBV therapy. The combination of AMD with MMF and PEG-IFN alone offered no advantage over RBV-containing 
regimens. More study will be necessary with combination therapy (Group A versus Group D) plus standard doses of ribavirin (1-1.2 g/day) to determine efficacy in relapse or breakthrough situations.

The ideal therapy with which to treat patients who do not respond or relapse after therapy with unmodified interferon/ribavirin regimens has not been definitively determined. It is known, however, that the risk of a nonresponse or relapse is increased in subjects who require dosage reduction of PEG-IFN and RBV during therapy (Ferenci et al., 2005; Shiffman et al., 2004). Steps to reduce the need for regimen alterations, including supportive medications (i.e., erythropoietin, filgrastim) and psychiatric evaluation, should be considered as part of any retreatment with PEG-IFN/RBV (Collantes \& Younossi, 2005). An assessment of adherence is also important, and adherence-building exercises should be considered. Treatment of alcohol and other substance abuse conditions is critical before beginning retreatment.

\section{Relapse or Nonresponse to Peginterferons}

Few studies have looked at treatment of patients who have failed therapy with PEG-IFN-alpha/RBV. Berg (2006a) took patients who relapsed after 24 weeks of PEG-IFN-alpha-2a at $180 \mu \mathrm{g} /$ week with RBV (800 mg or $1-1.2 \mathrm{~g}$ daily) and retreated them for an additional 48 weeks. Treatment was initiated at the same dose (PEG-IFN-alpha-2a/ribavirin) they had received before. The overall SVR was 55\%. Fifty-one percent and $64 \%$ of subjects infected with HCV genotypes 1 and 2 or 3 achieved an SVR, respectively. Kaiser (2006) compared the efficacy of consensus interferon/RBV with PEG-IFN-alpha-2a/RBV in subjects who had relapsed after 48 weeks of PEG-IFN/ribavirin therapy. Group A received daily consensus interferon $(9 \mu \mathrm{g})$, and Group B received standard PEG-IFN $(180 \mu \mathrm{g} / \mathrm{week})$ dosing. Both groups received weight-based RBV for a total of 72 weeks. Eighty-three percent of patients were infected with HCV genotype 1 . The SVR for Groups A and B were $69 \%$ and $44 \%$, respectively, $P<0.05$. A clinical study is under way to determine the safety and efficacy of daily high-dose consensus interferon/RBV therapy in subjects who are nonresponders to combined PEG-IFN-alpha and ribavirin (ClinicalTrials.gov identifier: NCT00266318).

The "REPEAT" study is a multinational trial to test the value of an induction dose of PEG-IFN-alpha-2a plus RBV compared with standard-dose PEG-IFN-alpha$2 \mathrm{a} / \mathrm{RBV}$ in patients who are nonresponders to PEG-IFN-alpha-2b/RBV therapy. Patients were randomized to four treatment groups. Groups A and B received PEGIFN-alpha-2a at $360 \mu \mathrm{g} /$ week for the first 12 weeks followed by $180 \mu \mathrm{g} /$ week for a total of either 72 or 48 weeks, respectively. Groups C and D received PEG-IFNalpha-2a at $180 \mu \mathrm{g} /$ week for a total of either 72 or 48 weeks, respectively (Marcellin \& Jensen, 2005). All groups received RBV (1-1.2 g/day). The results of the first 12 weeks of the trial have been presented. The high-dose induction groups of the study appear to be more effective in lowering HCV RNA concentrations than the standard PEG-IFN dosing arms. Forty-three percent of subjects in Groups A and B 
had undetectable HCV RNA concentrations at 12 weeks of therapy versus $26 \%$ in Groups $C$ and D. Whether these results will translate into an improved SVR awaits completion of the study.

\section{Role of Maintenance Therapy in Patients Who Fail to Respond to Interferon-Based Therapy}

The HALT-C, EPIC, and COPILOT trials are three randomized controlled studies whose goal is to determine whether maintenance therapy with PEG-IFN-alpha will decrease the progression of disease in subjects with chronic HCV infection and advance disease compared with no therapy or placebo (Shiffman et al., 2004; Poynard et al., 2005; Curry et al., 2005). Patients had failed prior unmodified interferon/RBV therapy. Whether maintenance therapy will be of value in preventing disease progression awaits the final results of these studies.

\section{Experimental Therapy}

It is clear that we have gone about as far as we can go with PEG-IFN/RBV therapy for patients with chronic HCV infection. New modalities that attack the hepatitis $\mathrm{C}$ virus at different sites are under development. The serine protease inhibitors are being investigated for their ability to inhibit hepatitis $\mathrm{C}$ viral replication. Agents under development include VX-950 and SCH 503034 (Reesink et al., 2005; Zeuzem et al., 2006a). Reesink (2005) performed a phase 1B trial with VX-950 in healthy adults and patients infected with HCV genotype 1. Patients assigned to the 750-mg q8h group experienced the greatest decrease in HCV RNA concentrations after 14 days of treatment (median drop of $4.4 \log _{10}$ ). The NS3 protease inhibitor (SCH 503034) was administered to HCV genotype-infected patients who had failed therapy with PEG-IFN-alpha-2b with or without RBV. Patients received varying doses of SCH 503034 alone or with PEG-IFN-alpha-2b for a period of 14 days using a three-way crossover design. A 2- to 3-week washout period occurred between each dosing regimen. Interestingly, undetectable HCV RNA concentrations were found in 4 of 10 patients after 14 days of PEG-IFN plus $400 \mathrm{mg}$ of SCH 503034. These inhibitors will need to be used in combination with other $\mathrm{HCV}$-active antiviral agents due to the emergence of resistant serine protease if used alone (Lin et al., 2006, Zeuzem et al., 2006). Combination phase II studies with PEG-IFN-alpha-2a and 2b are under way (ClinicalTrials.gov Identifier NCT00336479; ClinicalTrials.gov Identifier NCT00160251).

Valpoitabine (NM283) is a viral RNA polymerase inhibitor that is under study in $\mathrm{HCV}$ treatment-naïve and nonresponders to prior interferon-based therapies (Pockros et al., 2006; Dieterich et al., 2006). Pockros (2006) outlined the 24-week effects on HCV RNA baseline concentrations of valopicitabine alone, in combination with PEG-IFN-alpha-2a compared with PEG-IFN-alpha-2a/RBV. Patients were infected with HCV genotype 1 and were nonresponders to PEG-IFN/RBV therapy. Subjects were randomly assigned to five treatment groups, including PEG-IFN-alpha-2a at 
$180 \mu \mathrm{g} /$ week plus RBV (1-1.2 g/day) (A), PEG-IFN-alpha-2a at $180 \mu \mathrm{g} /$ week and various doses of valopicitabine $(\mathrm{B}-\mathrm{D})$, or valopicitabine monotherapy $(\mathrm{E})$. Subjects in the $800-\mathrm{mg} /$ day valopicitabine/PEG-IFN-alpha-2a group had a greater mean decline of HCV RNA (3.32 $\log _{10} \mathrm{IU} / \mathrm{mL}$ ) versus PEG-IFN-alpha-2a/RBV or valopicitabine monotherapy, $2.31 \log _{10} \mathrm{IU} / \mathrm{mL}$ and $0.54 \log _{10} \mathrm{IU} / \mathrm{mL}$, respectively. Dieterich (2006) administered valopicitabine/PEG-IFN-alpha-2a to treatment-naïve $\mathrm{HCV}$ genotype 1 infected patients and reported a mean decrease of $4.5 \log _{10} \mathrm{IU} / \mathrm{mL}$ in subjects after 8 weeks of combination therapy.

A Toll-like receptor 9 agonist (CPG 10101-CPG) is being investigated in phase II studies. The drug acts by stimulating the immune system. McHutchison (2006) has reported on the first 12 weeks of CPG monotherapy, CPG in combination therapy with PEG-IFN-alpha-2b with or without RBV or with RBV alone, compared with PEG-IFN-alpha-2b plus RBV. Subjects were infected with HCV genotype 1 and had relapsed after PEG-IFN /RBV therapy. At 12 weeks, 57\% and $86 \%$ of patients receiving PEG-IFN/RBV or PEG-IFN/RBV plus CPG had achieved an EVR, respectively $(P=0.21)$.

Interest in improving the tolerability of PEG-IFN/RBV therapy has led to the development of the drug viramidine. Viramidine is a pro-drug of RBV that is being investigated for use with interferon due to its lower incidence of anemia. Benhamou (2006) reported on the results of a phase III study comparing PEG-IFN-alpha-2b combined with weight-based RBV (1-1.2 g/day) or viramidine (V) (600 mg twice daily). An SVR was achieved in 52\% (RBV) and 38\% (V) of patients in each group (intent-to-treat) and did not meet the non-inferiority efficacy endpoint. Anemia was found in $24 \%$ and $5 \%$ of subjects in the RBV and V groups, respectively. The authors noted an increase in SVR with increasing $\mathrm{mg} / \mathrm{kg}$ dose of V. Anemia was not increased proportionally. Revision of the standard dose of viramidine is likely to result from this study.

A variety of other agents are under investigation for the management of treatment-naïve or nonresponders/relapsers to interferon-based therapies. Most of the agents discussed here are in phase II or early phase III studies, and whether they will have a role in the management of $\mathrm{HCV}$-infected individuals will be determined by results from controlled studies. Due to concerns about viral resistance when these agents are used alone, combination regimens including PEG-IFN will likely be necessary.

\section{Children}

The management of chronic HCV-infected children and adolescents with PEG-IFNbased therapy has not been extensively studied. A trial by González-Peralta (2005) recorded an overall SVR rate of 46\% (54/118) in children treated for 48 weeks with unmodified interferon/RBV. An SVR was realized in $36 \%$ and $84 \%$ of children infected with HCV genotypes $1 / 2$ or 3, respectively. Interestingly, Schwarz (2003) reported an SVR of 38\% (5/13) children receiving PEG-IFN-alpha-2a (180 $\mu \mathrm{g} / 1.73 \mathrm{~m}^{2} \times$ patient's body surface area) monotherapy for 48 weeks. Ninety-two percent $(12 / 13)$ of patients were infected by HCV genotype 1. Wirth (2005) treated 
62 children and adolescents with chronic HCV infection with PEG-IFN-alpha-2b $(1.5 \mu \mathrm{g} / \mathrm{kg} /$ week)/RBV (15 mg/kg daily). Subjects infected with HCV genotype 1 were treated for 48 weeks, while patients with HCV genotype 2 or 3 were given the option of receiving 24 weeks of therapy. The overall SVR was 56\%. The SVR rate in patients with HCV genotypes 1 and 2 or 3 were $48 \%$ and $100 \%$, respectively. Utilizing the same dosing regimen as Wirth (2005), Hasan (2006) found an SVR rate of $75 \%(9 / 12)$ in a small group of adolescents infected with HCV genotype 4. Although these studies do not show the superiority of PEG-IFN/RBV regimens over unmodified interferon/ribavirin treatments, the once-weekly dosing of the peginterferon may appeal to busy parents/children.

\section{Liver Transplantation}

Use of PEG-IFN therapy in the post-liver transplant population is an evolving practice with new clinical information being published at a rapid pace. As more liver transplantation programs emerge and grow, and more high-risk transplants are performed, recurrent hepatitis $\mathrm{C}$ in the recipients will likely rise, with the potential for graft loss (Lauer \& Walker, 2001; National Institutes of Health Consensus Development Conference Statement: Management of Hepatitis C, 2002). High doses of immunosuppressive agents immediately post-transplantation present a particular problem in terms of tolerability of treatment with PEG-IFN and RBV. For this reason, treatment is recommended to be held until months after transplantation, with two scenarios being explored most often. The first is the use of PEG-IFN as preemptive or "prophylactic" treatment before clinical onset of recurrent hepatitis C, relatively early (e.g., one month) post-transplant in high-risk patients with high viral loads. The second is the use of PEG-IFN for treatment of recurrent hepatitis C, later post-transplant (e.g., six months). Much of the literature describing this use has been published for unmodified interferon therapies (Singh et al., 1998; Sheiner et al., 1998; Firpi et al., 2002; Berenguer Prieto et al., 2004; Giostra et al., 2004; Bizollon et al., 2003). Although interferon-based therapies carry theoretical risks of inducing graft rejection, recent trials do not support the association (Kuo \& Terrault, 2006; Chalasani et al., 2005).

In a study of the two treatment scenarios mentioned above, preemptive treatment and active therapy of recurrent hepatitis $\mathrm{C}$ in patients following liver transplantation, Chalasani et al. (2005) enrolled 54 patients within 3 weeks of an orthotropic liver transplantation (OLT) for "prophylaxis" or preemptive therapy and enrolled 67 patients 6 to 60 months after transplantation for active treatment of recurrent $\mathrm{HCV}$ disease. In either treatment group, patients were randomized to treatment with $180 \mu \mathrm{g} /$ week of PEG-IFN-alpha-2a or no antiviral treatment for 48 weeks with a 24-week followup post-therapy. In the preemptive arm, patients who received PEGIFN had a significantly greater drop in HCV RNA concentrations at weeks 4 and 24 than untreated patients $(P<0.003$ and $P<0.02$, respectively). Likewise, patients in the treatment arm on PEG-IFN-alpha-2a had significantly lower viral loads than untreated patients at each scheduled post-baseline assessment $(P<0.001)$. Unfortunately, only 2 treated patients in the prophylaxis trial $(8 \%)$ and 3 in the 
treatment trial $(12 \%)$ achieved an SVR. Acute rejection rates were similar in the treated and untreated groups in both the prophylaxis $(12 \%$ vs. $21 \% ; P<0.5)$ and treatment $(12 \%$ vs. $0 \% ; P<0.1)$ trials.

A preemptive-only, randomized comparative study of single therapy or combination therapy with RBV of unmodified interferon-alpha-2b 3 MU three times a week versus PEG-IFN-alpha-2b $1.5 \mu \mathrm{g} / \mathrm{kg}$ once weekly was conducted by Shergill (2005). Therapy was initiated two to six weeks' post-transplantation and continued for 48 weeks. Fifty-one patients were treated, but with a high rate of dose reductions $(85 \%)$ and drug discontinuations (37\%) due to adverse events and intolerability. Rates of viral suppression at 48 weeks (ETR) were low for both groups, $4.5 \%$ for single therapy with either interferon product versus $22.7 \%$ for combination therapy with either product $(P=0.093)$. The difference was not statistically significant due to the low total number of patients. Even lower comparative rates were recorded for SVR at $4.5 \%$ for monotherapy and $18.2 \%$ for combination therapy. Comparisons could not be performed regarding unmodified versus PEG-IFN products due to the small number of patients. The authors concluded that while combination therapy was better than monotherapy, SVR rates are far less than in non-transplantation $\mathrm{HCV}$-infected patients, and a majority of patients did not tolerate the drug therapy well. In a post hoc analysis, the authors concluded that the best candidates for treatment are patients with better liver function (MELD score) prior to treatment and those who undergo living donor transplantation.

A French study investigated the benefit of active treatment of recurrent $\mathrm{HCV}$ disease post-liver transplantation. Dumortier (2004) treated 20 patients with 12 months of combination therapy with PEG-IFN-alpha-2b and RBV. They evaluated virological and biochemical responses to treatment. Patients were started on low-dose treatment at $0.5 \mu \mathrm{g} / \mathrm{kg} /$ week of PEG-IFN plus $400 \mathrm{mg}$ of RBV daily. Therapy was initiated at least 28 months' post-transplantation, and dosing was escalated as tolerated to a maximum dose of PEG-IFN of $1 \mu \mathrm{g} / \mathrm{kg} /$ week and 1,200 $\mathrm{mg}$ of RBV daily. A high rate of adverse events, at $20 \%$, led to drug discontinuation. Dose reductions of PEG-IFN to $0.5 \mu / \mathrm{kg} /$ week were required in $37.5 \%$ of the remaining patients, and dose reductions of RBV were required in $87 \%$ of the remaining patients. Using intent to treat, $55 \%$ of the patients had a virological response at 12 months, with an SVR of $45 \%$. Like most studies, virological outcomes were less for genotype 1 than other genotypes $(64 \%$ vs. $100 \%$, respectively, $P<0.05)$. Five of the patients in this study had a mild acute rejection episode.

Neff (2004) examined the benefits of treatment of recurrent HCV in liver transplant recipients using combination therapy with PEG-IFN-alpha- $2 \mathrm{~b}(1.5 \mu \mathrm{g} / \mathrm{kg} / \mathrm{wk})$ and RBV (400-600 mg/day) therapy for at least 48 weeks. The retrospective review identified 57 patients, who were divided into patients who were treatmentnaïve versus those who had received interferon-based therapy pre-transplant and were nonresponders to at least six months of combination therapy. Undetectable HCV RNA concentrations were attained in eight (27.6\%) treatment-naïve patients and six $(21 \%)$ treatment-experienced patients at the end of 48 weeks of therapy. An SVR was achieved in $75 \%(6 / 8)$ and 33\% (2/6) of treatment-naïve and treatment-experienced patients, respectively. Ribavirin or PEG-IFN dose reductions were required in both groups. Up to $69 \%$ of treatment-naïve patients had dose reductions. 
A Spanish study conducted by Planas (2005) treated patients with evidence of recurrent $\mathrm{HCV}$ infection after liver transplantation with PEG-IFN-alpha-2b at 1.5 $\mu \mathrm{g} / \mathrm{kg} /$ week plus weight-based ribavirin $(10.6 \mathrm{mg} / \mathrm{kg} /$ day $)$. The 30 patients were treated at a median of 43 months' post-transplantation. Treatment duration was dependent upon HCV genotype, 48 weeks for genotypes 1 and 4 or 24 weeks for genotypes 2 and 3. An end-of-treatment response was measured at 63\%, with an SVR measured at $47 \%$. Dose reductions were required in $40 \%$ of patients.

Other small case series include open-label reviews of patients with recurrent HCV after liver transplantation by Biselli (2005), Beckebaum (2004), Mukerjee (2003), and Oton (2005). Patients were treated with combination therapy including PEG-IFN plus RBV. All four are observational studies designed to examine the benefits of combination therapy with PEG-IFN-alpha-2b plus RBV. In the study by Biselli (2005), the dose chosen for PEG-IFN-alpha-2b was $1.0 \mu \mathrm{g} / \mathrm{kg} /$ week and RBV at $600 \mathrm{mg} /$ day. Therapy was continued for at least six months. Nine patients $(45 \%)$ had an end-of-treatment response, and an SVR was attained in $60 \%$ of treatment-naïve patients versus $30 \%$ of previously treated nonresponders. A drop-out rate of $45 \%$ was observed at six months. In the study by Beckebaum (2004), 12 patients were treated with 3 months of unmodified interferon, followed by 9 months of PEG-IFN-alpha-2b at $1.5 \mu \mathrm{g} / \mathrm{kg} /$ week plus RBV (10-12 mg/kg). An ETR was observed in $33 \%$ of patients. A disappointing $42 \%$ had no response after six months of treatment. The study by Mukherjee (2003) followed 39 patients receiving PEG-IFN-alpha-2b at $1.5 \mu \mathrm{g} / \mathrm{kg} /$ week and $\mathrm{RBV}$ at $800 \mathrm{mg} / \mathrm{day}$. In this more standard does study, 17 patients withdrew within the first three months due to drug intolerance. Four had not yet completed 3 months of treatment at the time of publication. Of the 18 patients who completed treatment, $17(94.4 \%)$ or $43.6 \%$ of the total enrolled had an early virological response (HCV RNA undetectable at 3 months). An end-of treatment response (ETR) was achieved in 15 (83.3\%) or $38.5 \%$ of the total enrolled patients at six months. An SVR occurred in 12 patients, with results pending for three other subjects. Oton (2005) reviewed outcomes in 21 treatment-naïve patients who received PEG-IFN-alpha-2b at $1.5 \mu \mathrm{g} / \mathrm{kg} /$ week plus RBV at a weight-based dose of at least $10.6 \mathrm{mg} / \mathrm{kg} /$ day. The time from liver transplantation was at least 1.7 years. All patients were infected with HCV genotype 1. Treatment was intended for at least 48 weeks. Two patients dropped out, one due to intolerance, the other due to non-drug-related cholangitis. Necessary dose adjustments were high, at 14\% for PEG-IFN and 32\% for RBV. Fourteen patients (66.7\%) had an ETR, with an SVR reported in $42.8 \%$ of patients, demonstrating one of the highest response rates among these observational studies.

Initial results of a randomized, multicenter study investigating the efficacy of PEG-IFN-alpha-2a in patients with recurrent HCV infection following liver transplantation were presented in abstract form (Vogel et al., 2002). The time of therapy initiation varied widely, within 6 to 60 months of liver transplantation. All patients were treatment-naive. Patients were assigned to receive either PEG-IFN at 180 $\mu \mathrm{g} /$ week or placebo. The majority of patients in both groups had a viral load $>1$ million IU/mL at baseline and HCV genotype 1. Treatment was continued for 48 weeks with a 24-week followup that was still pending. At 48 weeks of therapy, $35 \%$ of patients receiving active treatment with PEG-IFN and none of the patients receiving placebo had an undetectable HCV RNA level. 
The published experience for preemptive therapy or treatment of recurrent $\mathrm{HCV}$ infection in liver transplant patients demonstrates fairly low success rates with a reasonably high amount of drug intolerance. Larger prospective dose-ranging studies would help define the ideal approach. In the meantime, initiation of therapy with PEG-IFN plus RBV at lower doses with titration upward as tolerated, and careful monitoring and support with growth factors, appear to be a reasonable approach. The pharmaco-economic benefit of PEG-IFN-based therapies in this patient population has yet to be defined.

\section{Human Immunodeficiency Virus (HIV) Co-infection}

In the United States and Europe, between $15 \%$ and $30 \%$ of all people infected with HIV are also infected with HCV (Sulkowski et al., 2000; Sherman et al., 2002; Greub et al., 2000; Sulkowski et al., 2002). Rates are higher in people who contract the disease through intravenous drug abuse (Garfein et al., 2000) than among men who contract the disease through sexual contact with other men. However, there have been spikes in the incidence in the population of men who have sex with men (MSM), likely linked to the resurgence of unprotected sex (Sulkowski \& Thomas, 2003; Rauch et al., 2005; Ghosn et al., 2004). Co-infected patients often have lower CD4 counts, a more rapid progression of liver fibrosis, and increased mortality over people who are singly infected (Nunez et al., 2003; Brau, 2003; Kramer et al., 2005; Sulkowski et al., 2002; Tedaldi et al., 2003). Although there may be some disagreement among researchers, co-infection with HCV does not appear to affect progression or response to therapy of HIV disease (Sulkowski et al., 2002; Sullivan et al., 2006; Hershow et al., 2005).

Data are growing exponentially on the treatment and management of patients with HCV/HIV co-infection. The publication of two well-designed, large, randomized studies has expanded the level of evidence for treating co-infected patients (Table 4). The AIDS Pegasys RBV International Co-infection Trial (APRICOT) evaluated the efficacy and safety of unmodified interferon-alpha-2a (3 MU 3 times/week) plus RBV (800 mg/day) versus PEG-IFN-alpha-2a at $180 \circ \mathrm{g} /$ week plus placebo versus PEG-IFN plus RBV (800 mg/day) (Torriani et al., 2004). Patients were young, with a mean age of 40 years, mostly male, white and primarily infected with HCV genotype 1 (60\%). Inclusion criteria were compensated liver disease, a CD4 ${ }^{+}$cell count $\geq 100$ cells/mL, and stable HIV disease (with or without HIV therapy). Sustained virological response rates were lower than for mono-infected patients, and the highest SVR response occurred in the group treated with PEG-IFN plus RBV (40\%). However, the SVR rate for unmodified interferon plus RBV was only $12 \%$. The SVR rate for patients receiving PEG-IFN plus placebo (20\%) was also lower than the combination with RBV. Like mono-infection trials, patients infected with HCV genotype 1 were more treatment refractory. For these patients, the best chance for achieving an SVR was observed when subjects received the combination of PEG-IFN plus RBV (29\% vs. 14\% and 7\%) versus the PEG-IFN plus placebo or unmodified interferon plus RBV groups, respectively. 


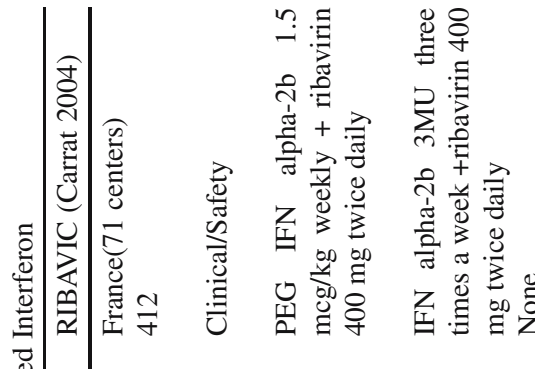

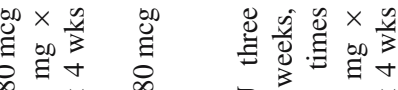
$\infty 0^{\circ} \times \infty$ สำ

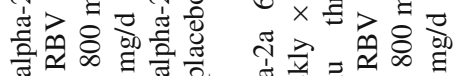

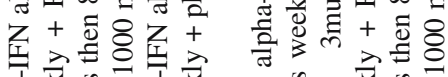

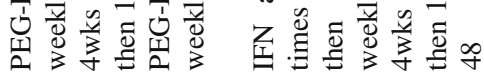

$\stackrel{\infty}{+}$

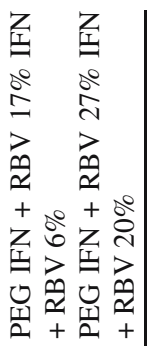

爯空

i $\frac{5}{8}$

वे

$+8+8$

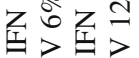
نे 핀 $+\frac{1}{2}+$

잉

$\stackrel{1}{\infty}$

기

究学

学 +

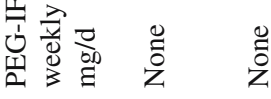

ڤั

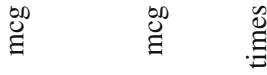

$\infty \quad \infty \quad$

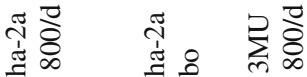

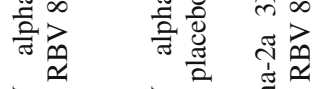

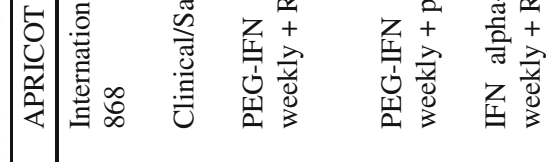

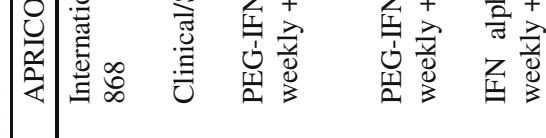

है

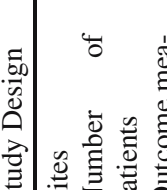

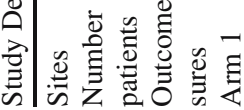

索先

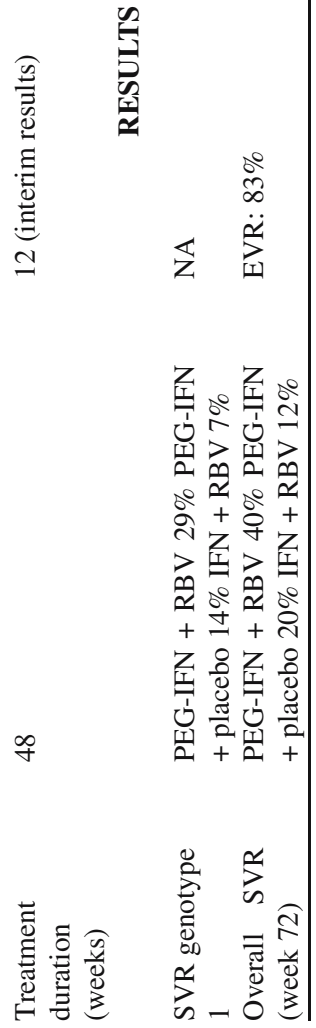


The RIBAVIC trial (Carrat et al., 2004), a multicenter, randomized, parallel group, open-label trial, examined the safety and efficacy of PEG-IFN-alpha-2b plus RBV versus unmodified interferon-alpha- $2 b$ plus RBV in HIV-HCV co-infected patients (Table 4). The study was conducted in 71 French centers. Dosing for PEGIFN-alpha-2b was $1.5 \mu \mathrm{g} / \mathrm{kg} /$ week versus interferon-alpha-2b $3 \mathrm{MU}$ three times a week, both arms with RBV at $800 \mathrm{mg} /$ day. An SVR was attained at a higher rate for the PEG-IFN regimen than unmodified interferon ( $27 \%$ vs. $20 \%,=0.047)$, respectively. Different rates of SVR were even more pronounced when comparing patients infected with genotype 1 who were assigned to PEG-IFN-alpha-2b versus unmodified interferon (17\% vs. $6 \%$, respectively, $P=0.006)$. When comparing SVR rates for genotypes 2 and 3, there was not a statistically significant difference in SVR rates between those treated with PEG-IFN product (44\%) versus unmodified interferon $(43 \%)$.

Another multicenter randomized trial by Chung (2004) evaluated the efficacy of unmodified interferon-alpha-2a or PEG-IFN-alpha-2a, both with escalating doses of RBV (600-1,000 mg/day) (Table 4). Patients treated with the PEG-IFN-alpha$2 \mathrm{a} / \mathrm{RBV}$ regimen experienced a higher SVR rate versus unmodified interferon/RBV (27\% and 12\%). An SVR was achieved in only 6\% (unmodified interferon group) and $14 \%$ (PEG-IFN group) of patients infected with HCV genotype 1, respectively.

The PRESCO trial (Ramos et al., 2006), in progress, examines the benefit of weight-based doses of ribavirin (1,000-1,200 mg/day) compared to the standard RBV dose ( $800 \mathrm{mg} /$ day) utilized in the APRICOT trial (Table 4). Data up to week 12 have been presented in abstract form. For HCV genotype 1 , an EVR $\left(2 \log _{10}\right.$ decrease in HCV RNA concentrations at 12 weeks of therapy) was observed in $78 \%$ of the study subjects. This compares to $63 \%$ in APRICOT and $80 \%$ of subjects in the HCV mono-infection trial (Fried et al., 2002). Differences were less pronounced in patients with genotypes 2 and 3 . Whether these results will translate into a better SVR rate awaits the conclusion of the study.

Voight (2006) performed a prospective, uncontrolled, multicenter trial in Germany, exploring the efficacy and safety of combination PEG-IFN-alpha-2b (1.5 $\mu \mathrm{g} / \mathrm{kg} /$ week) plus RBV (800 mg daily) for 48 weeks for HCV genotypes 1 and 4 and 24 weeks for genotypes 2 and 3 in HIV/HCV co-infected patients. An endof-treatment response was found in $52 \%$ of patients overall, but an SVR response occurred in only $25 \%$ of subjects. This rate was lowest for those with genotype 1 or $4(18 \%)$ and highest for genotype 2 or $3(44 \%)$. Discontinuation rates were high $(30 \%)$.

Soriano (2004) investigated whether an early virological response at 12 weeks (EVR- undetectable HCV RNA or $\geq 2 \log _{10}$ decrease of HCV RNA concentrations) could be used to make treatment decisions in HCV patients co-infected with HIV. Of the 89 co-infected patients, an EVR occurred in $58 \%$ of patients, and $32.6 \%$ attained an SVR. The negative and positive predictive value for achieving an SVR was $100 \%$ and $56 \%$, respectively. From these results, consideration of treatment discontinuation can be entertained after 12 weeks of therapy if there is no EVR regardless of infecting $\mathrm{HCV}$ genotype in $\mathrm{HCV} / \mathrm{HIV}$ co-infected patients receiving PEG-IFN-based therapies. 
In a later investigation by the same group (Soriano, 2004a), high relapse rates were observed in up to $32.8 \%$ of treated patients who have an ETR. As a result, other groups have explored prolonged treatment durations for co-infected patients, despite undetectable HCV-RNA concentrations at the end of therapy. An Italian group examined the benefits of continuing treatment of co-infected patients with chronic HCVgenotype 2/3, beyond 24 weeks, even if there was a treatment response to PEG-IEN plus RBV (Zanini et al., 2006). Unfortunately, many of the patients (36\%) could not tolerate even 24 weeks of therapy due to adverse events. Those able to complete therapy up to 48 weeks had a lower relapse rate than those who could only complete 24 weeks of therapy (11\% vs. $39 \%$ ).

The benefits of treating acute hepatitis $\mathrm{C}$ in HIV-infected patients are still not well known. A German group is studying treatment with PEG-IFN plus RBV for acute HCV infection in patients with HIV (Vogel et al., 2006). The majority of patients were infected with genotype 1 . The interim analysis was that, after 24 weeks of therapy with PEG-IFN-alpha-2a with or without RBV, $61 \%$ of patients had undetectable HCV RNA levels. No significant differences in these outcomes between HCV genotypes or with the addition of RBV were seen. Early virological responses at weeks 4 and 12 were the only significant predictors of this response. The discontinuation rate was low, $6 \%$ due to adverse events.

A French group (Dominguez et al., 2006) published results of a prospective pilot study of 25 patients with acute HCV infection (less than six months) treated with PEG-IFN-alpha-2a at $180 \mu \mathrm{g} /$ week and RBV at $800 \mathrm{mg} /$ day. Nineteen started treatment and 14 were available for an assessment at 24 weeks after the end of therapy. The SVR for this group was high at $71 \%$ given few dropouts and exclusions. In addition to the high SVR, the authors reported that no patients required dose adjustments due to adverse events.

A cost-benefit analysis for treatment of chronic $\mathrm{HCV}$ in co-infected patients examined the relative benefit of treatment with PEG-IFN alone, or with RBV versus treatment with unmodified interferon (Kuehne et al., 2002). The quality-of-life benefit was estimated using aversion of progression to cirrhosis with the decrement being the associated side effects of drug treatment. This was applied to a hypothetical cohort of 1 million HIV-positive adult patients with a mean CD4 cell count greater than 350 and uncompensated liver disease. Treatment with either interferon product benefited patients, with an increase in Quality Adjusted Life Years (QALY) ranging between 6.2 and 13.9 months for any genotype. For all genotypes, the use of unmodified interferon plus RBV in patients with moderate liver disease came at a cost benefit of $\$ 50,000$ per QALY. Patients infected with HCV genotype 1 and treated with PEG-IFN plus RBV have better clinical outcomes and subsequently an additional 1.6 quality-adjusted life months at a cost of $\$ 40,000$ per QALY. For HCV non-genotype 1, where clinical outcomes are similar between pegylated and unmodified interferon products at a much higher drug cost for the pegylated product, there is a benefit of only three additional weeks at an inequitably high cost, $\$ 105,300$ per QALY. The authors identified that further cost benefits could be realized if it is ever definitively demonstrated that treatment of HCV in HIV co-infected patients results in improved tolerance of antiretroviral medications. 
Guidelines now favor the use of PEG-IFN-alpha-2a plus RBV over regimens with unmodified interferon-alpha-2a or regimens without RBV in the management of $\mathrm{HIV} / \mathrm{HCV}$ co-infected patients. The time to start therapy remains controversial. Lee and Dieterich (2004) recommend initiation of HCV therapy for patients with higher CD4+ cell count ( $>350$ cells $/ \mathrm{mL}$ ), with evidence of HCV-related liver disease (fibrosis) or when patients cannot maintain antiretroviral therapy due to recurrent druginduced hepatotoxicity. Others suggest starting therapy in patients with higher CD4 cell counts, before the initiation of HAART to avoid drug interactions and additive toxicities. The HIV-HCV International Panel recommends treatment for any HIV co-infected patient with a CD4+ cell count $>350$ or with a CD4+ cell count between 200 and 350 with consideration of response based on HCV genotype and viral load. Deferral of therapy is recommended in those with a CD4+ cell count $<200$ (Soriano et al., 2004b). In patients already receiving HAART, those regimens that include didanosine (ddI) should be substituted with another drug given the increased risk of mitochondrial toxicities, particularly when used in combination with RBV (Mauss et al., 2004) As discussed, there are benefits to longer treatment durations unique to this co-infected group. Treatment beyond 24 weeks in patients without a 12-week response (EVR) is generally not beneficial (Strader et al., 2004; Alberti et al., 2005; Sulkowski, 2006). However, unlike the mono-infected subject, for patients with a 12-week response, a 48-week treatment should be considered, regardless of the genotype, including genotypes 2 and 3. No conclusion can be made regarding the choice of pegylated product as no randomized trial has been performed to compare PEG-IFN-alpha-2a with PEG-IFN-alpha-2b in the HCV/HIV co-infected population. More frequent and more diligent monitoring of these patients is in order, with careful consideration of the implications of the individual antiretroviral combination and use of adjuvant drugs to support cell lines.

\section{Adverse Event Profile}

Second only to nonresponse to therapy, drug-related adverse events are often the primary reason for discontinuation of PEG-IFN therapies. While the incidence of some adverse events, such as myalgias, fever, and general malaise, may be less than with unmodified interferon, the pegylation of IFN does not protect patients from other adverse events. These include the more debilitating neuropsychiatric and hematologic adverse events (Fried et al., 2002). A black box warning regarding such reactions is described in each of the manufacturer's product package inserts. Careful screening of patients before initiating therapy with frequent followup of core laboratory findings may decrease the need to alter or discontinue therapy due to adverse events. Some adverse events may be managed with dose reductions and/or supportive treatments. A summary of common types of drug-related adverse events appears in Table 5 .

In controlled trials of PEG-IFN versus unmodified interferon preparations (Zeuzem et al., 2000; Heathcote et.al., 2000), protocol-defined dose reductions were required in up to $32 \%$ of PEG-IFN-alpha-2a treated patients, compared with 
Table 5 Common and Clinically Significant Side Effects of Pegylated Interferon Therapies [(pegylated IFN alpha-2a- Pegasys ${ }^{\mathrm{TM}}$ ) (pegylated IFN alpha-2b-Peg Intron $^{\mathrm{TM}}$ )]

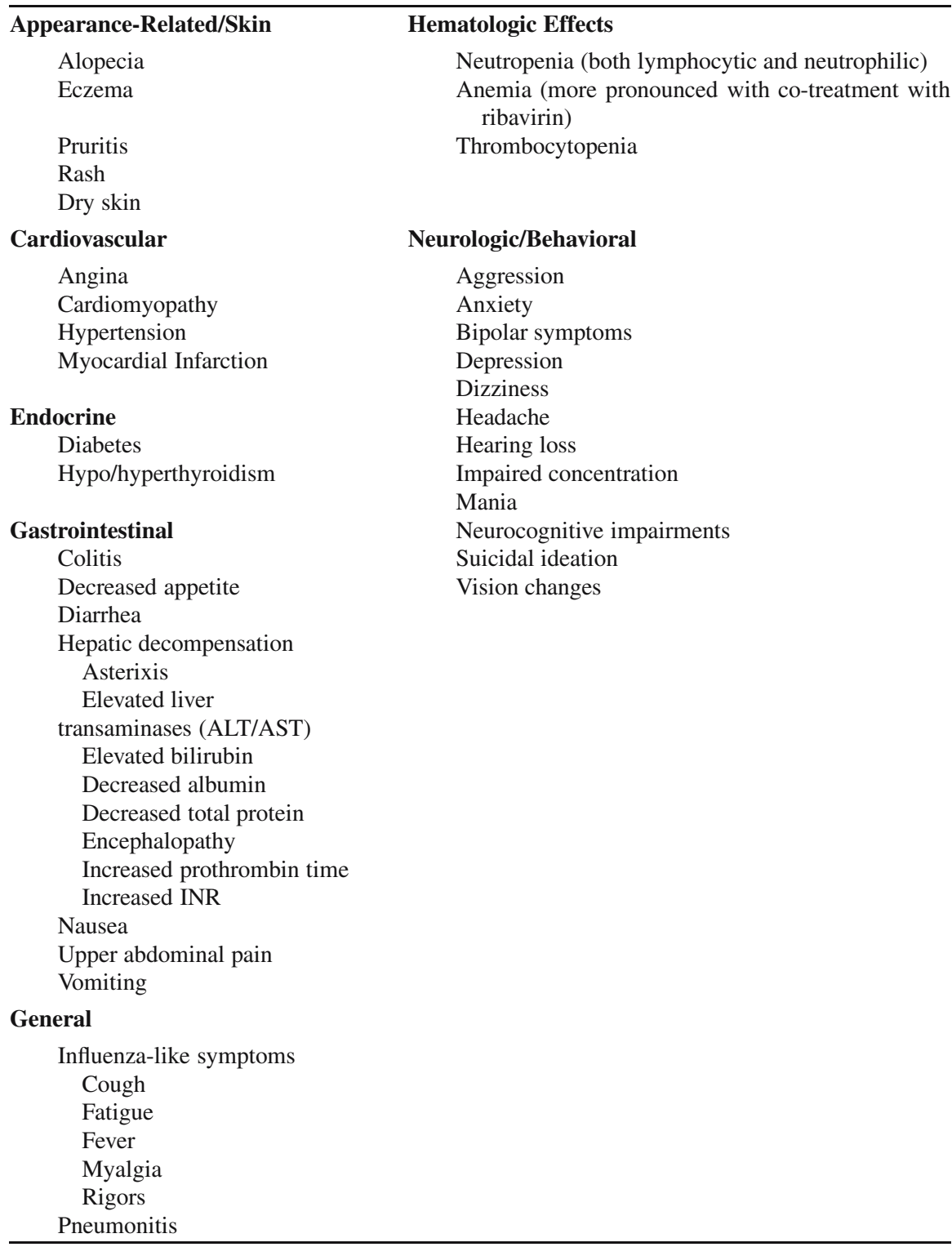

up to $27 \%$ of those treated with unmodified interferon. The primary concern about dose reduction is that while it may allay adverse events, it can also allow for incomplete suppression or eradication of the virus, as described by Fried (2000). The length of therapy also plays a role in the frequency and severity of adverse events. Drug discontinuation secondary to adverse drug events was recorded at higher rates in patients treated for 48 weeks $(15 \%)$ versus those treated for 24 weeks 
Table 6 Treatment Discontinuation of Standard IFN Versus PEG-IFN Due to Clinical Adverse Events or Lab Abnormalities ${ }^{\mathrm{a}}$

\begin{tabular}{|c|c|c|}
\hline Trials and Comparative Arms & $\begin{array}{l}\text { Standard } \\
\text { IFN Group }\end{array}$ & PEG-IFN Group \\
\hline Mono-Infection Trials & \multicolumn{2}{|c|}{ Discontinuation Rates (\%) } \\
\hline $\begin{array}{l}\text { Zeuzem et al. (2000)(PEG-IFN alpha-2a } \\
\text { vs. unmodified IFN alpha-2a) }\end{array}$ & 7 & 10 \\
\hline $\begin{array}{l}\text { Heathcote et al. (2000)(PEG-IFN alpha-2a } \\
90 \mathrm{mcg} / \mathrm{wk} \text { vs. } 180 \mathrm{mcg} / \mathrm{wk} \text { vs. } \\
\text { unmodified IFN alpha-2a) }\end{array}$ & 10 & 90 mcg wk 11180 mcg wk 14 \\
\hline $\begin{array}{l}\text { Fried et al. (2002)(PEG-IFN alpha-2a vs. } \\
\text { unmodified IFN alpha-2a) }\end{array}$ & 10 & 10 \\
\hline $\begin{array}{l}\text { Pockros et al. (2004)(PEG-IFN alpha-2a } \\
135 \mathrm{mcg} / \text { wk vs. } 180 \mathrm{mcg} / \text { wk vs. } \\
\text { unmodified IFN alpha-2a) }\end{array}$ & 11 & $135 \mathrm{mcg} / \mathrm{wk} 9180 \mathrm{mcg} / \mathrm{wk} 10$ \\
\hline $\begin{array}{l}\text { Hadziyannis et al. }(2004)(\text { PEG-IFN } \\
\text { alpha-2a + ribavirin } 800 \text { mg/day vs. } \\
\text { PEG-IFN alpha- } 2 \mathrm{a}+\text { ribavirin } 1000 \\
\text { mg/day) }\end{array}$ & NA & $\begin{array}{l}\text { Ribavirin } 800 \mathrm{mg} / \mathrm{d} 16 \text { Ribavirin } \\
1000 \mathrm{mg} / \mathrm{d} 15\end{array}$ \\
\hline $\begin{array}{l}\text { Manns et al. (2001)(PEG-IFN alpha-2b vs. } \\
\text { unmodified IFN alpha-2b) }\end{array}$ & 13 & $\begin{array}{l}1.5 \mathrm{mcg} / \mathrm{kg} \text { wk } 140.5 \mathrm{mcg} / \mathrm{kg} \text { wk } \\
13\end{array}$ \\
\hline \multicolumn{3}{|l|}{ HIV/HCV Co-infection Trials } \\
\hline $\begin{array}{l}\text { ACTG 5071, Chung et al. (2004)(PEG-IFN } \\
\text { alpha-2a vs. unmodified IFN alpha-2a) }\end{array}$ & 12 & 12 \\
\hline $\begin{array}{l}\text { RIBAVIC, Carrat et al. (2004)(PEG-IFN } \\
\text { alpha-2b vs. unmodified IFN alpha-2b) }\end{array}$ & 17 & 16 \\
\hline $\begin{array}{l}\text { APRICOT, Torriani et al. (2004)(PEG-IFN } \\
\text { alpha-2a vs. unmodified IFN alpha-2a) }\end{array}$ & 14 & 12 \\
\hline
\end{tabular}

(5\%). Drug discontinuation related to adverse drug events overall are compared in Table 6 for unmodified interferon versus PEG-IFN-based therapies from the larger randomized trials. The primary reasons for drug discontinuation were hematologic abnormalities and neurocognitive disorders. A higher rate of discontinuation is noted in the patients with HIV co-infection. Dose reductions are only slightly higher with longer treatment courses, $30 \%$ versus $33 \%$ as noted in the Food and Drug Administration briefing document (2002).

Constitutional symptoms resembling influenza-like illness have been noted in up to $51 \%$ of patients treated with PEG-IFNs (Zeuzem et al., 2000; Heathcote et al., 2000). Symptoms are often transient, and patients tend to develop tolerance over time. In the larger comparative trials, influenza-like symptoms occurred more frequently in patients treated with unmodified interferon plus RBV than with PEG-IFN plus RBV; $50 \%$ compared with $42 \%(P=0.02)$ (Fried et al., 2002; Zeuzem et al., 2000).

Neuropsychiatric disorders, such as anxiety and depression, affect up to $26 \%$ of patients during treatment with PEG-IFN products. A warning exists for all interferon products regarding the potential new onset or exacerbation of neuropsychiatric disorders, including depression, suicidal ideation, increased addictive behaviors, 
bipolar symptoms, mania, and aggressive behaviors. This warning is especially emphasized in patients with underlying neuropsychiatric disorders, particularly if they are not being treated or monitored for these conditions. A hypothesis for this adverse event was studied by Schwaiger (2003), wherein serotonergic activity in patients treated with PEG-IFN was measured and greatly reduced in those treated with the drug. Byrnes (2005) reported on a pre and post-evaluation of 10 patients treated with PEG-IFN to evaluate the potential confounding effect of HCV on neuronal function. They performed baseline brain MRI and 1H-MRS (spectroscopy), measurements of neurotransmitters, in addition to neuropsychological evaluation (neuropsychometric tests, Beck's depression inventory, and quality-of-life and selfreported cognitive dysfunction questionnaires) prior to, and 12 weeks following, initiation of PEG-IFN. The study demonstrated that as HCV viral load was reduced, there was a reduction in inflammatory markers, but depression scores increased and cognitive function declined. A history of depression is directly correlated with a higher incidence of drug-related psychiatric events during PEG-IFN therapy (Castera et al.,2004). However, there are some differences relative to unmodified interferon products. In the trial by Fried et al. (2002), depression was observed less frequently in the PEG-IFN-treated group compared with those treated with unmodified IFN-alpha-2b ( $22 \%$ vs. $30 \%, P=0.01)$. Other trials confirmed this pattern (Zeuzem et al., 2000; Heathcote et al., 2000), although significantly morbid depression has been described in patients receiving either product. In parallel, the dose finding trial by Pockros et al. (2004) demonstrated a similar rate of depression for patients treated with PEG-IFN product versus unmodified interferon. Neurocognitive decline, such as decreased alertness, attention deficits, decreased vigilance, and impaired shortterm memory, was demonstrated in a cohort of 70 patients treated with PEG-IFNs by Krauss (2005). Overall, neuropsychiatric disorders, including depression, mark the highest-ranking reason for drug withdrawal, particularly in those patients treated for 48 weeks versus 24 weeks (FDA brief, 2002).

Bone marrow suppression, resulting in low cell counts, such as anemia and neutropenia, is another common treatment-limiting adverse event of PEG-IFN therapies. This results from direct inhibition of progenitor cell proliferation in the bone marrow by interferon (Ganser et al., 1987). Initial laboratory data should be recorded as a baseline for the absolute neutrophil count, hemoglobin, and platelets. Patients with low counts at baseline (a neutrophil count $<1,500$ cells $/ \mathrm{mm}^{3}$ or a baseline hemoglobin $<10 \mathrm{~g} / \mathrm{dL}$ or a baseline platelet count $<90,000$ cells $/ \mathrm{mm}^{3}$ ) should be treated cautiously with lower starting doses of PEG-IFN and careful monitoring of cell lines during therapy. Severe, persistently low counts may result in infectious complications including opportunistic infections. Therapy with PEG-IFN should be interrupted or discontinued if counts do not respond to dose modifications.

Hematologic abnormalities are the most common reason for dose modifications in many of the trials (Fried et al., 2002; Chung et al., 2004; Torriani et al., 2004; Pockros et al., 2004; Carrat et al., 2004). Drug-related neutropenia can begin early, with a nadir in the first four weeks of therapy. Rates of neutropenia have been reported to be higher in patients treated with PEG-IFN products than with unmodified interferon in randomized trials (Fried et al., 2002; Chung et al., 2004; Torriani et al., 2004; Carrat et al., 2004; Heathcote et al., 2000). Neutropenia defined as 
grade 4 (ANC $<500 / \mathrm{mL}$ ) has been documented in multiple trials. Dose reductions are employed in up to $11 \%$ of the patients treated with the PEG-IFN versus $7 \%$ of patients receiving unmodified interferon. In an analysis of the effects on hematologic cell lines, Schmid (2005) analyzed 133 patients undergoing treatment with unmodified interferon, unmodified interferon plus RBV, PEG-IFN-alpha-2a plus RBV, or PEG-IFN-alpha-2b plus RBV. Leukopenia was common to all arms. The maximum decrease in neutrophils and lymphocytes occurred in patients treated with PEGIFN products, 55\% for PEG-IFN-alpha-2a and 52\% for PEG-IFN-alpha-2b versus $37 \%$ for unmodified IFN $(P<0.05)$. As an exception, the trial by Heathcote $(2000)$ demonstrated similar rates of grade 4 neutropenia among groups (3\% with unmodified interferon, $3 \%$ and $1 \%$ with the PEG-IFN-alpha- 2 a at 90 and $180 \mu \mathrm{g} / \mathrm{wk})$. Dose reductions for PEG-IFN-alpha-2a to $135 \mu \mathrm{g} /$ week from $180 \mu \mathrm{g} / \mathrm{week}$ and to 0.75 $\mu \mathrm{g} / \mathrm{kg} /$ week from $1.5 \mu \mathrm{g} / \mathrm{kg} /$ week for PEG-IFN-alpha-2b are recommended when the ANC falls below 750. Treatment discontinuation is recommended if the ANC falls below 500 .

Thrombocytopenia has been observed, particularly early in treatment (within 2 weeks). Similar comparative rates of thrombocytopenia in the trial by Fried (2002) were observed between patients receiving PEG-IFN-alpha-2a plus RBV, or PEGIFN-alpha-2a plus placebo as compared to unmodified interferon plus RBV at $4 \%$ versus $6 \%$ versus $<1 \%$, respectively. Severe thrombocytopenia, classified as grade 3 , or a platelet count between 20,000 and $50,000 / \mathrm{mL}$, occurred equally between unmodified and PEG-IFN products in the study by Zeuzem (2000). One HIV/HCV co-infection study (Chung et al., 2004) described two patients with grade 4 thrombocytopenia $(<20,000 / \mathrm{mL})$, one in the unmodified and one in the PEG-IFN-treated groups. However, the study by Heathcote et al. (2000) demonstrated a higher incidence of thrombocytopenia in patients receiving PEG-IFN-alpha-2a, 26\% versus $7 \%$ of all patients treated with unmodified interferon $(P<0.001, P=0.04$, respectively). In an observational crossover study, Homincik (2003) examined the effects of one dose of unmodified interferon-alpha-2a followed by weekly PEG-IFN-alpha-2a for 36 weeks on both platelet count as well as platelet activity. Decreases in platelet count were noted uniformly, but platelet activity was relatively unchanged. In the analysis of drug-related hematologic effects of six prospective trials by Schmid (2005), median decreases in platelet counts were similar in the patients treated with unmodified interferon alone (25\%) versus those treated with PEG-IFN products plus RBV, $21 \%$ for PEG-IFN-alpha-2a and 23\% for PEG-IFN-alpha-2b. An unusual case of late-onset (six months after drug discontinuation) drug-related autoimmune thrombocytopenia (PEG-IFN-alpha-2b plus RBV) was reported by Elefsiniotis (2006). Drug-related thrombocytopenia was not associated with increased bleeding episodes in any of the major trials, but when thrombocytopenia is severe, the risk of bleeding rises proportionally. The presence of cirrhosis of the liver adds to this risk. Dose reductions for thrombocytopenia have been required in up to $21 \%$ of patients with cirrhosis versus $6 \%$ for the overall population in a monotherapy study group and $16 \%$ for cirrhotics versus $4 \%$ for the overall population in the combination study group (FDA Brief, 2002). Recovery of platelet counts occurs by four weeks after treatment is completed or discontinued. Dose reductions to 90 $\mu \mathrm{g} /$ week from $180 \mu \mathrm{g} /$ week for PEG-IFN-alpha-2a are recommended if the platelet 
count falls below 50,000. Therapy should be discontinued if the platelet count falls below 25,000 .

Drug-related anemia has also been well documented, particularly in patients cotreated with RBV. Data relative to erythropoietin levels in treated patients indicate that patients cannot maintain erythropoietin levels adequate to offset treatmentrelated anemia (Balan et al., 2003). Hemoglobin values appear to decrease similarly when comparing PEG-IFN to unmodified interferon; in one study, they fell by a maximum of $3.7 \mathrm{~g} / \mathrm{dL}$ for PEG-IFN-alpha-2a plus RBV, compared to $3.6 \mathrm{~g} / \mathrm{dL}$ for unmodified interferon-alpha- $2 b$ plus RBV. However, when examining rates relative to the percent of patients whose hemoglobin falls below $10 \mathrm{~g} / \mathrm{dL}$, Schmid (2005) demonstrated higher rates among patients treated with PEG-IFN-alpha-2a with RBV (29\%) versus $6 \%$ of patients treated with unmodified interferon-alpha$2 \mathrm{~b}$ with $\mathrm{RBV}(P<0.05)$. The common denominator remains the additive anemic effects mediated by ribavirin. The proposed mechanism is direct hemolysis by RBV as demonstrated by De Franceschi (2000). A handful of patients with HIV co-infection have had observed grade 4 anemia, Hgb less than $6.5 \mathrm{~g} / \mathrm{dL}$ (Chung et al., 2004). All three hematologic abnormalities have been documented at higher rates in patients with a lower body mass index (BMI), perhaps reflecting the use of fixed doses of PEG-IFN-alpha-2a. High RBV blood levels and concomitant treatment with zidovudine have also been identified as predictors of treatment-related anemia (Rendon et al., 2005). Treatment should be discontinued if the Hgb falls below $8.5 \mathrm{~g} / \mathrm{dL}$.

New onset cardiovascular dysfunction has been documented rarely (21 total reported cases) in patients treated with unmodified interferon (Kuwata et al., 2002; Cohen et al., 1990; Sonnenblick et al., 1990). These conditions include cardiomyopathy, myocardial infarction, angina, and hypertension. A baseline EKG and serial monitoring in patients with pre-existing cardiovascular disease are recommended. Risk reduction measures should also be considered in patients at a high risk for cardiovascular complications. A recent case report by Condat (2006) details a case of fatal cardiomyopathy in a patient receiving PEG-IFN/RBV therapy.

Ocular changes have been described with unmodified interferon treatment of hepatitis C and newly with PEG-IFN-alpha-2b (Farel et al., 2004; Ahmed et al., 2003; Schulman et al., 2003). In the case series review by Farel (2004), patients co-infected with HIV and HCV who were treated with PEG-IFN-alpha-2b plus RBV underwent serial ophthalmologic exams every three months, revealing pathology in $35 \%$ of the patients. These included cotton wool spots, cataracts, and decreased red-green color vision. The color vision changes were reversed in one patient 10 weeks after discontinuation of combination therapy. The other patient had sustained visual changes from weeks 10 through 23 of therapy. Visual changes spontaneously resolved. None of the patients had diabetes or hypertension. Speculation of the underlying mechanism for this side effect lies in an observational study by Sugano (1998) wherein the authors measured plasma levels of complement 5a that revealed a drug-induced increase in plasma levels of complement 5a. Complement 5a is purported to deposit in the retinal vasculature, leading to local capillary rupture. Baseline and a followup ophthalmologic exam are recommended based on these data. 
Interferon treatment for chronic HCV infection may exacerbate or result in hepatic decompensation, particularly in patients co-infected with HIV and receiving highly active antiretroviral therapy (HAART). A baseline liver biopsy and serial laboratory panels for liver injury (serum AST/ALT, total bilirubin) and synthetic function (albumin, PT, INR, total protein) are recommended. An analysis of risk factors for development of hepatic decompensation was performed for the APRICOT trial by Torriani (2004). All patients had advanced cirrhosis as a predisposing factor. Additional risk factors were co-treatment with didanosine and evidence of cholestasis at baseline. Adverse events include potentially acute liver transaminase flares, elevations in bilirubin, and evidence of decompensation (e.g., encephalopathy, elevated bleeding times, asterixis).

Thyroid disorders have been linked to unmodified interferon and PEG-IFN therapy (Imigawa et al., 1995; Fonseca et al., 1991; Preziati et al., 1995; Lisker-Melman et al., 1992). Induction of anti-thyroid antibodies and autoimmune thyroiditis is the primary mechanism by which hypothyroidism is induced by interferon products. A baseline TSH and a followup TSH are recommended in the Veteran's Health Administration guidelines (2005). Some patients require supplementation with levothyroxine.

Allergy or drug hypersensitivity is a rare event linked to PEG-IFN use. Like other drugs, the reaction is not predictable and may manifest itself as an acute IgEmediated event, with urticaria, hypotension, and anaphylaxis. Anti-IFN antibodies have been positive in a handful $(4.8 \%)$ of patients in the larger trials (Fried et al., 2002), but no notable sequelae were observed as a result. Skin rashes have been documented in multiple trials. A severe skin rash was described in a case series by Jessner (2002) wherein three patients using PEG-IFN developed a delayed rash requiring drug discontinuation. Two of the three patients were switched to unmodified interferon therapy with resolution and without recurrence of the rash. The third patient was not rechallenged.

Other notable case reports include a documented interstitial pneumonitis with adult respiratory distress syndrome (Abi-Nassif et al., 2003). The patient described had no previous history of pulmonary disease but, upon presentation, required admission to the intensive care unit. The patient died 26 days after admission, of bacteremia and fungemia. The mechanism of this potentially related AE is unknown but may be secondary to a localized autoimmune response to the medication.

Appearance-related side effects include alopecia, dry skin, and injection site reactions. Decreased appetite leading to weight loss and anorexia are also reported. Drug-induced eczema and other skin disorders secondary to interferon therapies have been well documented (Moore et al., 2004; Shen et al., 2005; Dalekos et al., 1998; Dereure et al., 2002). Hyperpigmentation has been described of the tongue and skin, particularly in dark-skinned non-Caucasian patients (Gurguta et al., 2005). Other notable dermatological diseases noted with interferon therapy include cutaneous sarcoidosis and psoriasis, as described and reviewed recently by Hurst and Mauro (2005) and Ketikoglou (2005), respectively.

Adverse events attributed to PEG-IFNs can be difficult to manage, requiring dose adjustments and potentially drug discontinuation. A summary of discontinuation rates in some of the major trials, including the HIV co-infection trials, 
appears in Table 6. Discontinuation rates were notably higher in the co-infection trials due to a higher frequency of drug-related adverse events. The addition of preemptive agents or drugs to treat or palliate adverse drug effects while continuing PEG-IFN is an option. These include granulocyte cell-stimulating factor or granulocyte-macrophage colony-stimulating factor for neutropenia (Lebray et al., 2005), oprelvekin (NEUMEGA ${ }^{\circledR}$ ) for thrombocytopenia, erythropoeitin for anemia (Afdhal et al., 2004; Sulkowski et al., 2005; Shiffman et al., 2005), and selective serotonin reuptake inhibitors (Krauss et al., 2002) for depression.

\section{Teratogenicity}

Peginterferons are classified as pregnancy category $\mathrm{C}$ when used without RBV. The addition of RBV increases the severity of this classification to category $\mathrm{X}$ (PEGASYS ${ }^{\circledR}$ and PEG-INTRON ${ }^{\circledR}$ package inserts). Little to no collaborative data are available on the safety of PEG-IFNs in humans or animals during pregnancy. In Rhesus monkeys, unmodified interferon administered at 20 to 500 times the human weekly dose was associated with no teratogenic events. No information is currently available on the distribution of PEG-IFNs into breast milk, and as such, there are no published data on the safety of the drug in the breastfed child.

\section{Conclusion}

The pegylation of the interferon molecule represents a significant breakthrough in the management of chronic HCV infection when compared with unmodified interferon. The therapeutic effect is especially obvious when the pegylated interferons are combined with RBV. In addition, pegylation of interferon allows for less frequent administration, which may improve adherence to therapy. Despite extensive research, efforts to improve the SVR rate for subjects infected with genotypes 1 and 4 above the current 40-50\% and 61-69\% levels remains elusive. The likelihood of attaining an SVR in subjects infected with HCV genotype 2 or 3 with combination therapy with PEG-IFN/RBV regimens is excellent. However, new data indicate that response to therapy of genotype 3 may be less than that of genotype 2 . More research is under way to address the issue of difficult-to-treat patients including subjects who do not respond to treatment or relapse after an end-of-treatment response. Other difficult-to-treat patients include African Americans as well as subjects undergoing liver transplantation. New guidelines to manage $\mathrm{HCV}$ co-infection in patients with HIV disease have been developed. Improved attention to adverse events has allowed patients to continue therapy and complete more of therapy, thus improving the chance of achieving an SVR. The combination of PEG-IFN products with new agents that attack hepatitis $\mathrm{C}$ in a variety of different sites appear promising, and we await the completion of phase III studies. 


\section{References}

Abi-Nassif, S., Mark, E.J., Fogel, R.B., Hallisey, R.K., Jr. (2003). Pegylated interferon and ribavirin-induced interstitial pneumonitis with ARDS. Chest, 124: 406-410.

Afdhal, N.H., Dieterich, D.T., Pockros, P.J. (2004). Epoetin alfa maintains ribavirin dose in HCVinfected patients: A prospective, double blind, randomized controlled study. Gastroenterology, 126: $1302-1311$.

Afdhal, N., Jacobson, I., Brown, R., Freilich, B., Santoro, J., Griffel, L., Bass C. (2006). The effect of liver fibrosis and cirrhosis on SVR in 4913 patients with hepatitis C: Results from the Win-R trial. Gastroenterology, 130 (4 Suppl 2): A-771; abstract 655.

Ahmed, F., Jacobson, I.M., Chen, S.T., Cofrancesco, S., Cooley, J., Demicco, M., Freilich, B., Hudes, B., Jensen, J., Levin, A., Lyche, K., McCone, J., Monsour, H.P., Peine, C., Pimstone, N., Rosenfield, T., Strauss, R., Stokes, K., Terrault, N., Tsai, N., Wasserman, R.B., Woolf, G.M., Brown, R.S., Brass, C. (2003). Serious ophthalmologic events during pegylated interferon and ribavirin therapy for chronic hepatitis C: Observations from the WIN-R trial. Hepatology, 38 (4 Suppl 1): 734-735A.

Alberti, A., Clumeck, N., Collins, S., Gerlich, W., Lundgren, J.D., Palu, G., Reiss, P., Thiebaut, R., Weiland, O., Yazdanpanah, Y., Zeuzem, S. (The ECC Jury) (2005). Short statement of the first European consensus conference on the treatment of chronic hepatitis B and C in HIV-coinfected patients. Journal of Hepatology, 42: 615-624.

Algranati, N.E., Sy, S., Modi, M. (1999). A branched methoxy 40 Kda polyethylene glycol (PEG) moiety optimizes the pharmacokinetics (PK) of peginterferon $\alpha-2 \mathrm{a}$ (PEG-INF) and may explain its enhanced efficacy in chronic hepatitis C (CHC). Hepatology, 30: 190A; abstract 120.

Arora, S., O'Brien, C., Zeuzem, S., Shiffman, M.L., Diago, M., Tran, A., Pockros, P.J., Reindollar, R.W., Gane, E., Patel, K., Wintfeld, N., Green, J. (2006). Treatment of chronic hepatitis $\mathrm{C}$ patients with persistently normal alanine aminotransferase levels with the combination of peginterferon $\alpha-2 \mathrm{a}(40 \mathrm{Kda})$ plus ribavirin: Impact on health-related quality of life. Journal of Gastroenterology and Hepatology, 21: 406-412.

Asahina, Y., Izumi, N., Enomoto, N., Uchihara, M., Kurosaki, M., Onuki, Y., Nishimura, Y., Ueda, K., Tsuchiya, K., Nakanishi, H., Kitamura, T., Miyake, S. (2005). Mutagenic effects of ribavirin and response to interferon/ribavirin combination therapy in chronic hepatitis C. Journal of Hepatology, 43: 623-629.

Bailon, P., Palleroni, A., Schaffer, C.A., Spence, C.L., Fung, W.J., Porter, J.E., Ehrlich, G.K., Pan, W., Xu, Z.X., Modi, M.W., Farid, A., Berthold, W., Graves, M. (2001). Rational design of a potent, long-lasting from of interferon: A $40 \mathrm{kDa}$ branched polyethylene glycol-conjugated interferon alpha-2a for the treatment of hepatitis C. Bioconjugates and Chemistry, 12: 195-202.

Balan, V., Schwartz, D., Wu, G.Y., Muir, A.J., Ghalib, R., Jackson, J., Keeffe, E.B., Rossaro, L., Burnett, A., Goon, B.L., Bowers, P.J., Leitz, G.J. (2005). Erythropoietic response to anemia in chronic hepatitis $\mathrm{C}$ patients receiving combination pegylated interferon/ribavirin. American Journal of Gastroenterology, 100: 299-307.

Bani-Sadr, F., Carrat, F., Pol, S., Hor, R., Rosenthal, E., Goujard, C., Morand, P., Lunel-Fabiani, F., Salmon-Ceron, D., Piroth, L., Pialoux, G., Bentata, M., Cacoub, P., Perronne, C. for the ANRS Hc02-Ribavic Study Team. (2005). Risk factors for symptomatic mitochondrial toxicity in HIV/hepatitis C virus-coinfected patients during interferon plus ribavirin-based therapy. Journal of AIDS, 40(1): 47-52.

Barril, G., Quiroga, J.A., Sanz, P., Rodrìguez-Salvanés, F., Selgas, R., Carreño, V. (2004). Peglyated interferon- $\alpha 2$ a kinetics during experimental haemodialysis: Impact of permeability and pore size of dialysers. Alimentary and Pharmacology Therapy, 20: 37-44.

Beckebaum, S., Cicinnati, V.R., Zhang, X., Malago, M., Dirsch, O., Erim, Y., Frilling, A., Broelsch, C.E., Gerken, G. (2004). Combination therapy with peginterferon alpha-2B and ribavirin in liver transplant recipients with recurrent HCV infection: Preliminary results of an open prospective study. Transplant Proceedings, 36: 1489-1491.

Benhamou, Y., Pockros, P., Rodriguez-Torres, M., Gordon, S., Shiffman, M., Lurie, Y., Afdhal, N., Lamon, K., Kim, Y., Murphy, B. (2006). The safety and efficacy of viramidine ${ }^{\circledR}$ plus 
pegylated interferon alpha- $2 \mathrm{~b}$ versus ribavirin plus pegylated interferon alpha- $2 \mathrm{~b}$ in therapynaïve patients infected with HCV: Phase 3 results. Journal of Hepatology, 44 (Suppl 2): S273; abstract 751.

Berenguer, M., Prieto, M., Palau, A., Carrasco, D., Rayón, J.M., Calvo, F., Berenguer, J. (2004). Recurrent hepatitis $\mathrm{C}$ genotype $1 \mathrm{~b}$ following liver transplantation: Treatment with combination interferon-ribavirin therapy. European Journal of Gastroenterology and Hepatology, 16: $1207-1212$.

Berg, C., Goncales, F.L., Bernstein, D.E., Sette, H., Rasenack, J., Diago, M., Jensen, D.M., Graham, P., Cooksley, G. (2006a). Re-treatment of chronic hepatitis C patients after relapse: Efficacy of peginterferon-alpha-2a (40 kDa) and ribavirin. Journal of Viral Hepatology, 13: 435-440.

Berg, T., VonWagner, M., Nasser, S., Sarrazin, C., Heintges, T., Gerlach, T., Buggisch, P., Goeser, T., Rasenack, J., Pape, G.R., Schmidt, W.E., Kallinowski, B., Klinker, H., Spengler, U., Martus, P., Alshuth, R., Zeuzem, S. (2006). Extended treatment duration for hepatitis C virus type 1: Comparing 48 versus 72 weeks of peginterferon-alfa-2a plus ribavirin. Gastroenterology, 130: 1086-1097.

Bernfort, L., Sennfält, K., Reichard, O. (2006). Cost-effectiveness of peginterferon alfa-2b in combination with ribavirin as initial treatment for chronic hepatitis $\mathrm{C}$ in Sweden. Scandinavian Journal of Infectious Diseases, 38: 497-505.

Biselli, M., Andreone, P., Gramenzi, A., Lorenzini, S., Loggi, E., Bonvicini, F., Cursaro, C., Bernardi, M. (2006). Pegylated interferon plus ribavirin for recurrent hepatitis C infection after liver transplantation in naive and non-responder patients on a stable immunosuppresive regimen. Digest of Liver Diseases, 38: 27-32.

Bizollon, T., Ahmed, S.N.S., Radenne, S., Chevallier, M., Chevallier, P., Parvaz, P., Guichard, S., Ducerf, C., Baulieux, J., Zoulim, F., Trepo, C. (2003). Long term histological improvement and clearance of intrahepatic hepatitis $\mathrm{C}$ virus RNA following sustained response to interferonribavirin combination therapy in liver transplanted patients with hepatitis $\mathrm{C}$ virus recurrence. Gut, 52: 283-287.

Bodenheimer, H.C., Lindsay, K.L., Davis, G.L., Lewis, J.H., Thung, S.N., Seeff, L.B. (1997). Tolerance and efficacy of oral ribavirin treatment of chronic hepatitis C: A multicenter trial. Hepatology, $26:$ 473-477.

Bonny, C., Roche, C., Fontaine, H., Poynard, T., Héxode, C., Larrey, D., Marcellin, P., Bourlière, M., Bronowicki, J.P., Merle, P., Zarski, J.P., Nicolas, C., Randl, K., Bommelaer, G., Abergel, A. (2005). Eficacy of interferon (standard or pegylated) plus ribavirin in naive patients with hepatitis C virus genotype 5. A French national study. Journal of Hepatology, 42 (Suppl 2): 200; abstract 549 .

Brau, N. (2003). Update on chronic hepatitis C in HIV/HCV-coinfected patients: Viral interactions and therapy. AIDS, 27: 2279-2290.

Brennan, B., Morrison, R., Hagedorn, C., Marbury, T.C., Sulkowski, M., Grippo, J., Gries, J-M. (2005). Effect of ethnicity on the pharmacokinetics of ribavirin (COPEGUS ${ }^{\circledR}$ ) and peginterferon alfa-2a (40KD) (PEGASYS $\left.{ }^{\circledR}\right)$ in patients with chronic hepatitis C. Hepatology, 42 (Suppl 1): 653A; abstract 1161.

Bressler, B., Wang, K., Gries, J.-M., Heathcote, J. (2005). Pharmacokinetics and response of obese patients with chronic hepatitis $\mathrm{C}$ treated with different doses of PEG-IFN alpha 2A (40KD) (PEGASYS $^{\circledR}$ ). Hepatology, 42 (Suppl 1): 661A; abstract 1183.

Brown, R.S., Jacobson, I.M., Afdhal, N., Freilich, B., Regenstein, F., Flamm, S., Kwo, P., Pauly, M.P., Griffel, L.H., Brass, C.A. (2006). Differences in treatment outcome to antiviral therapy based on genotype and viral load in hepatitis $\mathrm{C}$ genotypes 2 and 3 in the Win-R trial. Gastroenterology, 130 (4 Suppl 2): A-767; abstract 523.

Bruno, R., Sacchi, P., Maiocchi, L., Zocchetti, C., Ciappina, V., Patruno, S., Filice, G., (2005). Area-under-the-curve for peginterferon alpha-2a and peginterferon alpha- $2 \mathrm{~b}$ is not related to body weight in treatment-naive patients with chronic hepatitis C. Antiviral Therapy, 10: 201-205.

Burton, J.R., Klarquist, J., Im, K.A., Belle, S.H., Rosen, H.R. (2006). Stronger baseline HCVspecific immunity is associated with a higher likelihood of a sustained virological response 
to combination antiviral therapy of chronic hepatitis C. Gastroenterology, 130 (4 Suppl 2): abstract S1057.

Buti, M., Casado, M.A., Fosbrook, L., Esteban R. (2005). Financial impact of two different ways of evaluating early virological response to peginterferon $\alpha-2 b$ plus ribavirin therapy in treatment-naïve patients with chronic hepatitis $\mathrm{C}$ virus genotype 1 . Pharmacoeconomics 23 : 1043-1055.

Buti, M., Sanchez-Avila, F., Lurie, Y., Stalgis, C., Valdéz, A., Martell, M., Esteban, R. (2002). Viral kinetics in genotype 1 chronic hepatitis $\mathrm{C}$ patients during therapy with 2 different doses of peginterferon alfa-2b plus ribavirin. Hepatology, 35: 930-936.

Byrnes, V., Miller, A., Weinstein, C., Hill, E., Lenkinski, R., Alsop, D., Afdhal, N.H. (2005). Cerebral metabolic and neuropsychiatric effects of pegylated interferon (PIFN) therapy in hepatitis C. Gastroenterology, 128 (Suppl 2): A684 [abstract].

Cammà, C., Di Bona, D., Schepis, F., Heathcote, E.J., Zeuzem, S., Pockros, P.J., Marcellin, P., Balart, L., Alberti, A., Craxì, A. (2004). Effect of peginterferon alfa-2a on liver histology in chronic hepatitis C: A meta-analysis of individual patients' data. Hepatology, 39: 333-342.

Carrat, F., Bani Sadr, F., Pol, S., Rosenthal, E., Lunel-Fabiani, F., Benzekri, A., Morand, P., Goujard, C., Pialoux, G., Piroth, L., Salmon-Ceron, D., Degott, C., Cacoub, P., Perronne, C. for the ANRS HCO2 RIBAVIC Study Team. (2004). Pegylated interferon alfa-2b vs standard interferon alfa-2b, plus ribavirin, for chronic hepatitis $\mathrm{C}$ in $\mathrm{HIV}$-infected patients: A randomized controlled trial. JAMA, 292: 2839-2848.

Castera, L., Constant, A, Henry, C., Champenoit, P., Sauve, G., de Ledinghen V., Bernard P.H., Foucher, J., Demotes-Mainard, J., Couzigou, P. (2004). Psychiatric events during peginterferon and ribavirin therapy in chronic hepatitis $\mathrm{C}(\mathrm{CHC})$ : Results of a prospective study in 98 patients. Journal of Hepatology, 40 (Suppl 1): 139 [abstract].

Chalasani, N., Manzarbeitia, C., Ferenci, P., Vogel, W., Fontana, R.J., Voigt, M., Riely, C., Martin, P., Teperman, L., Jiao, J., Lopez-Talavera, J.C. for the Pegasys Transplant Study Group. (2005). Peginterferon alfa-2a for hepatitis C after liver transplantation: Two randomized, controlled trials. Hepatology, 41: 289-298.

Chatelut, E., Rostaing, L., Grégoire, N., Payen, J.L., Pujol, A., Izopet, J., Houin, G., Canal, P. (1999). A pharmacokinetic model for alpha interferon administered subcutaneously. British Journal of Clinical Pharmacology, 47: 365-371.

Chung, R.T., Andersen, J., Volberding, P., Robbins, G.K., Liu, T., Sherman, K.E., Peters, M.G., Koziel, M.J., Bhan, A.K., Alston, B., Colquhoun, D., Nevin, T., Harb, G., van der Horst, C. for the AIDS Clinical Trials Group A5071 Study Team (2004). Peginterferon alfa-2a plus ribavirin versus interferon alfa-2a plus ribavirin for chronic hepatitis $\mathrm{C}$ in HIV-coinfected persons. New England Journal of Medicine, 351: 451-459.

ClinicalTrials.gov Identifier NCT00077649. A randomized, double-blind study of the effect of PEGASYS and ribavirin combination therapy on viral kinetics and virologic response in interferon-naïve patients with chronic hepatitis $\mathrm{C}$ genotype 1 infection. (Study ID number: NV17318). (http://www.clinicaltrials.gov/ct/show/NCT00077649?order=1). Accessed 9/4/06.

ClinicalTrials.gov Identifier NCT 00255008. SEASON South East Asian study of novel genotypes in hepatitis $\mathrm{C}$ infection: Pegylated-interferon and ribavirin therapy (PEGATRON REDIPEN combination therapy (PEG-Intron ${ }^{\mathbb{R}}$ ) REDIPEN plus REBETOL ${ }^{\mathrm{R}}$ ) in treatment naïve patients with genotypes 1, 6, 7, 8, 9: A comparison of race and genotype on treatment outcome (http://www.clinicaltrials.gov/ct/show/NCT00255008?order=3). Accessed 9/4/06.

ClinicalTrials.gov Identifier NCT00255034. Effects of 48 weeks versus 24 weeks of therapy with peg-Intron/ribavirin in patients with chronic hepatitis C, genotype 3 (study P04143) (http://www.clinicaltrials.gov/ct/show/NCT00255034). Accessed 7/29/06.

ClinicalTrials.gov Identifier NCT00266318. Study of high dosage CIFN plus RBV for HCV genotype 1 infected patients who are nonresponders to prior therapy (http://www.clinicaltrials.gov/ct/show/NCT00266318?order=2). Accessed 8/13/06.

ClinicalTrials.gov Identifier NCT00336479. A phase 2 study of VX-950 in combination with peginterferon-2a (Pegasys $\left.{ }^{\circledR}\right)$, with ribavirin (Copegus ${ }^{\circledR}$ ) in subjects with genotype 1 hepatitis $\mathrm{C}$ who have not received prior treatment. (Study VX05-950-104) (http://www.clinicaltrials.gov/ct/show/NCT00336479?order=1). Accessed 8/24/06. 
ClinicalTrials.gov NCT00160251. PEG-Intron/REBETOL vs PEG-Intron/SCH503034 with and without ribavirin in chronic hepatitis $\mathrm{C} \mathrm{HCV}-1$ peginterferon alfa/ribavirin nonresponders: A SCH 503034 dose-finding phase 2 study. (Study P03659AMS1) (http://www.clinicaltrials.gov/ct/show/NCT00160251?order=1). Accessed 8/30/06.

Cohen, M.C., Huberman, M.S., Nesto, R.W. (1990). Interferon alfa-induced cardiac dysfunction. New England Journal of Medicine, 322: 1469.

Collantes, R.S., Younossi, Z.M. (2005). The use of growth factors to manage the hematologic side effects of PEG-interferon alfa and ribavirin. Journal of Clinical Gastroenterology, 39 (Suppl 1): S9-S13.

Condat, B., Asselah, T., Zanditenas, D., Estampes, B., Cohen, A., O’Toole, D., Bonnet, J., Ngo, Y., Marcellin, P., Belazquez, M. (2006). Fatal cardiomyopathy associated with pegylated interferon/ribavirin in a patient with chronic hepatitis C. European Journal of Gastroenterology and Hepatology, 18: 287-289.

Conjeevaram, H.S., Fried, M.W., Jeffers, L.J., Terrault, N.A., Wiley-Lucas, T.E., Afdhal, N., Brown, R.S., Belle, S.H., Hoofnagle, J.H., Kleiner, D.E., Howell, C.D. for the Virahep-C Study Group (2006). Peginterferon and ribavirin treatment in African Americans and Caucasian American patients with hepatitis C genotype 1. Gastroenterology, 131: 470-477.

Curry, M., Cardenas, A., Afdhal, N.H. (2005). Effect of maintenance PEG-INTRON therapy on portal hypertension and its complications: Results from the COPILOT study. Journal of Hepatology, 42 (Suppl 2): 40; abstract 95.

D'Heygere, F., George, C., Nevens, R., Van Vlierberghe, H., Van Der Meeren, O. (2005). Patients infected with HCV-5 present the same response rate as patients infected with HCV-1: Results from the Belgian randomised trial for naive and relapsers (BERNAR-1). Journal of Hepatology, 42 (Suppl 2): 203; abstract 558.

Dalekos, G.N., Hatzis, J., Tsianos, E.V. (1998). Dermatologic disease during interferon alpha therapy for chronic viral hepatitis. Annals of Internal Medicine, 128: 409-410.

Davis, G.L. (2002). Monitoring of viral levels during therapy of hepatitis C. Hepatology, 36 (Suppl 1): S145-S151.

De Franceschi, L., Fattovich, G., Turrini, F., Ayi, K., Brugnara, C, Manzato, F., Noventa, F., Stanzial, A., Solero, P., Corrocher, R. (2000). Hemolytic anemia induced by ribavirin therapy in patients with chronic hepatitis $\mathrm{C}$ virus infection: Role of membrane oxidative damage. Hepatology, 31: 997-1004.

Dereure, O., Raison-Pevron, N., Larrey, D., Blanc, F., Guilhou, J.J. (2002). Diffuse inflammatory lesions in patients treated with interferon alfa and ribavirin for hepatitis C: A series of 20 patients. British Journal of Dermatology, 147: 1142-1146.

Dev, A.T., McCaw, R., Sundararajan, V., Bowden, S., Sievert, W. (2002). Southeast Asian patients with chronic hepatitis C: The impact of novel genotypes and race on treatment outcome. Hepatology, 36: 1259-1265.

Diago, M.., Romero-Gomez, M.., Crespo, J., Olveira, A., Perez, R., Barcena, R., SanchezTapias, J.M., Munoz-Sanchez, M. (2006). Pharmacokinetics and pharmacodynamics of induction doses of peginterferon alpha-2a (40 KD) (PEGASYS $\left.{ }^{\circledR}\right)$ and ribavirin $\left(\right.$ COPEGUS $\left.{ }^{\circledR}\right)$ in HCV genotype 1 patients who failed to respond to interferon/ribavirin. Journal of Hepatology, 44 (Suppl 2): S210; abstract 566.

DiBisceglie, A.M., Fan, X., Chambers, T., Strinko, J. (2006). Pharmacokinetics, pharmacodynamics and hepatitis $\mathrm{C}$ viral kinetics during antiviral therapy: The null responder. Journal of Medical Virology, 78: 446-451.

Dieterich, D., Lawitz, E., Nguyen, T., Younes, Z., Santoro, J., Gitlin, N., McEniry, D., Chasen, R., Goff, J., Knox, S., Kleber, K., Belanger, B., Brown, N. (2006). Early clearance of HCV RNA with valopicitabine (NM283) plus peg-interferon in treatment-naive patients with HCV1 infection: First results form a phase IIb trial. Journal of Hepatology, 44 (Suppl 2): S271; abstract 736 .

Dominguez, S., Ghosn, J., Valantin, M.A., Schruniger, A., Simon, A., Bonnard, P., Caumes, E., Pialoux, G., Benhamou, Y., Thibault, V., Katlama, C. (2006). Efficacy of early treatment of acute hepatitis $\mathrm{C}$ infection with pegylated interferon and ribavirin in HIV-infected patients. AIDS, 20: 1157-1161. 
Dumortier, J., Scoazec, J., Chevallier, P., Boillot, O. (2004). Treatment of recurrent hepatitis C after liver transplantation: A pilot study of peginterferon alfa- $2 \mathrm{~b}$ and ribavirin combination. Journal of Hepatology, 40: 669-674.

Dusheiko, G., Main, J., Thomas, H., Reichard, O., Lee, C., Dhillon, A., Rassam, S., Fryden, A., Reesink, H., Bassendine, M., Norkrans, G., Cuypers, T., Lelie, N., Tefler, P., Watson, J., Weegink, C., Sillikens, P., Weiland, O. (1996). Ribavirin treatment for patients with chronic hepatitis C: Results of a placebo-controlled study. Journal of Hepatology, 25: 591-598.

Elefsiniotis, I.S., Pantazis, K.D., Fotos, N.V., Moulakakis, A., Mavrogiannis, C. (2006). Late onset autoimmune thrombocytopenia associated with pegylated interferon alfa- $2 \mathrm{~b}$ plus ribavirin treatment for chronic hepatitis C. Journal of Gastroenterology and Hepatology, 21: $622-623$.

Elmakhzangy, H., Rekacewicz, C., Shouman, S.I., Mohamed, H.N., Esmat, G., Ismail, A., Rafaat, R., El Hosseiny, M., El Daly, M., El Kafrawy, S., Abdel Hamid, M., Fontanet, A., Pol, S., Mohamed, M.K. (2005). Combined pegylated interferon alfa-2a and ribavirin treatment of chronic hepatitis C in Egypt (ANRS 1211 Trial). Journal of Hepatology, 42 (Suppl 2): 203; abstract 559.

Farel, C., Suzman, D.L., McLaughlin, M. (2004). Serious ophthalmic pathology compromising vision in $\mathrm{HCV} / \mathrm{HIV}$ co-infected patients treated with peg interferon alpha-2b and ribavirin. AIDS, 18: 1805-1809.

Ferenci, P., Bergholz, U., Laferl, H., Scherzer, T.M., Maieron, A., Gschwantler, M., Brunner, H., Hubmann, R.R., Datz, C., Bischof, M., Stauber, R., Steindl-Munda, P. (2006). 24 week treatment regimen with peginterrferon alpha-2a (40 KD) (PEGASYS $\left.{ }^{\circledR}\right)$ plus ribavirin (COPEGUS ${ }^{\mathrm{R}}$ ) in HCV genotype 1 or 4 "super-responders." Journal of Hepatology, 44 (Suppl 2): S6; abstract 8.

Ferenci, P., Fried, M.W., Shiffman, M.L., Smith, C.I., Marinos, G., Gonçales, F.L., Häussinger, D., Diago, M., Carosi, G., Dhumeaux, D., Craxì, A., Chaneac, M., Reddy, K.R. (2005). Predicting sustained virological responses in chronic hepatitis $\mathrm{C}$ patients treated with peginterferon alfa-2a (40KD)/ribavirin. Journal of Hepatology, 43: 425-433.

Firpi, R., Abdelmalek, M., Soldevila-Pico, C. (2002). Combination of interferon alfa-2b and ribavirin in liver transplant recipients with histological recurrent hepatitis C. Liver Transplantation, 8: 1000-1006.

Fonseca, V., Thomas, M., Dusheiko, G. (1991). Thyrotropin receptor antibodies following treatment with recombinant alpha-interferon in patients with hepatitis. Acta Endocrinology, 125: 491-493.

Food and Drug Administration Antiviral Drugs Committee Briefing document. Pegylated interferon alfa 2a (Pegasys ${ }^{\circledR}$ ). Bethesda, MD (May 16, 2006). http://www.fda.gov/ ohrms/dockets/ac/02/briefing/3909b1.htm.

Fried, M.W., Shiffman, M.L., Reddy, K.R., Smith, C., Marinos, G., Gonçales, F.L., Häussinger, D., Diago, M., Carosi, G., Dhumeaux, D., Craxi, A., Lin, A., Hoffman, J., Yu, J. (2002). Peginterferon alfa-2a plus ribavirin for chronic hepatitis C virus infection. New England Journal of Medicine, 347: 975-982.

Fried, M.W. (2002). Side effects of therapy of hepatitis C and their management. Hepatology, 36 (5 Suppl 1): S237-S244.

Gaglio, P., Choi, J., Zimmerman, D., Heller, L., Brown R.S. (2005). Weight based ribavirin in combination with pegylated interferon alpha 2-B does not improve SVR in HCV infected patients who failed prior therapy: Results in 454 patients. Hepatology, 42 (4 Suppl 1): 219A; abstract 59 .

Gane, E., Diago, M., Mohankumar, A., Wintfeld, N., Patel, K., Zeuzem, S., Shiffman, M., Reindollar, R. (2005). Health-related quality of live (HRQL) in chronic hepatitis C (CHC) patients with elevated vs. persistently "normal" ALT levels (PNALT): Comparison of data from patients treated with peginterferon alfa-2a (40 KD) plus ribavirin in two multinational trials. Gastroenterology 128 (4 Suppl 2): A-747; abstract M956.

Ganser, A., Carlo-Stella, C., Greher, J., Volkers, B., Hoelzer, D. (1987). Effect of recombinant interferons alpha and gamma on human bone marrow-derived megakaryocytic progenitor cells. Blood, 70: 1173-1179. 
Garfein, R.S., Doherty, M.C., Monterroso, E.R., Thomas, D.L., Nelson, K.E., Vlahov, D. (1998). Prevalence and incidence of hepatitis $\mathrm{C}$ virus infection among young adult injection drug users. Journal of AIDS Human Retrovirology, 18 (Suppl 1): S11-S19.

Ghosn, J., Pierre-François, S., Thibault, V., Duvivier, C., Tubiana, R., Simon, A., Valantin, M.A., Dominguez, S., Caumes, E., Katlama, C. (2004). Acute hepatitis C in HIV-infected men who have sex with men. HIV Medicine, 5: 303-306.

Giostra, E., Kullak-Ublick, G., Keller, W. (2004). Ribavirin/interferon-alpha sequential treatment of recurrent hepatitis C after liver transplantation. Transplantation International, 17: 169-176.

Glue, P., Rouzier-Panis, R., Raffanel, C., Sabo, R., Gupta, S.K., Salfi, M., Jacobs, S., Clement, R.P., the Hepatitis C Intervention Therapy Group. (2000a). A dose-ranging study of pegylated interferon alfa-2b and ribavirin in chronic hepatitis C. Hepatology, 32: 647-653.

Glue, P., Fang, J.W.S., Rouzier-Panis, R., Raffanel, C., Sabo, R., Gupta, S.K., Salfi, M., Jacobs, S., the Hepatitis C Intervention Therapy Group. (2000b). Pegylated interferon $\alpha-2 b$ : Pharmacokinetics, pharmacodynamkics, safety, and preliminary efficacy data. Clinical Pharmacology Therapy, 68: 556-567.

González-Peralta, R.P., Kelly, D.A., Harber, B., Molleston, J., Murray, K.F., Jonas, M.M., Shelton, M., Mieli-Verganti, G., Lurie, Y., Martin, S., Lang, T., Baczkowski, A., Geffner, M., Gupta, S., Laughlin, M., for the International Pediatric Hepatitis C Therapy Group. (2005). Interferon alfa- $2 b$ in combination with ribavirin for the treatment of chronic hepatitis $\mathrm{C}$ in children: Efficacy, safety, and pharmacokinetics. Hepatology, 42: 1010-1018.

Greub, G., Ledergerber, B., Battegay, M., Grob, P., Perrin, L., Furrer, H., Burgisser, P., Erb, P., Boggian, K., Piffaretti, J.-C., Hirschel, B., Janin, P., Francioli, P., Flepp, M., Telenti, A. for the Swiss HIV Cohort Study (2000). Clinical progression, survival, and immune recovery during antiretroviral therapy in patients with HIV-1 and hepatitis C virus co infection: The Swiss HIV Cohort Study. Lancet, 356: 1800-1805.

Gross, J., Johnson, S., Kwo, P., Afdhal, N., Flamm, S., Therneau, T.M. (2005). Double-dose peginterferon alfa- $2 b$ with weight based ribavirin improves response for interferon/ribavirin non-responders with hepatitis C: Final results of "RENEW." Hepatology, 42 (4 Suppl 1): 219A220A; abstract 60 .

Gross, J., Johnson, S.M., Therneau, T.M., Kwo, P.Y. (2005a). Double-dose peginterferon alfa-2b plus weight-based ribavirin for re-treatment of African-American non-responders with hepatitis C. Gastroenterology, 128 (4 Suppl 2): A-684; abstract 87.

Gupta, S.K., Glue, P., Jacobs, S., Belle, D., Affrime, M. (2003). Single-dose pharmacokinetics and tolerability of pegylated interferon-alpha $2 \mathrm{~b}$ in young and elderly healthy subjects. British Journal of Clinical Pharmacology, 56: 131-134.

Gupta, S.K., Pittenger, A.L., Swan, S.K., Marbury, T.C., Tobillo, E., Batra, V., Sack, M., Glue, P., Jacobs, S., Affrime, M. (2002). Single-dose pharmacokinetics and safety of pegylated interferon- $\alpha 2 b$ in patients with chronic renal dysfunction. Journal of Clinical Pharmacology, 42: 1109-1115.

Gurguta, C., Kauer, C., Bergholz, U., Formann, E., Steindl-Munda, P., Ferenci, P. (2006). Tongue and skin hyperpigmentation during PEG-interferon-alpha/ribavirin therapy in dark skinned non-Caucasian patients with chronic hepatitis C. American Journal of Gastroenterology, 101: 197-198.

Hadziyannis, S.J., Sette, H., Morgan, T.R., Balan, V., Diago, M., Marcellin, P., Ramadori, G., Bodenheimer, H., Bernstein, D., Rizzetto, M., Zeuzem, S., Pockros, P.J., Lin, A., Ackrill, A.M. PEGASYS International Study Group. (2004). Peginterferon alpha 2a and ribavirin combination therapy in chronic hepatitis C: A randomized study of treatment duration and ribavirin dose. Annals of Internal Medicine, 140: 346-355.

Harris, J.M., Martin, N.E., Modi, M. (2001). Pegylation: A novel process for modifying pharmacokinetics. Clinical Pharmacokinetics, 40: 539-551.

Hasan, F., Alsarraf, K., Qabandi, W. (2006). Pegylated interferon alfa-2b plus ribavirin for the treatment of chronic hepatitis $\mathrm{C}$ genotype 4 in adolescents: A pilot study. Gastroenterology, 130 (Suppl 2): A-840; abstract T1819. 
Hasan, F., Asker, H., Al-Khalid, J., Siddique, I., Al-Ajmi, M., Owaid, S., Varghese, R., Al-Nakib, B. (2004). Peginterferon alfa-2b plus ribavirin for the treatment of chronic hepatitis C genotype 4. American Journal of Gastroenterology, 99: 1733-1737.

Hassanein, T., Cooksley, G., Sulkowski, M., Smith, C., Marinos, G., Lai, M-Y., Pastore, G., TrejoEstrada, R., Vale, A.H.E., Wintfeld, N., Green, J. (2004). The impact of peginterferon alfa2a plus ribavirin combination therapy on health-related quality of life in chronic hepatitis $\mathrm{C}$. Journal of Hepatology, 40: 675-681.

Heathcote, E.J., Pockros, P.J., Fried, M.E., Bain, M.A., DePamphilis, J., Modi, M. (1999). The pharmacokinetics of pegylated-40K interferon alfa-2a (PEG-IFN) in chronic hepatitis $\mathrm{C}(\mathrm{CHC})$ patients with cirrhosis. Gastroenterology, 116: A735; abstract G3190.

Heathcote, E.J., Shiffman, M.L., Cooksley, W.G.E., Dusheiko, G.M., Lee, S.S., Balart, L., Reindollar, R., Reddy, R.K., Wright, T.L., Lin, A., Hoffman, J., DePamphilis, J. (2000). Peginterferon alfa-2a in patients with chronic hepatitis C and cirrhosis. New England Journal of Medicine, 343: 1673-1680.

Herrine, S.K., Brown, R.S., Bernstein, D.E., Ondovik, M.S., Lentz, E., Te, H. (2005). Peginterferon $\alpha-2$ a combination therapies in chronic hepatitis $C$ patients who relapsed after or had a viral breakthrough on therapy with standard interferon $\alpha-2 b$ plus ribavirin: A pilot study of efficacy and safety. Digestive Disease Sciences, 50: 719-726.

Herrmann, E., Lee, J.-H., Marinos, G., Modi, M., Zeuzem, S. (2003). Effect of ribavirin on hepatitis $\mathrm{C}$ viral kinetics in patients treated with pegylated interferon. Hepatology, 37: 1351-1358.

Hershow, R.C., O’Driscoll, P.T., Handelsman, E., Pitt, J., Hillyer, G., Serchuck, L., Lu, M., Chen, K.T., Yawetz, S., Pacheco, S., Davenny, K., Adeniyi-Jones, S., Thomas, D.L. (2005). Hepatitis $\mathrm{C}$ virus coinfection and HIV load, $\mathrm{CD}_{4}{ }^{+}$cell percentage, and clinical progression to AIDS or death among HIV-infected women: Women and infants transmission study. Clinical Infectious Diseases, 40: 859-867.

Homoncik, M., Jessner, W., Sieghardt, W. (2003). Effect of therapy with interferon-alpha and pegylated interferon-alpha on platelet plug formation in patients with chronic hepatitis C. Journal of Hepatology, 38 (Suppl 2): 145; abstract 497.

Hornberger, J., Dusheiko, G., Lewis, G., Patel, K. (2005). An evaluation of the cost-effectiveness of peginterferon alfa-2a (40KD) (PEGASYS ${ }^{\mathrm{R}}$ ) plus ribavirin (COPEGUS ${ }^{\circledR}$ ) for the first treatment of mild chronic hepatitis C (CHC). Hepatology, 42 (4 Suppl 1): 653A; abstract 1162 .

Howell, C., Dowling, T., Haritos, M., Terrault, N., Thelma, W.-L., Taylor, M. (2006). Relationship between serum peginterferon and 2,5-OAS kinetics and virologic responses in African Americans and Caucasians patients with chronic hepatitis C, genotype 1, during peginterferon combination therapy. Gastroenterology, 130 (4 Suppl 2): abstract 199.

Hui, C.K., Yuen, M.F., Sablon, E., Chan, A.O., Wong, B.C., Lai, C.L. (2003). Interferon and ribavirin therapy for chronic hepatitis $C$ virus genotype 6: A comparison with genotype 1. Journal of Infectious Diseases, 187: 1071-1074.

Hultgren, C., Milich, D.R., Weiland, O., Sällberg, M. (1998). The antiviral compound ribavirin modulates the Thelper (Th) 1/Th 2 subset balance in hepatitis B and C virus-specific immune responses. Journal of General Virology, 79: 2381-2391.

Hurst, E.A., Mauro, T. (2005). Sarcoidosis associated with pegylated interferon alfa and ribavirin treatment for chronic hepatitis C. Archives of Dermatology, 141: 865-868.

Imagawa, A., Itoh, N., Hanafusa, T., Oda, Y., Waguri, M., Miyagawa, J. (1995). Autoimmune endocrine disease induced by recombinant interferon- $\alpha$ therapy for chronic active type $\mathrm{C}$ hepatitis. Endocrinology and Metabolism, 80: 922-926.

Izumi, N., Iino, S., Okuno, T., Omata, M., Kiyosawa, K., Kumada, H., Hayashi, N., Yamada, G., Sakai, T. (2006). High response rates with peginterferon $\alpha-2 a(40 K D)$ (PEGASYS $\left.{ }^{\circledR}\right)$ PLUS ribavirin (Copegus ${ }^{\circledR}$ ) in Japanese non-responders or relapsers to conventional interferon. Journal of Hepatology, 44 (Suppl 2): S216; abstract 582.

Jacobson, I., Brown, R., McCone, J., Black, M., Albert, C., Dragutsky, M., Siddiqui, F., Hargrave, T., Kwo, P., Gitlin, N.l, Lambiasi, L., Galler, G., Araya, V., Freilich, B., Harvey, J., Bass, C., and the WIN-R Study Group. (2004). Weight-based ribavirin dosing improves 
virologic response in $\mathrm{HCV}$-infected genotype 1 African-American (AA) compared to flat dose ribavirin with peginterferon alfa-2b combination therapy. Hepatology 40 (4 Suppl 1): 217A; abstract 125 .

Jacobson, I.M., Brown, R.S., Freilich, B., Afdhal, N., Kwo, P., Santoro, J., Becker, S., Wakil, A., Pound, D., Godofsky, E., Straus, R., Bernstein, D., Flamm, S., Bala, N., Araya, V., Davis, M., Monsour, H., Vierling, J., Regenstein, F., Balan, V., Dragutsky, M., Epstein, M., Herring, R.W., Rubin, R., Galler, G., Pauly, M.P., Griffel, L.H., Brass, C.A., The WIN-R Study Group. (2005). Weight-based ribavirin dosing (WBD) increases sustained viral response (SVR) in patients with chronic hepatitis $\mathrm{C}(\mathrm{CHC})$ : Final results of the WIN-R study, a US community based trial. Hepatology, 42 (Suppl 1): 749A; abstract LB03.

Jacobson, I.M., Brown, R.S., Freilich, B., Afdhal, N., Kwo, P., Santoro, J., Becker, S., Wakil, A., Pound, D., Ahmed, F., Griffel, L.H., Brass, C.A. (2006). Stratification of high viral load: Impact on sustained virologic response in the Win-R trial. Gastroenterology, 130 (4 Suppl 2): A837; abstract T1806.

Jacobson, I.M., Gonzalez, S.A., Ahmed, F., Lebovics, E., Min, A.D., Bodenheimer, H.C., Esposito, S.P., Brown, R.S., Bräu, N., Klion, F.M., Tobias, H., Bini, E.J., Brodsky, N., Cerulli, M.A., Aytaman, A., Gardner, P.W., Beders, J.M., Spivack, J.E., Rahmin, M.G., Berman, D.H., Ehrlich, J., Russo, M.W., Chait, M., Rovner, D., Edlin, B.R. (2005). A randomized trial of pegylated interferon $\alpha-2 b$ plus ribavirin in the retreatment of chronic hepatitis C. American Journal of Gastroenterology, 100: 2453-2462.

Jeffers, L.J., Cassidy, W., Howell, C.D., Hu, S., Reddy, K.R. (2004). Peginterferon alfa-2a (40kd) and ribavirin for Black American patients with chronic HCV genotype 1. Hepatology, 39: $1702-1708$.

Jensen, D.M., Morgan, T.R., Marcellin, P., Pockros, P.J., Reddy, K.R., Hadziyannis, S.J., Ferenci, P., Ackrill, A.M., Willems, B. (2006). Early identification of HCV genotype 1 patients responding to 24 weeks peginterferon $\alpha-2 \mathrm{a}(40 \mathrm{kd}) /$ ribavirin therapy. Hepatology, 43 : 954-960.

Jessner, W., Kinaciyan, T., Formann, E. (2002). Severe skin reactions during therapy for chronic hepatitis $\mathrm{C}$ associated with delayed hypersensitivity to pegylated interferons. Hepatology, 36: 361A; abstract 793.

Kaiser, S., Hass, H., Lutze, B., Gregor, M. (2006). Comparison of daily Consensus interferon versus peginterferon alfa-2a extended therapy of 72 weeks for peginterferon/ribavirin relapse patients. Gastroenterology, 130: A-784; abstract S1060.

Kamal, S.M., El Tawil, A.A., Nakano, T., He, Q., Rasenack, J., Hakam, S.A., Saleh, W.A., Ismail, A., Aziz, A.A., Ali Madwar, M. (2005). Peginterferon $\alpha-2 b$ and ribavirin therapy in chronic hepatitis $C$ genotype 4: Impact of treatment duration and viral kinetics on sustained virological response. Gut, 54: 858-866.

Kamal, S.M., Fehr, J., Roesler, B., Peters, T., Rasenack, J.W. (2002). Peginterferon alone or with ribavirin enhances $\mathrm{HCV}$-specific $\mathrm{CD} 4^{+}{ }^{-}$-Helper 1 responses in patients with chronic hepatitis C. Gastroenterology, 123: 1070-1083.

Kamal, S.M., Fouly, A.E., Kamel, R.R., Hockenjos, B., Al Tawil, A., Khalifa, K.E., He, Q., Koziel, M.J., El Naggar, K.M., Rasenack, J., Afdhal, N.H. (2006a). Peginterferon alfa-2b therapy in acute hepatitis C: Impact of onset of therapy on sustained virologic response. Gastroenterology, 130: 632-638.

Kamal, S.M., Moustafa, K.N., Chen, J., Fehr, J., Moneim, A.A., Khalifa, K.E., El Gohary, L.A., Ramy, A.H., Madwar, M.A., Rasenack, J., Afdhal, N.H. (2006b). Duration of peginterferon therapy in acute hepatitis C: A randomized trial. Hepatology, 43: 923-931.

Ketikoglou, I., Karatapanis, S., Elefsiniotis, I., Kafiri, G., Moulakakis, A. (2005), Extensive psoriasis induced by pegylated interferon alpha- $2 \mathrm{~b}$ treatment for chronic hepatitis B. European Journal of Dermatology, 15: 107-109.

Khuroo, M.S., Khuroo, M.S., Dahab, S.T. (2004). Meta-analysis: A randomized trial of peginterferon plus ribavirin for the initial treatment of chronic hepatitis $\mathrm{C}$ genotype 4. Alimentary Pharmacology and Therapy, 20: 931-938.

Kozlowski, A., Harris J.M. (2001). Improvements in protein PEGylation: Pegylated interferons for treatment of hepatitis C. Journal of Controlled Release, 72: 217-224. 
Kramer, J.R., Giordano, T.P., Souchek, J., El-Serag, H.B. (2005). Hepatitis C co infection increases the risk of fulminant hepatic failure in patients with HIV in the HAART era. Journal of Hepatology, 42: 309-314.

Kraus, M.R., Schäfer, A., Faller, H., Csef, H., Scheurlen, M. (2002). Paroxetine for the treatment of interferon-alpha-induced depression in chronic hepatitis C. Alimentary Pharmacology and Therapy, 16: 1091-1099.

Kraus, M.R., Schafer, A., Wibmann, S., Reimer, P., Scheurlen, M. (2005). Neurocognitive changes in patients with hepatitis $\mathrm{C}$ receiving interferon alfa-2b and ribavirin. Clinical Pharmacology and Therapy, 77: 90-100.

Kuehne, F., Bethe, U., Freedberg, K., Goldie, S. (2002). Treatment for hepatitis C virus in HIVinfected patients: Clinical benefits and cost-effectiveness. Archives of Internal Medicine, 162: 2545-2556.

Kuo, A., Terrault, N.A. (2006). Management of hepatitis C in liver transplant recipients. American Journal of Transplantation, 6: 449-458.

Kuwata, A., Ohashi, M., Sugiyama, M., Ueda, R., Dohi, Y. (2002). A case of reversible dilated cardiomyopathy after alpha-interferon therapy in a patient with renal cell carcinoma. American Journal of Medicine, 324: 331-334.

Lam, N.P., Pitrak, D., Speralakis, R., Lau, A.H., Wiley, T.E., Layde, T.J. (1997). Effect of obesity on pharmacokinetics and biologic effect of interferon-alpha in hepatitis C. Digestive Disease Sciences, 42: 178-185.

Lamb, M.W., Martin, N.E. (2002). Weight-based versus fixed dosing of peginterferon (40 kDa) alfa-2a. Annals of Pharmacotherapy, 36: 933-935.

Lamb, M.W., Marks, I.M., Wynohradnyk, L., Modi, M.W., Preston, R.A., Pappas, C. (2001). 40 KDA peginterferon alfa-2a (PEGASYS ${ }^{\circledR}$ ) can be administered safely in patients with endstage renal disease. Hepatology, 34: 326A; abstract 618.

Lauer, G.M., Walker, B.D. (2001). Hepatitis C virus infection. New England Journal of Medicine, 345: 41-52.

Lebray, P., Nalpas, B., Vallet-Picard, A., Broissand, C., Sobesky, R., Serpaggi, J., Fontaine, H., Pol, S. (2005). The impact of haematopoietic growth factors on the management and efficacy of antiviral treatment in patients with hepatitis C virus. Antiviral Therapy, 10: 769-776.

Lee, S.S., Heathcote, E.J., Reddy, K.R., Zeuzem, S., Fried, M.W., Wright, T.L., Pockros, P.J., Häussinger, D., Smith, C.I., Lin, A., Pappas, S.C. (2002). Prognostic factors and early predictability of sustained viral response with peginterferon alfa-2a (40KD). Journal of Hepatology, 37: 500-506.

Lee, W., Dieterich, D. (2004). Challenges in the management of HIV and hepatitis C virus coinfection. Drugs, 64: 693-700.

Lin, K., Perni, R.B., Kwong, A.D., Lin, C. (2006). VX-950, a novel hepatitis C (HCV) NS34a protease inhibitor, exhibits potent antiviral activities in HCV replicon cells. Antimicrobial Agents and Chemotherapy, 50: 1813-1822.

Lindsay, K.L., Trepo, C., Heintges, T., Schiffman, M.L., Gordon, S.C., Hoefs, J.C., Schiff, E.R., Goodman, Z.D., Laughlin, M., Yao, R., Albrecht, J.K., for the Hepatitis Interventional Therapy Group. (2001). A randomized, double blind trial comparing pegylated interferon alfa- $2 \mathrm{~b}$ to interferon alfa-2b as initial treatment for chronic hepatitis C. Hepatology, 34: 395-403.

Lisker-Melman, M., Di Bisceglie, A.M., Usala, S.J., Weintraub, B., Murray, L.M., Hoofnagle, J.H. (1992). Development of thyroid disease during therapy of viral hepatitis with interferon alfa. Gastroenterology, 102: 2155-2160.

Lutchman, G., Hoofnagle, J.H. (2003). Viral kinetics in hepatitis C. Hepatology, 37: 1257-1259.

Luxon, B.A., Grace, M., Brassard, D., Bordens, R. (2002). Pegylated interferons for the treatment of chronic hepatitis C infection. Clinical Therapy, 24: 1363-1383.

Macias, J., Castellano, V., Merchante, N., Palacios, R.B., Mira, J.A., Saez, C., Garcia-Garcia, J.A., Lozano, F., Gomez-Mateos, J.M., Pineda, J.A. (2004). Effect of antiretroviral drugs on liver fibrosis in HIV-infected patients with chronic hepatitis C: Harmful impact of nevirapine. AIDS, 18: 767-774..

Mangia, A., Santoro, R., Minerva, N., Ricci, G.L., Carretta, V., Persico, M., Vinelli, F., Scotto, G., Bacca, D., Annese, M., Romano, M., Zechini, F., Sogari, F., Spirito, F., Andriulli, A. (2005). 
Peginterferon alfa- $2 \mathrm{~b}$ and ribavirin for 12 vs. 24 weeks in HCV genotype 2 or 3. New England Journal of Medicine, 353: 2609-2617.

Manns, M.P., McHutchison, J.G., Gordon, S.C., Rustgi, V.K., Shiffman, M., Reindollar, R., Goodman, Z.D., Koury, K., Ling, M., Albrecht, J.K. (2001). Peginterferon alfa-2b plus ribavirin compared with interferon alfa-2b plus ribavirin for initial treatment of chronic hepatitis $\mathrm{C}$ : A randomized trial. Lancet, 358: 958-965.

Marcellin, P., Jensen, D. (2005). Retreatment with PEGASYS ${ }^{\circledR}$ in patients not responding to prior peginterferon alfa-2b/ribavirin (RBV) combination therapy-efficacy analysis of the 12-week induction period of the REPEAT study. Hepatology, 42 (4 Suppl 1): 749A; abstract LB04.

Martin, N.E., Modi, M.W., Reddy, R. (2000a). Characterization of pegylated (40KDA) interferon alfa-2a (PEGASYS) in the elderly. Hepatology, 32: 348A; abstract 755.

Martin, P., Mitra, S., Farrington, K., Martin, N.E., Modi, M.W. (2000b). Pegylated (40 KDA) alfa-2a (PEGASYS) is unaffected by renal impairment. Hepatology, 32: 370A; abstract 842.

Mauss, S., Berger, F., Goelz, J., Jacob, B., Schmutz, G. (2004a). A prospective controlled study of interferon-based therapy of chronic hepatitis $\mathrm{C}$ in patients on methadone maintenance. Hepatology, 40: 120-124.

Mauss, S., Valenti, W., DePamphilis, J. (2004b). Risk factors for hepatic decompensation in patients with HIV/HCV co infection and liver cirrhosis during interferon-based therapy. AIDS, 18: $21-25$.

McHutchison, J.G., Ghalib, R., Lawitz, E., Kwo, P., Freilich, B., Muir, A., Masciari, F., Morris, M.L., Himes, J.L., Al-Adhami, M., Bacon, B.R. (2006). Early viral response to CPG 10101, in combination with pegylated interferon and/or ribavirin, in chronic HCV genotype 1 infected patients with prior relapse response. Journal of Hepatology, 44 (Suppl 2): S269; abstract 730 .

Meier, V., Bürger, E., Mihm, S., Saile, B., Ramadori, G. (2003). Ribavirin inhibits DNA, RNA, and protein synthesis in PHA-stimulated human peripheral blood mononuclear cells: Possible explanation for therapeutic efficacy in patients with chronic HCV infection. Journal of Medical Virology, 69: 50-58.

Modi, M.W., Fried, M., Reindollar, R.W., Rustgi, V.R., Kenny, R., Wright, T.L., Gibas, A., Martin, N.E. (2000a). The pharmacokinetic behavior of pegylated (40KDA) interferon alfa2a (PEGASYS) in chronic hepatitis C patients after multiple dosing. Hepatology, 32: 394A; abstract 939 .

Modi, M.W., Fulton, J.S., Buckmann, D.K., Wright, T.L., Moore, D.J. (2000b). Clearance of pegylated (40 KDA) interferon alfa-2a (PEGASYS ${ }^{T M}$ ) is primarily hepatic. Hepatology, 32: 371A; abstract 848 .

Moore, M.M., Elpern, D.J., Carter, D.J. (2004). Severe, generalized nummular eczema secondary to interferon alfa-2b plus ribavirin combination therapy in a patient with chronic hepatitis $\mathrm{C}$ virus infection. Archives in Dermatology, 140: 215-217.

Mukherjee, S., Lyden, E., McCashland, T.M., Schafer, D.F. (2005). Interferon alpha 2b and ribavirin for the treatment of recurrent hepatitis $\mathrm{C}$ after liver transplantation: Cohort study of 38 patients. Journal of Gastroenterology and Hepatology, 20: 198-203.

Mukherjee S., Rogge J., Weaver L., and Schafer D.F. (2003). Pilot study of pegylated interferon Alfa- $2 \mathrm{~b}$ and ribavirin for recurrent hepatitis $\mathrm{C}$ after liver transplantation. Transplant Proceedings, 35: 3042-3044.

National Institutes of Health Consensus Development Conference Statement: Management of hepatitis C. (2002). Hepatology, 36 (Suppl 1): S3-S20.

Neff, G.W., Montalbano, M., O'Brien, C.B., Nishida, S., Safdar, K., Bejarano, P.A., Khaled, A.S., Ruiz, P., Slapak-Green, G., Lee, M., Nery, J., De Medina, M., Tzakis, A., Schiff, E.R. (2004), Treatment of established recurrent hepatitis $\mathrm{C}$ in liver-transplant recipients with pegylated interferon-alfa-2b and ribavirin therapy. Transplantation, 78: 1303-1307.

Neumann, A.U., Lam, N.P., Dahari, H., Gretch, D.R., Wiley, T. E., Layden, T.J., Perelson, A.S. (1998). Hepatitis $C$ viral dynamics in vivo and the antiviral efficacy of interferon-alpha therapy. Science, 282: 103-107.

Neumann, A.U., Zeuzem, S., Ferrari, C., Lurie, Y., Negro, F., Germanidis, G., Esteban, J., Hellstrand, K., Pellegrin, B., Soulier, A., Haagmans, B., Abrignani, S., Colucci, G., 
Schalm, S.W., Pawlotsky, J.-M.. (2002). DITTO-HCV early viral kinetics report novel decline patterns in Gen 1 but not Gen 2-3 patients treated with PEG-interferon-alfa-2a and ribavirin. Journal of Hepatology, 36 (Suppl 1): 121; abstract 430.

Nevens, F., Van Vlierberghe, H., D’Heygere, F., Delwaide, J., Adler, M., Henrion, J., Henry, J.P., Hendlisz, A., Michielsen, P., Bastens, B., Brenard, R., Van Der Meeren, O. (2005). Peginterferon $\alpha-2 \mathrm{a}(40 \mathrm{kDa})$ plus ribavirin is as effective in patients relapsing after conventional interferon based therapy as in naïve patients: Results from the Bernar-1 trial. Journal of Hepatology, 42 (Suppl 2): 214; abstract 588.

Nguyen, M.D., Trinh, H.N., Garcia, R.T., Ning, J., Keeffe, B. (2003). Evaluation and outcomes of combination therapy with interferon or peginterferon plus ribavirin in 67 Southeast Asian patients with hepatitis C genotype 6, 7, 8, and 9. Hepatology, 38 (4 Suppl 1): 645A; abstract 1014.

Nunez, M., Benito, J.M., Lopez, M. (2003). Hepatitis C virus increases lymphocyte apoptosis in HIV-infected patients. In 43rd Interscience Conference on Antimicrobial Agents and Chemotherapy, Chicago, IL, September [abstract H-1717].

Oton, E., Barcena, R., Garcia-Garzon, S., Moreno-Zamora, A., Moreno, A., Garcia-Gonzalez, M., Blesa, C., Foruny, J.R., Ruiz, P. (2005). Pegylated interferon and ribavirin for the recurrence of chronic hepatitis $\mathrm{C}$ genotype 1 in transplant patients. Transplant Proceedings, 37: 3963-3964.

Pawlotsky, J.-M., Dahari, H., Neumann, A.U., Hezode, C., Germanidis, G., Lonjon, I., Castera, L., Dhumeaux, D. (2004). Antiviral action of ribavirin in chronic hepatitis C. Gastroenterology, 126: 703-714.

Pawlotsky, J.-M., Hezode, C., Pellegrin, B., Soulier, A., won Wagner, M., Brouwer, J.T., Missale, G., Germanidis, G., Lurie, Y., Negro, F., Esteban, J., Hellstrand, K., Ferrari,C., Zeuzem, S., Schalm, S.W., Neumann, A. (2002). Early HCV genotype 4 replication kinetics during treatment with peginterferon alfa-2a (PEGASYS)-ribavirin combination. A comparison with HCV genotypes 1 and 3 kinetics. Hepatology, 36: 291A; abstract 511.

Peginterferon alfa-2a, Pegasys [package insert]. Nutley, NJ: Roche Pharmaceuticals; 2004.

PEG-INTRON(R) Powder for Injection, peginterferon alfa-2b [package insert]. Kenilworth, NJ, Schering Corporation; 2005.

Planas, J.M., Gonzalez, E.R., Grana, E.B., Botella, A.G., Peinado, C.B., Poza, J.L., Garrido, M.J., Turrion, V.S., Martinez, V.C. (2005). Peginterferon and ribavirin in patients with HCV cirrhosis after liver transplantation. Transplant Proceedings, 37: 2207-2208.

Pockros, P., O’Brien, C., Godofsky, E., Rodriguez-Torres, M., Afdhal, N., Pappas, S.C., Lawitz, E., Bzowej, N., Rustgi, V., Sulkowski, M., Sherman, K., Jacobson, I., Chao, G., Knox, S., Pietropaolo, K., Brown, N. (2006). Valopicitabine (NM283), alone or with PEG-interferon, compared to PEG interferon/ribavirin (pegIFN/RBV) retreatment in hepatitis C patients with prior non-response to pegIFN/RBV: Week 24 results. Gastroenterology, 130 (4 Suppl 2): A748; abstract 4.

Pockros, P.J., Carithers, R., Desmond, P., Dhumeaux, D., Fried, M.W., Marcellin, P., Shiffman, M.L., Minuk, G., Reddy, K.R., Reindollar, R.W., Lin, A., Brunda, M.J., for the PEGASYS ${ }^{\circledR}$ International Study Group. (2004). Efficacy and safety of two-dose regimens of peginterferon alpha-2a compared with interferon alpha-2a in chronic hepatitis C: A multicenter, randomized controlled trial. American Journal of Gastroenterology, 99: 1298-1305.

Poynard, T., Schiff, E., Terg, R., Goncales, F., Flamm, S., Diago, M., Reichen, J., Moreno, R., Tanno, H., McHutchison, J., Fainboim, H., Berg, T., Mattos, A., Burak, K., Mukhopadhyay, P., Bedossa, P., Griffel, L., Burroughs, M., Brass, C., Albrecht, J. (2005). Sustained virologic response (SVR) with PEG-Interferon-alfa 2b/ribavirin weight based dosing in previous interferon/ribavirin HCV treatment failures; week 12 virology as a predictor of SVR in the $\mathrm{EPIC}^{3}$ trials. Gastroenterology, 128 (Suppl 2): A681; abstract 5.

Preziati, D., La Rosa, L., Covini, G., Marcelli, R., Rescalli, S., Persani, L. (1995). Autoimmunity and thyroid function in patients with chronic active hepatitis treated with recombinant interferon alpha-2a. European Journal of Endocrinology, 132: 587-593.

Ramos, B., Nunez, M., Rendon, A. (2006). High ribavirin doses and early virological response in HCV/HIV-coinfected patients. Program and abstracts of the 2nd International Workshop 
on HIV and Viral Hepatitis Co infection; January 12-14, Amsterdam, The Netherlands. Abstract 36.

Rasenack, J., Zeuzem, S., Feinman, V., Heathcote, E.J., Manns, M., Yoshida, E.M., Swain, M.G., Gane, E., Diago, M., Revicki, D.A., Lin, A., Wintfeld, N., Green, J. (2003). Peginterferon $\alpha-2 a$ (40 kD) [PEGASYS ${ }^{\mathrm{R}}$ ] improves HR-QOL outcomes compared with unmodified interferon $\alpha-2 \mathrm{a}\left[\right.$ Roferon $\left.^{\circledR}-\mathrm{A}\right]$ in patients with chronic hepatitis C. Pharmacoeconomics, 21: 341-349.

Rauch, A., Rickenbach, M., Weber, R. (2005). Association of unsafe sex and increased incidence of hepatitis C infection in HIV-infected men who have sex with men. Program and abstracts of the 12th Conference on Retroviruses and Opportunistic Infections; February 22-25, Boston, MA. Abstract 943.

Reddy, K.R., Wright, T.L., Pockros, P.J., Shiffman, M., Everson, G., Reindollar, R., Fried, M.W., Purdum, P.P., Jensen, D., Smith, C., Lee, W.M., Boyer, T.D., Lin, A., Pedder, S., DePamphilis, J. (2001). Efficacy and safety of pegylated (40-kd) interferon $\alpha$-2a compared with interferon $\alpha$-2a in noncirrhotic patients with chronic hepatitis C. Hepatology, 33: 433-438.

Reesink, H.W., Zeuzem, S., Weegink, C.J., Forestier, N., van Vliet, A., van de Wetering de Rooij, J., McNair, L.A., Purdy, S., Chu H-M., Jansen, P.L. (2005). Final results of a Phase 1B, multipledose study of VX-950, a hepatitis C virus protease inhibitor. Hepatology 42 (4 Suppl 1): 234A; abstract 96.

Rendon, A.L., Nunez, M., Romero, M., Barreiro, P., Martin-Carbonero, L., Garcia-Samaniego, J., Jimenez-Nacher, I., Gonzalez-Lahoz, J., Soriano V. (2005). Early monitoring of ribavirin plasma concentrations may predict anemia and early virological response in HIV/hepatitis C virus-coinfected patients. Journal of AIDS, 39: 401-405.

Rhodes, S., Erlich, H., Im, K.A., Wang, J., Li J., Bugawan, T., Jeffers, L., Tong, X., Su, X., Lee, L.J., Liang, T.J., Yang, H. (2006). Association between HLA allele a*02, B*58, Dpb*1701 and sustained virologic response to pegylated interferon and ribavirin therapy in chronic HCV genotype 1-infected, treatment naïve Caucasian and African Americans. Gastroenterology, 130 (4 Suppl 2): A-771; abstract 656.

Sakai, T., Iino, S., Okuno, T., Omata, M., Kiyosawa, K., Kumada, H., Yamada, G., Hayashi, N. (2006). High response rates with peginterferon alpha-2a (40KD) (PEGASYS ${ }^{\circledR}$ ) plus ribavirin (COPEGUS ${ }^{\mathrm{R}}$ ) in treatment-naïve Japanese chronic hepatitis $\mathrm{C}$ patients: A randomized, double-blind, multicentre, phase III trial. Journal of Hepatology, 44 (Suppl 2): S224; abstract 605 .

Sánchez-Tapias, J.M., Diago, M., Escartín, P., Enríquez, J., Romero-Gómez, M., Bárcena, R., Crespo, J., Andrade, R., Martínez-Bauer, E., Pérez, R., Testillano, M., Planas, R., Solá, R., García-Bengoechea, M., Garcia-Samaniego, J., Munoz-Sánchez, M., Moreno-Otero, R.; TeraViC-4 Study Group. (2006). Peginterferon-alfa 2a plus ribavirin for 48 versus 72 weeks in patients with detectable hepatitis C virus RNA at week 4 of treatment. Gastroenterology, 131: 451-460.

Schmid, M., Kreil, A., Jessner, W., Homoncik, M., Datz, C., Gangl, A., Ferenci, P., PeckRadosavljevic, M. (2005). Suppression of haematopoiesis during therapy of chronic hepatitis $\mathrm{C}$ with different interferon $\alpha$ mono and combination therapy regimens. Gut, 54: 1014-1020.

Schulman, J.A., Liang, C., Kooragayala, L.M., King, J. (2003). Posterior segment complications in patients with hepatitis $\mathrm{C}$ treated with interferon and ribavirin. Ophthalmology, 110: 437-442.

Schwaiger, M., Pich, M., Granke, L. (2003). Chronic hepatitis C infection, interferon alpha treatment and peripheral serotonergic dysfunction. Hepatology, 38 (Suppl 1): 300A; abstract 301 .

Schwarz, K., Mohan, P., Narkewicz, M., Molleston, J.P., Te, H.S., Hu, S., Sheridan, S., Lamb, M., Pappas, S.C., Harb, G. (2003). The safety, efficacy and pharmacokinetics of peginterferon alfa-2a (40KD) in children with chronic hepatitis C. Gastroenterology, 124 (Suppl 1): A-700; abstract 215 .

Seeff, L. (2002). Natural history of chronic hepatitis C. Hepatology, 36 (Suppl 1): S35-S46.

Sheiner, P.A., Boros, P., Klion, F.M., Thung, S.N., Schluger, L.K., Lau, J.Y., Mor, E., Bodian, C., Guy, S.R., Schwartz, M.E., Emre, S., Bodenheer, H.C., Miller, C.M. (1998). The efficacy of prophylactic interferon alfa- $2 \mathrm{~b}$ in preventing recurrent hepatitis $\mathrm{C}$ after liver transplantation. Hepatology, 28: 831-838. 
Shen, Y., Pielop, J., Hsu, S. (2005). Generalized nummular eczema secondary to peg interferon alfa- $2 \mathrm{~b}$ and ribavirin combination therapy for hepatitis $\mathrm{C}$ infection. Archives of Dermatology, 141: 102-103.

Shepherd, J., Brodin, H., Cave, C., Waugh, N., Price, A., Gabbay, J. (2004). Pegylated interferon $\alpha-2 a$ and $-2 b$ in combination with ribavirin in the treatment of chronic hepatitis C: A systematic review and economic evaluation. Health Technology Assessment, 8: 1-125.

Shergill, A., Khalili, M., Bollinger, K., Roberts, J., Ascher, N., Terrault, N. (2005). Applicability, tolerability and efficacy of preemptive antiviral therapy in hepatitis $\mathrm{C}$ infected patients undergoing liver transplantation. American Journal of Transplantation, 5: 118-124.

Sherman, K.E., Rouster, S.D., Chung, R.T., Rajicic, N. (2002). Hepatitis C virus prevalence among patients infected with human immunodeficiency virus: A cross-sectional analysis of the US adult AIDS Clinical Trials Group. Clinical Infectious Diseases, 34: 831-837.

Sherman, M., Bain, V., Villeneuve, J-P., Myers R.P., Cooper, C., Martin, S., Lowe, C. (2004). The management of chronic viral hepatitis: A Canadian consensus conference 2004. Canadian Journal of Gastroenterology, 18: 715-728.

Shiffman, M.L., Diago, M., Tran, A., Pockros, P., Reindollar, R., Prati, D., Rodriguez-Torres, M., Lardelli, P., Blotner, S., Zeuzem, S. (2006). Chronic hepatitis C in patients with persistently normal alanine transaminase levels. Clinical Gastroenterology and Hepatology, 4: 645-652.

Shiffman, M.L., DiBisceglie, A.M., Lindsay, K.L, Morishima, C., Wright, E.C., Everson, G.T., Lok, A.S., Morgan, T.R., Bonkovsky, H.L., Lee, W.M., Dienstag, J.L., Ghany, M.G., Goodman, Z.D., Everhart, J.E., and the HALT-C Trial Group (2004). Peginterferon alfa-2a and ribavirin in patients with chronic hepatitis $\mathrm{C}$ who have failed prior treatment. Gastroenterology, 126: 1015-1023.

Shiffman, M.L., Price, A., Hubbard, S. (2005). Treatment of chronic hepatitis C virus (HCV) genotype 1 with peg interferon alfa-2b (PEGIFN), high weight based dose ribavirin (RVN) and epoetin alfa (EPO) enhances sustained virologic response (SVR). Program and abstracts of the 56th Annual Meeting of the American Association for the Study of Liver Diseases; November 11-15, San Francisco, CA. Abstract 55.

Siebert, U., Sroczynski, G., Rossol, S., Wasem, J., Ravens-Sieberer, U., Kurth, B.M., Manns, M.P., McHutchison, J.G., Wong, J.B., German Hepatitis C Model (GEHMO) Group, International Hepatitis Interventional Therapy (IHIT) Group. (2003). Gut, 52: 425-432.

Singh, N., Gayowski, T., Wannstedt, C.F., Shakil, A.O., Wagener, M.M., Fung, J.J., Marino, I.R. (1998). Interferon-alpha for prophylaxis of recurrent viral hepatitis C in liver transplant recipients: A prospective, randomized, controlled trial. Transplantation, 65: 82-86.

Sonnenblick, M., Rosenmann, D., Rosin, A. (1990). Reversible cardiomyopathy induced by interferon. $B M J, 300:$ 1174-1175.

Soriano, V., Puoti, M., Sulkowski, M. (2004b). Care of patients with hepatitis C and HIV coinfection. AIDS, 18: 1-12.

Soriano, V., Nunez, M., Camino, N., Maida, I., Barreiro, P., Romero, M., Martin-Carbonero, L., Garcia-Samaniego, J., Gonzalez-Lahoz, J. (2004a). Hepatitis C virus-RNA clearance in HIVco-infected patients with chronic hepatitis $\mathrm{C}$ treated with pegylated interferon plus ribavirin. Antiviral Therapy, 9: 505-509.

Soriano, V., Perez-Olmeda, M., Rios, P., Nunez, M., Garcia-Samaniego, J., Gonzalez-Lahoz, J. (2004b). Hepatitis C virus (HCV) relapses after anti-HCV therapy are more frequent in HIVinfected patients. AIDS Research Human Retroviruses, 20: 351-354.

Strader, D.B., Wright, T., Thomas, D.L., Seeff, L.B. (2004). Diagnosis, management, and treatment of hepatitis C. Hepatology, 39: 1147-1171.

Su, X., Rhodes, S., Yee, L., Im, K., Tong, X., Howell, C., Haritos, M., Liang, T.J., Taylor, M.W., Yang, H. (2006). Association of interferon signaling pathway and interferon stimulated genes with response to pegylated interferon and ribavirin therapy in HCV infected Caucasian and African American patients. Gastroenterology, 130 (4 Suppl 2): A-748; abstract 2 .

Sugano, S., Suzuki, T., Watanabe, M., Ohe, K., Ishii, K., Okajima, T. (1998). Retinal complications and plasma C5a levels during interferon alpha therapy for chronic hepatitis C. American Journal of Gastroenterology, 93: 2441-2444. 
Sulkowski, M., Moore, R., Mehta, S., Chaisson, R., Thomas, D. (2002). Hepatitis C and progression of HIV disease. JAMA, 288: 199-206.

Sulkowski, M.S., Thomas, D.L. (2003). Hepatitis C in the HIV-infected person. Annals of Internal Medicine, 138: 197-207.

Sulkowski, M.S., Dieterich, D.T., Bini, E.J., Brau, N., Alvarez, D., DeJesus, E., Leitz, G.J. for the HIV/HCV Coinfection Study Group. (2005a). Epoetin alfa once weekly improves anemia in HIV/hepatitis $\mathrm{C}$ virus-coinfected patients treated with interferon/ribavirin: A randomized controlled trial. Journal of AIDS, 39: 504-506.

Sulkowski, M.S., Mast, E.E., Seeff, L.B., Thomas, D.L. (2000). Hepatitis C virus infection as anopportunistic disease in persons infected with human immunodeficiency virus. Clinical Infectious Diseases, 30 (Suppl 1): S77-S84.

Sulkowski, M.S., Wright, T., Rossi, S.J., Arora, S., Lamb, M., Wang, K., Gries, J.M., Yalamanchili, S. (2005b). Peginterferon alfa-2a does not alter the pharmacokinetics of methadone in patients with chronic hepatitis $\mathrm{C}$ infection undergoing methadone maintenance therapy. Clinical and Pharmacological Therapy, 77: 214-224.

Sulkowski, M.S. (2006). Treatment algorithm for the management of hepatitis C in HIV-coinfected persons. Journal of Hepatology, 44: S49-S55.

Sullivan, P.S., Hanson, D.L., Teshale, E.H., Wotring, L.L., Brooks, J.T. (2006). Effect of hepatitis $\mathrm{C}$ infection on progression of HIV disease and early response to initial antiretroviral therapy. AIDS, 20: 1171-1179.

Sullivan, S.D., Jensen, D.M., Bernstein, D.E., Hassanein, T.I., Foster, G.R., Lee, S.S., Cheinquer, H., Craxi, A., Cooksley, G., Klaskala, W., Pettit, K., Patel, K.K., Green, J. (2004). Cost-effectiveness of combination peginterferon $\alpha-2 \mathrm{a}$ and ribavirin compared with interferon $\alpha-2 \mathrm{~b}$ and ribavirin in patients with chronic hepatitis C. American Journal of Gastroenterology, 99: 1490-1496.

Swain, M.G., Foster, G., Hadziyannis, S., Heathcote, J., Jensen, D., Lee, S., Pockros, P., Sulkowski, M., Trepo, C. (2005). Clustering of poor prognostic factors in heavier patients with chronic hepatitis $\mathrm{C}(\mathrm{CHC})$ : Baseline characteristics and outcomes with peginterferon alfa2a (40KD) (PEGASYS ${ }^{\circledR}$ ) plus ribavirin (RBV, COPEGUS ${ }^{\circledR}$ ) in randomized, international, Phase III trials. Hepatology, 42 (Suppl 1): 687A; abstract 1244.

Taliani, G., Gemignani, G., Ferrari, C., Aceti, A., Bartolozzi, D., Blanc, P.L., Capanni, M., Esperti, F., Forte, P., Guadagnino, V., Mari, T., Marino, N., Milani, S., Pasquazzi, C., Rosina, F., Tacconi, D., Toti, M., Zignego, A.L., Messerini, L., Stroffolini, T., the Nonresponder Retreatment Group. (2006). Pegylated interferon alfa-2b plus ribavirin in the retreatment of interferonribavirin nonresponder patients. Gastroenterology, 130: 1098-1106.

Tam, R.C., Pai, B., Bard, J., Lim, C., Averett, D.R., Ohan, U.T., Milovanovic, T. (1999). Ribavirin polarizes human $\mathrm{T}$ cell responses towards and Type 1 cytokine profile. Journal of Hepatology, 30: $376-382$.

Tang, K.H., Hermann, E., Cooksley, H., Tatman, N., Chokshi, S., Williams, R., Zeuzem, S., Naoumov, N.V. (2005). Relationship between early HCV kinetics and T-cell reactivity in chronic hepatitis $\mathrm{C}$ genotype 1 during peginterferon and ribavirin therapy. Journal of Hepatology, 43: 776-782.

Tedaldi, E.M., Baker, R.K., Moorman, A.C., Alzola, C.F., Furhrer, J., McCabe, R.E., Wood, K.C., Holmberg, S.D., the HIV Outpatient Study (HOPS) Investigators. (2003). Influence of co infection with HCV on morbidity and mortality due to HIV infection in the era of HAART. Clinical Infectious Diseases, 36: 363-367.

Torriani, F., Rodriguez-Torres, M., Rockstroh, J., Lissen, E., Gonzalez-Garcia, J., Lazzarin, A., Carosi, G., Sasadeusz, J., Katlama, C., Montaner, J., Sette, H., Passe, S., De Pamphilis, J., Duff, F., Schrenk, U.M., Dieterich. D.T., for the APRICOT Study Group. (2004). Peginterferon alfa-2a plus ribavirin for chronic hepatitis $\mathrm{C}$ virus infection in $\mathrm{HIV}$-infected patients. New England Journal of Medicine, 351: 438-450.

Veteran's Health Administration (2005). Management and treatment of hepatitis C virus infection in HIV-infected adults: Recommendations from the Veteran's Affairs Hepatitis C Resource Center Program and national Hepatitis C Program Office. American Journal of Gastroenterology, 100: 2338-2354. 
Vogel, M., Baumgarten, A., Klausen, G. (2006). Pegylated interferon in the treatment of acute $\mathrm{HCV}$ infection in HIV positive individuals-Interim analysis of a large German multicenter study. Program and abstracts of the 2nd International Workshop on HIV and Viral Hepatitis Coinfection, January 12-14, Amsterdam, The Netherlands. Abstract 25.

Vogel,W., Ferenci, P., Fontana, R. (2002). Peginterferon alfa-2a (40KD) (PEGASYS $\left.{ }^{\circledR}\right)$ in liver transplant recipients with established recurrent hepatitis C: Interim results of an ongoing randomized multicenter trial. Hepatology, 36: 312A; abstract 596.

Voigt, E., Schulz, C., Klausen, G., Goelz, J., Mauss, S., Schmutz, G., Jessen, H., Weitner, L., Mutz, A., Schranz, D., Rockstroh, J.K., for the KAAD Study Group. (2006). Pegylated interferon $\alpha-2 b$ plus ribavirin for the treatment of chronic hepatitis $\mathrm{C}$ in HIV-coinfected patients. Journal of Infection, 53: 36-42.

Von Wagner, M., Huber, M., Berg, T., Hinrichsen, H., Rasenack, J., Heintges, T., Bergk, A., Bernsmeier, C., Häussinger, D., Herrmann, E., Zeuzem, S. (2005). Peginterferon- $\alpha-2 a$ (40KD) and ribavirin for 16 or 24 weeks in patients with genotype 2 or 3 chronic hepatitis C. Gastroenterology, 129: 522-527.

Wang, Y.S., Youngster, S., Bausch, J., Zhang, R., McNemar, C., Wyss, D.F. (2000). Identification of the major positional isomer of pegylated interferon alpha-2b. Biochemistry, 39: 10634-10640.

Wills, R.J. (1990). Clinical pharmacokinetics of interferons. Clinical Pharmacokinetics, 19: 390-399.

Wills, R.J., Dennis, S., Speigel, H.E., Gibson, D.M., Nadler, P.I. (1984). Interferon kinetics and adverse reactions after intravenous, intramuscular, and subcutaneous injection. Clinical and Pharmacological Therapy, 35: 722-727.

Wirth, S., Pieper-Boustani, H., Lang, T., Ballauff, A., Kullmer, U., Gerner, P., Wintermeyer, P., Jenke, A. (2005). Peginterferon alfa-2b plus ribavirin treatment in children and adolescents with chronic hepatitis C. Hepatology, 41: 1013-1018.

Yoshida, E., Heathcote, J., Bailey, R., Anderson, F., Kaita, K., Krajden, M., Deschênes, M., Bain, V., Lee, S., Sherman, M., Peltekian, K., Simonyi, S. (2005). "Real" world experience with peginterferon alfa-2a (40 KD) plus ribavirin in chronic hepatitis C: Results of a multicenter open-label expanded access program in Canada. Gastroenterology, 128 (4 Suppl 2): A-723; abstract S1572.

Zanini, B., Puoti, M., Quiros-Roldan, E. (2006). The optimal duration of treatment for HIVinfected patients with chronic hepatitis $\mathrm{C}$ and genotype 2 or 3 is 48 weeks: Results of a randomized controlled trial. Program and abstracts of the 2nd International Workshop on HIV and Viral Hepatitis Coinfection; January 12-14, Amsterdam, The Netherlands. Abstract 27.

Zarski, J-P., Smith, C., Hadziyannis, S.J., Rakela, J., Hassanein, T., Lee, S.-D. (2005). Are there differences in baseline characteristics or treatment outcomes with peginterferon $\alpha-2 \mathrm{a}(40 \mathrm{kDa})$ and ribavirin in patients infected with HCV genotype 1a versus 1b. Journal of Hepatology, 42 (Suppl 2): 228; abstract 624.

Zehnter, E., Mauss, S., John, C., Heyne, R., Möller, B., Lutz, T., Bokemeyer, B., Kihn, R., Moog, G., Alshuth, U., Hüppe, D. (2006). Efficacy and safety of peginterferon alpha-2a (40 $\mathrm{KD}$ ) [PEG] plus ribavirin [RBV] 1000/1200 mg/d in genotype 1 patients with chronic hepatitis C and "normal" ALT levels. Journal of Hepatology, 44 (Suppl 2): S231; abstract 622.

Zeuzem, S., Buti, M., Ferenci, P., Sperl, J., Horsmans, Y., Cianciara, J., Ibranyi, E., Weiland, O., Noviello, S., Brass, C., Albrecht, J. (2006b). Efficacy of 24 weeks treatment with peginterferon alfa- $2 \mathrm{~b}$ plus ribavirin in patients with chronic hepatitis $\mathrm{C}$ infected with genotype 1 and low pretreatment viremia. Journal of Hepatology, 44; 97-103.

Zeuzem, S., Diago, M., Gane, E., Reddy, K.R., Pockros, P., Prati, D., Shiffman, M., Farci, P., Gitlin, N., O'Brien, C.B., Lamour, F., Lardelli, P., for the PEGASYS Study NR16071 Investigator Group. (2004a). Peginterferon alfa-2a (40 kilodaltons) and ribavirin in patients with chronic hepatitis C and normal aminotransferase levels. Gastroenterology, 127: 1724-1732.

Zeuzem, S., Feinman, S.V., Rasenack, J., Heathcote, E.J., Lai, M-Y., Gane, E., O’Grady, J., Reichen, J., Diago, M., Lin, A., Hoffman J., Brunda, M.J. (2000). Peginterferon alfa-2a in patients with chronic hepatitis C. New England Journal of Medicine, 343: 1666-1672. 
Zeuzem, S., Herrmann, E, Lee, J-H., Fricke, J., Neumann, A.U., Modi, M., Colucci, G., Roth, K. (2001). Viral kinetics in patients with chronic hepatitis C treated with standard or peginterferon o2a. Gastroenterology, 120: 1438-1447.

Zeuzem, S., Hultcrantz, R., Bourlier, M., Goeser, T., Marcellin, P., Sanchez-Tapias, J., Sarrazin, C., Harvey J., Brass C., Albrecht, J. (2004b). Peginterferon alfa-2b plus ribavirin for treatment of chronic hepatitis $\mathrm{C}$ in previously untreated patients infected with HCV genotypes 2 or 3 . Journal of Hepatology, 40: 993-999.

Zeuzem, S., Pawlotsky, J.-M., Lukasiewicz, E., von Wagner, M., Goulis, I., Lurie, Y., Gianfranco, E., Vrolijk, J-M., Esteban, J.I., Hexode, C., Latgging, M., Negro, F., Soulier, A., Verheij-Hart, E., Hansen, B., Tal, R., Ferrari, C., Schalm, S.W., Neumann, A.U., for the DITTOHCV Study Group. (2005). International, multicenter, randomized, controlled study comparing dynamically individualized versus standard treatment in patients with chronic hepatitis C. Journal of Hepatology, 43: 250-257.

Zeuzem, S., Sarrazin, C., Wagner, F., Rouzier, R., Forestier, N., Gupta, S., Hussain, M., Shah, A., Cutler, D., Zhang, J. (2006a) The HCV NS3 protease inhibitor SCH 503034 in combination with PEG-IFN $\alpha-2 b$ in the treatment of HCV-1 PEG-IFN $\alpha$-2b non-responders: Antiviral activity and HCV variant analysis. Journal of Hepatology, 44 (Suppl 2): S35; abstract 78. 